. THE : F A RM E R $\mathbf{S}$.

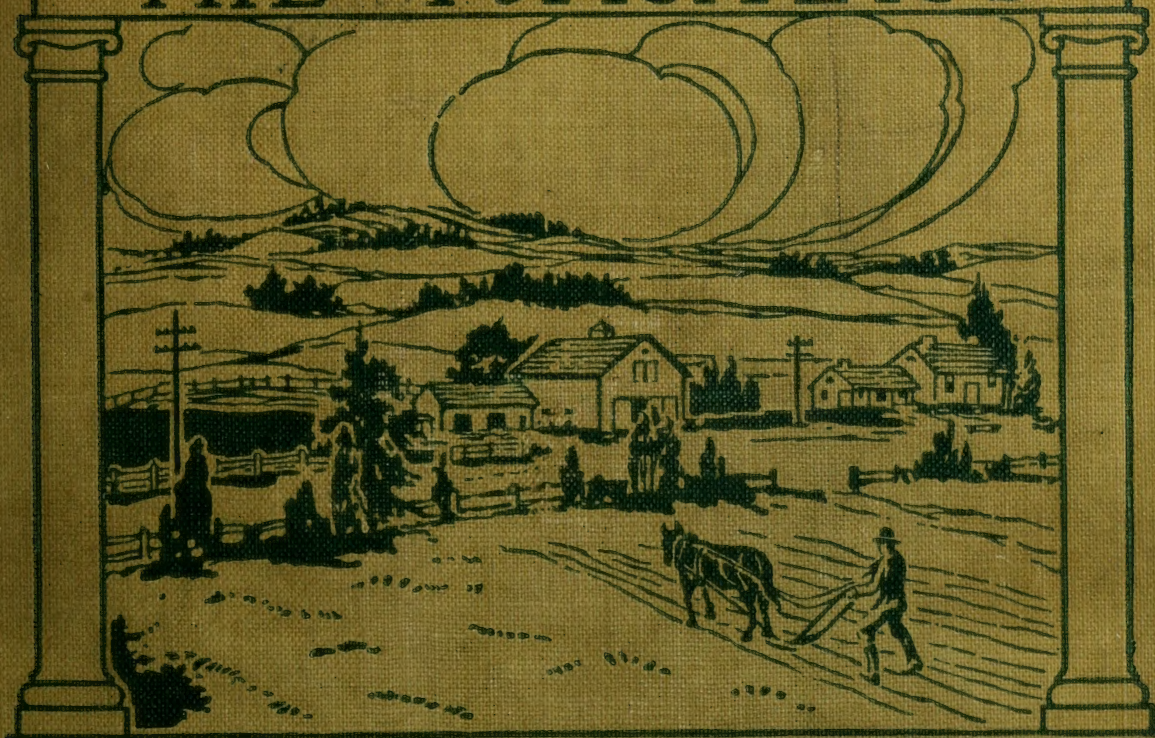

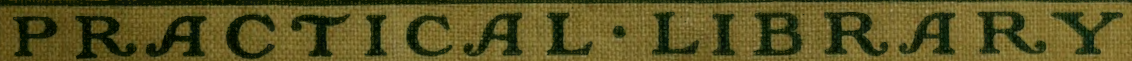
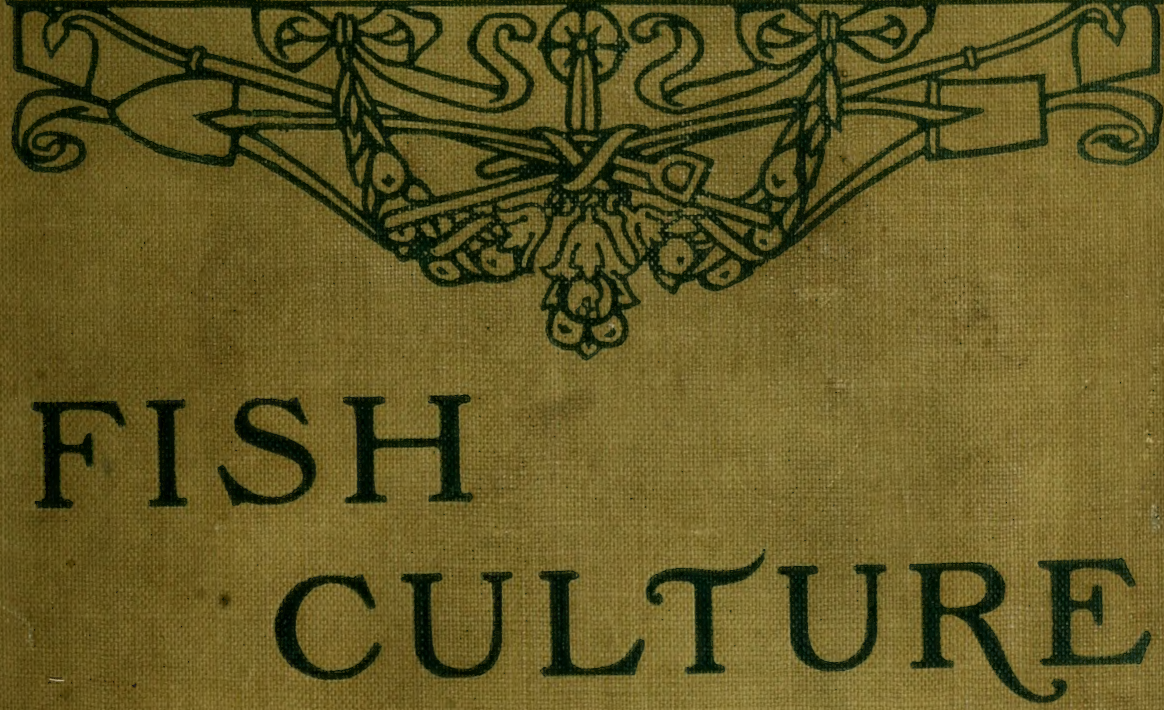

WILLIAM $\cdot \mathrm{E} \cdot \mathrm{MEEH} A \mathrm{~N}$ 


$$
\text { ฮै }
$$






\section{THE FARMER'S PRACTICAL LIBRARY}

EDITED BY ERNEST INGERSOL

\section{FISH CULTURE \\ BY \\ WILLIAM E. MEEHAN}




\section{The Farmer's Practical Library}

\section{EDITED BY ERNEST INGERSOLL \\ Cloth $16 \mathrm{mo}$ Illustrated}

From Kitchen to Garret. By Virginia Terhune Van de Water.

Neighborhood Entertainments. By RENEE B. STERN, of the Congressional Library.

Home Waterworks. By CarLeton J. LYNDE, Professor of Physics in Macdonald College, Quebec.

Animal Competitors. By ERnest INGERsoll. Health on the Farm. By Dr. H. F. HARRIS, Secretary Georgia State Board of Health.

Co-operation Among Farmers. Вy ЈонN Lee Coulter.

Roads, Paths and Bridges. By L. W. PAGE, Chief of the Office of Public Roads, U. S. Department of Agriculture.

Poems of Country Life. By George S. BRYAN.

Electricity for the Farm and Home. By FRANK KOESTER.

Fish Culture in Ponds and Other Inland Waters. By WILLIAM E. MEEHAN, Supt. Public Aquarium, Philadelphia.

Village Improvement. By PARRIS $T$. FARWELL. In preparation.

The Satisfactions of Country Life. By Dr. James W. Robertson, Principal of Macdonald College, Quebec. In prep. aration.

The Farm Mechanic. By L. W. Chase, Professor of Farm Mechanics in the University of Nebraska. In preparation. 



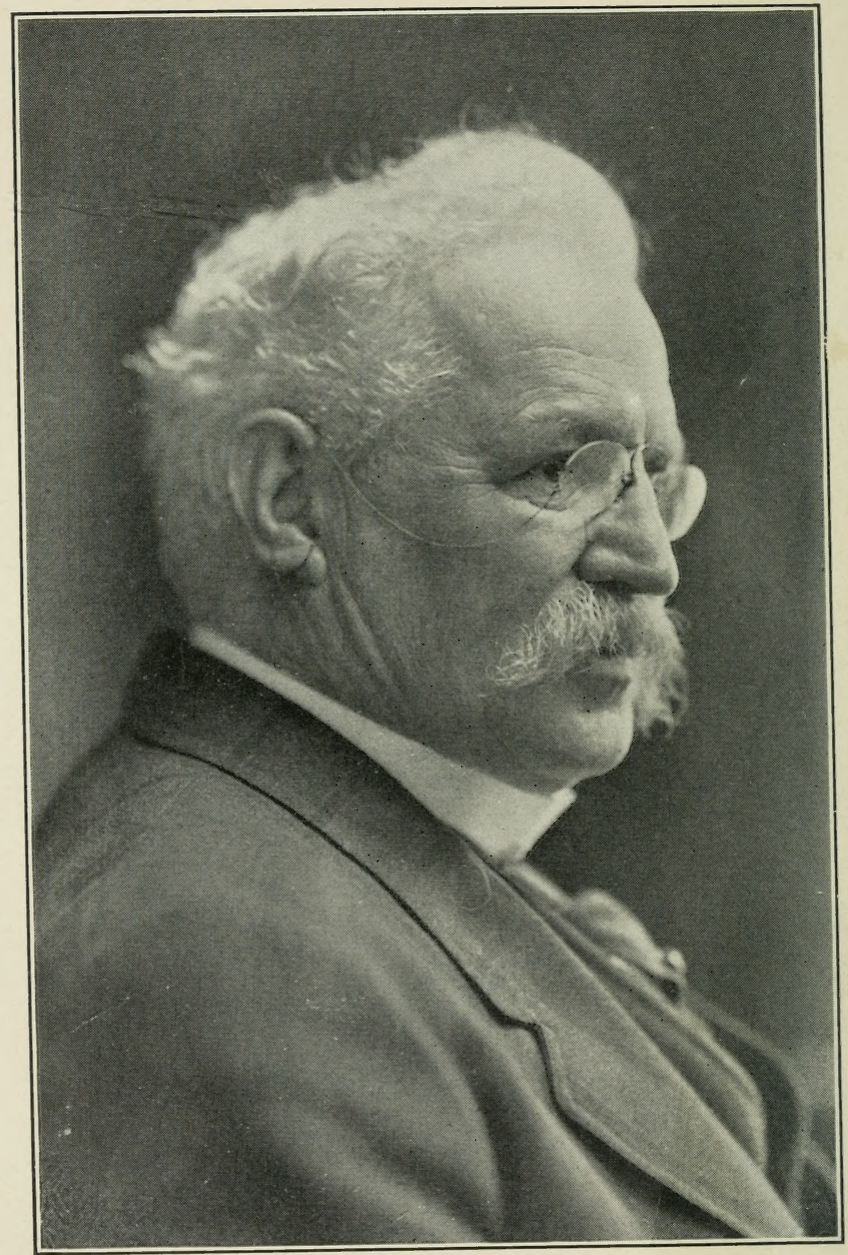

THE HON. WILLIAM E. MEEHAN. 


\section{FISH CULTURE IN PONDS AND OTHER INLAND WATERS}

BY

\section{WILLIAM E. MEEHAN}

Formerly Fish Commissioner of Penhsylvania, Superintendent

Public Aquarium, Philadelphia

\section{ILLUSTRATED}

1月ew work

STURGIS \& WALTON

COMPANY

1913 


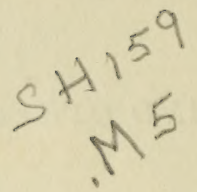

Copyright, 1918, вY

\section{STURGIS \& WALTON COMPANY}

Set up and electrotyped. Published June, 1918
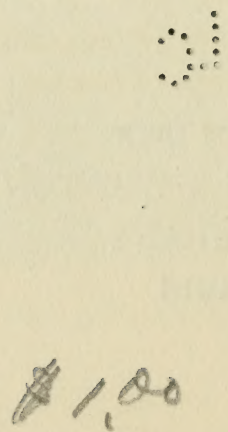

(C) CI.A358158 


\section{CONTENTS}

CHAPTER

PAGE

I Pond-Culture of Black Bass . . . . . 3

II Spawning of Black Bass and Care of Fry . 24

III Rock-Bass, Calico-Bass, and Sun-Fishes . 49

IV Cat-Fish Culture . . . . . . . . 59

V Carp Culture . . . . . . . . . . . 70

VI Water for Trout Culture . • . • • . 86

VII Trout Ponds and How to Build Them . • 93

VIII Construction of a Trout-Hatchery . . . . 111

IX Taking and Fertilising Trout Eggs . • • 126

$\mathrm{X}$ Trout Hatching, and Care of Fry . . . . . 138

XI Rearing Young Trout . . . . . . . . 160

XII The Atrantic Salmon . . . . . . . . 174

XIII Hatching Fishes' Eggs in Jars . . . . . 178

XIV Culture of the Yellow Perch . . • . . 188

XV Rearing Pickerel and Muscallonge . • . 200

XVI White Perch, Striped Bass, Smelts and Suck-

ERS • • • • • • • • • • • • . 207

XVII Frog Culture . . . . . . . . . . . 219

XVIII Making and Managing an Aquarium • . 234

XIX The Culture and Cure of Goldfish . • . 252

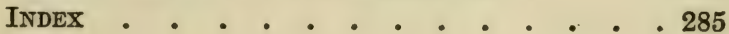





\section{ILLUSTRATIONS}

Portrait of the Author . . . . . . Frontispiece

FACING

PAGE

Breeding-Ponds for Black Bass or Sun-fish . . . . 8 An Ideal Pond for Brood-Bass . . . . . . 8 ,

Bass Hatchery at Mill Creek, Mich., Showing Retaining

Wall to Prevent Flooding . . . . . . . . . 12

Large-mouthed Black Bass (Micropterus salmoides) . . 24

Small-mouthed Black Bass (Micropterus Dolomieu) . . 24

Cribs Surrounding Bass Nests . . . . . . . . 42

Pond for Calico, or Grass, Bass, at Linlithgo, N. Y. . . 48

The Pumpkin-Seed or Sun-fish (Lepomis gibbosus) . 54

The Long-Eared Sun-fish (Lepomis auritus) . . . . . 54

The Calico, Grass, Bass (Pomoxys sparoides) • • . 56

The Rock-Bass (Ambloplites rupestris) . . . . . . 56

Yellow Cat-fish (Leptops olivaris) . . . . . . 60

Common Bullhead (Ameiurus nebulosus) . . . . 60

Methods of Shading Trout Ponds . . . . . . . 96

Intake from a Trout Pond . . . . . . . . . 104

A Dam and Covered Raceway . . . . .. . . . 104

A Trout Hatching-trough . . . . . . . . 116

Feeding Mature Trout . . . . . . . . . 116

Chain-Pickerel, in an Aquarium . . . . . . . 200

Striped Bass (Roccus lineatus) . . . . . . . . 214

Common, or White, Sucker (Catostomus teres) . . . 214 





\section{FISH CULTURE}

\section{CHAPTER I \\ POND-CULTURE OF BLACK BASS}

WHEN the propagation of bass was first undertaken in the United States, it was speedily discovered that it is impossible to express eggs and milt artificially from the ripe female and male. The handling of ripe bass produces a nervous condition which prevents their ejectment, and affects even a fish taken from the nest in the act of spawning. Fish-culturists were then driven to resort to pond-culture; that is, to prepare bodies of water in which the fish might naturally spawn and hatch their young.

Temperature and Volume of Water.-As bass naturally inhabit warmer waters than trout, it follows that water for a bass-cultural plant in the Northern States must not be directly from a spring or be of low temperature. 
River, stream or lake water, which during the spawning season will not fall below 55 degrees, preferably below 60 degrees, and only becomes muddy after exceptionally heavy storms, and then for a short time only, is necessary. During the breeding season, higher temperatures than those named, and water perpetually clean, are very much to be desired. At 50 degrees the fish will not spawn; and at 45 degrees both eggs and fry will die.

A great volume of water is unnecessary, although desirable, since it insures one against any fear of a shortage in drought. Under ordinary circumstances 500 gallons of water a minute will be ample to operate a very large plant, but, whatever the volume, it is of the utmost importance that it be under complete control. A fish-culturist who cannot regulate his water-supply is likely to lose two-thirds of his chances for successful work.

Water that becomes roily through storms is not objectionable, provided the roiling is not continued too long or is of too frequent occurrence, especially while the nests contain eggs. For a short time muddy water has no percept- 


\section{POND-CULTURE OF BLACK BASS , 5}

ible effect on fry, or advanced fry, and is beneficial to mature fish.

As a rule the best water for both kinds of bass is from a stream draining a lake. It is even more desirable when taken directly from the lake itself, because it is better aerated and probably contains more plankton, or minute surface forms of animal life which are essential as food for advanced fry and young bass', and which are taken unconsciously by the large fish. Next to water flowing from a lake is stream water which is not too frequently spring: fed; and after this in value is river water.

Choice of Site.-Three conditions are necessary as a basis for successful cultivation of small-mouthed bass; a favourable site, properly constructed ponds, and suitable water. Nearly all other problems which may and will arise are either subordinate or sequences.

When seeking a suitable site for bass-ponds, a decided pitch in the ground is not vital, as it is only necessary to have sufficient for complete drainage. A relatively large area of ground is required if many thousand young fish are to be fed, say at least 25 acres. A pond of half 
or three quarters of an acre cannot be expected to yield more than 100,000 young fish, even with a suitable number of accompanying fry-ponds; indeed, not more than 50,000 or 60,000 could ordinarily be expected.

Character of the Bottom.-When the smallmouthed bass seeks a site for a nest it almost invariably selects a gravelly or rocky bottom; but this is about the last selection the experienced bass-culturist will make for his pond. His first choice would probably be a heavy clay: through which water cannot percolate, or a spot where the bottom can be made water-tight by puddling it with clay. A stony or gravelly. bottom is not desirable, at least for breedingponds, because the fish-culturist cannot have absolute control over his brood-fish, as it would be impossible to force them to use artificial nests. Mucky ground for smallmouth-breeding should be avoided, because in moving about the fish are apt to keep the water muddy, thus preventing frequent observation,-a very important feature in bass-culture. Swamp-land is worthy of very favourable consideration, because, while the surface is apt to be wet and 


\section{POND-CULTURE OF BLACK BASS}

soggy, the underlying material is likely to be clay or heavy loam, impervious to seepage. On the size and character of the gravelly spots or muck-holes in it must rest the availability of such property for the purposes of bass-ponds. A pond cannot be built over a muck-hole of any considerable depth.

Dams and Reservoirs.-A wise man will not build a pond for breeding bass by throwing a dam across the stream which supplies the water for his establishment. There are cogent reasons for not using the bed of a stream for such a purpose, among which are the fact that the water-supply is beyond the owner's control, and in case of heavy rains he stands a good chance of losing his entire stock. Not having entire control of the supply, the fishculturist would also be at the mercy of varying conditions of water-temperature. Furthermore, mud is almost certain to gather in the bottoms, and there is danger of eggs being smothered by it.

All ponds for a bass-cultural plant should therefore be built to the right or left of the supplying stream, and the water let into them 
by pipe or sluice, arranged as is recommended hereafter.

The first work to be done is to make such arrangements as will insure the easy flowing of water from the sources to any part of the grounds. If the fall in the land is sufficient, a pipe of adequate size may be laid in the creek at the upper end of the grounds, or above them, so that the water can be carried to the pond by gravity. When such piping is not feasible, a dam must be built at the upper end of the property high enough to carry the water where desired. What may be called the reservoir, or supply-dam, should not be solid from shore to shore, but have a wide sluiceway at the channel-point, closed by splash-boards or gates, which may be removed or opened during freshets to carry away the surplus water and maintain the reservoir at as nearly a normal height as possible.

Where it can be done, an ideal plan is to establish a regular reservoir at the upper end of the establishment, where the water can rest awhile, subside and breed plankton, and from which the supply for the hatchery can be drawn. 


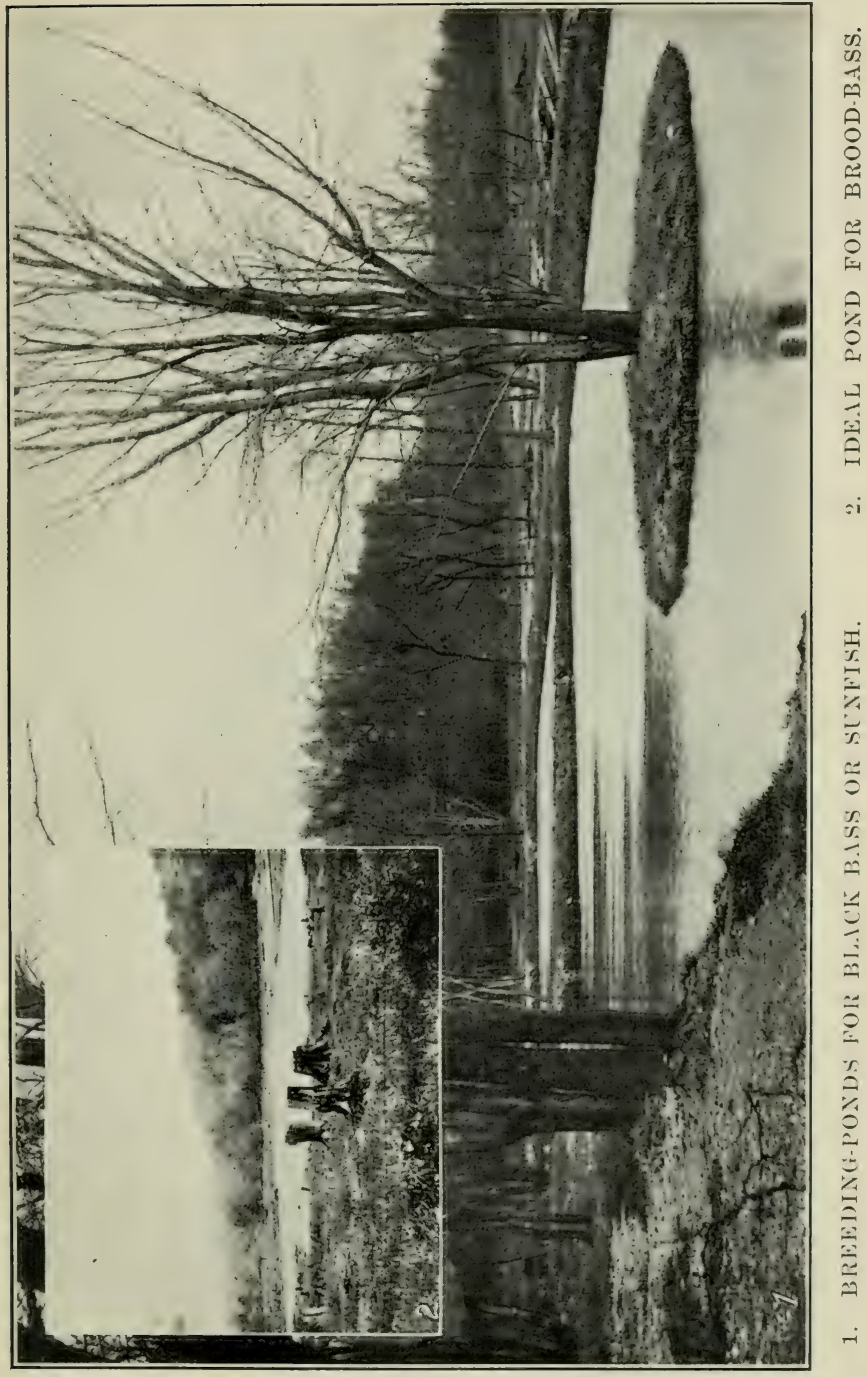



Concrete is the best material for dams across a stream, but whether built of concrete, timber or masonry, the lower face should not be perpendicular, especially if the stream is large or its volume frequently changes, for if it is the falling water will rapidly wash a big pool at the base of the dam and is apt to cut under the foundation. To ensure permanency the lower face of the dam should be sloped, either unbrokenly or in a slightly reversed curve from the crown. The curved construction is the most approved form to prevent pool formation and undermining.

Construction of Ponds.-Ponds for black bass may be dug below the surface of the ground or built above it to accommodate the pitch of the land, the fancy of the owner, or the reputation of the supplying stream for flooding. If the land is flat, and the water to be introduced by means of a dam across the stream, naturally the ponds will be dug below the surface, and perhaps in addition will need sides built up for some distance above. If the land has a decided pitch, then the natural course will be to build the ponds entirely or almost entirely above the 
surface. Such construction may be considered as ideal, because perfect drainage is then certain.

Earlier bass-culture was conducted in ponds of very small dimensions, but with advancing experience the area for breeding-fish was increased, until now some almost approach the size of lakes. Few now in use for breeders are less than 200 by 75 feet; and the tendency is to make them much larger. Four to five acres, however, is about the limit that can conveniently be cared for; and those who breed bass feel that even that space can be more satisfactorily handled, and with better results, when divided into two or three breeding-ponds than as a single body of water. Owing to the expense of constructing very large ponds, and the length of time required for their completion, it is advisable when starting a bass plant to build one or two ponds about 300 by 100 feet in order that there may be an early stock of young fish.

Depth and Bottom.-The bottom of a pond for fish-cultural purposes is divided into two parts, one called the "kettle," and the other the "spawning-shelf," or simply "shelf." The 


\section{POND-CULTURE OF BLACK BASS 11}

first is an area at the outlet end of the pond deeper than the shelf and intended as the winter quarters of the bass. The second is the area in which the bass spawn and spend the greater part of the year, and is the shoalest part of the pond, as well as of the greatest extent.

Some culturists prefer to construct a bottom which slopes gradually downward from the upper or inlet end to the lower or outlet. Unquestionably fish seem to do as well in a pond of this character, and it does not necessarily mean a loss of the spawning area. Bass often build their nests in from six to eight feet of water, although in such instances it is usually late in the season. Ponds with a sloping bottom throughout are not nearly as easily handled and cared for as those in which the water over the spawning shelf is approximately of even depth. One desirable feature is the greater ease with which the action and progress of the fish may be watched during the spawning period, or at any other time. Close observation of bass is essential during the height of the spawning season. At times there will be freshly laid eggs, eyed eggs, eggs just hatched, fry 
freshly hatched, fry collected and ready to rise towards the surface of the water, all at the same time.

Fry have been seen at nine oclock in the morning tight against the bottom, and at three o'clock in the afternoon swimming near the surface. On occasions fry may be hugging the stones on the nest, and half an hour later be swimming freely two or three inches above the bottom. In deep water or on sloping bottoms, movements of the fry are apt to escape notice. Before the culturist is aware of it, he will find the edges of his pond black with advanced fry which have escaped being impounded, and which he will find extremely difficult to capture in their entirety.

Sides and Outlets.-Ponds with sides of natural earth are better than those with sides constructed of concrete, stones or boards. Besides, the cost of artificial walls would be so great as to be almost prohibitive. The only drawback to the natural earth is the proneness of muskrats to pierce them with holes, which destroy the banks and often allow water to escape. The sides of a bass-pond should always be 

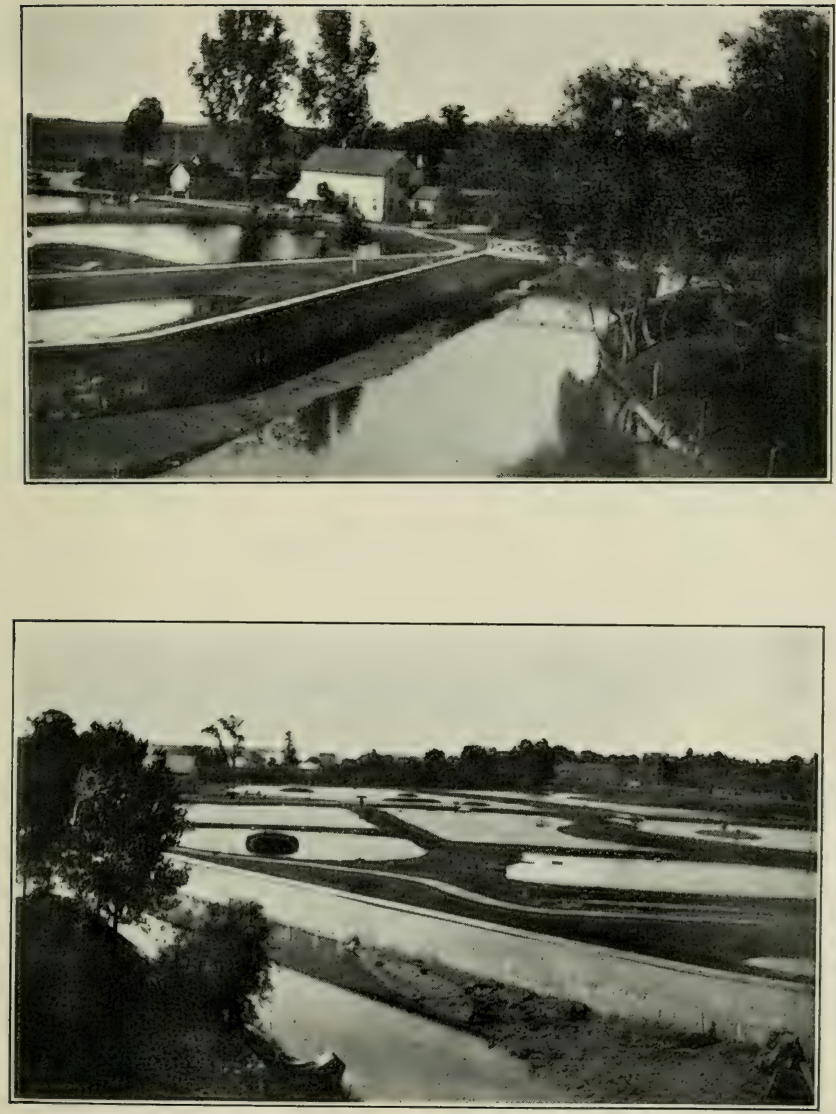

BASS HATCHERY AT MILL CREEK, MICH., SHOWING RETAINING-WALL TO PREVENT FLOODING. 

sodded to the water's edge, both for beauty and for the encouragement of grasshoppers and crickets, which will occasionally fall into the water and furnish food for the fish. There should be a valve or regulating board at every water-intake, so as to guage and control the quantity of water used. The inflow-pipe or sluice ought to be carefully screened, in order to prevent the entry of any undesirable waterlife, as eels, and mud-puppies (otherwise known as water-dogs or hellbenders) either of which can do considerable damage. The outlet of the brood-pond may be by splash-board or pipe, but whichever is adopted it must be enclosed by screens, to prevent either mature or small fish from escaping. The desirable place for the outlet is the centre of the breast of the pond. It is also very important that arrangements be made by which the water can be drawn off gradually when desired, so as not to create a suction sufficient to carry out of the pond any small fish, which may have escaped from cribs or pounds.

Brood-ponds should contain aquatic plants, such as the common water-lily (Nymphia 
odorata). During hot summer days bass love to lie underneath the shade of its leaves, but care must be taken not to permit the plants to gain such a strong hold as to clog the pond and prevent free work.

Quarters for Fry and Fingerlings.-Ponds for the exclusive use of the advanced fry or fingerlings of bass are just as necessary as ponds for brood-fish. It is difficult to have too many ponds. It is recommended that there be not less than five fry-ponds for every broodpond of about ten thousand square feet, and each of considerable area, with a combined area equal at least to that of the brood-pond. The more room there is for the advanced fry and fingerlings the less will be the amount of cannibalism.

A large number of medium-sized ponds for advanced fry and fingerlings, instead of one or two large ponds, is preferable, because it is essential to control or closely supervise the fish, which cannot be done if the body of water is very large. The dimensions of the fry-ponds will be governed by the available ground, the quantity of natural food which can be bred, 


\section{POND-CULTURE OF BLACK BASS 15}

the convenience of handling, and the number of fish to be placed therein.

Again, it is emphasised on general principles that the smaller the number of advanced fry; placed in a rearing-pond, the greater will be the percentage when the period arrives for their distribution. A pond of less than 30 by 20 feet ought not to be considered for a moment, since it would hardly rear 2,000 fish to be two months old, probably much less. About 2500 square feet, carrying approximately 20,000 advanced fry to the age of thirty days, or the fingerling stage, may be considered as a minimum.

The depth of water in the fry-pond is an important consideration. Young bass being rapid growers during the first few months, in order that they may develop freely and quickly should have the highest temperature of water naturally obtainable, so long as it does not exceed 85 degrees. It is for this reason that fry ponds for bass are seldom more than two feet deep, with a minimum of 12 inches, and with a kettle at the lower end to facilitate the use of a net when the water is drained off to take out the fish. 
The shape of a fry-pond is immaterial, providing there are not many angles to prevent quick and easy seining; yet it is an economy to have fry-ponds longer than their width, so that they may be more easily seined, since the method is to seine them lengthwise and not across.

Fry-ponds are to be located as close to the breeding-ponds as possible, chiefly on account of convenience in transferring, and close together, so that when sorting takes place the different sizes of fish may be quickly changed from one to another. If there be any considerable number they should be divided into groups, each with a separate drainage system, and a separate water-supply; for, as high temperatures are necessary, such waters lose their health-giving qualities very rapidly.

As soon as possible ponds enough should be built to have two complete sets for use in alternate years, so that while one set is used the other can be drawn entirely clear of water from September until March. Two sets of ponds will be found useful also because of the rapid growth of aquatic plants, an essential feature 


\section{POND-CULTURE OF BLACK BASS 17}

of a brood-pond. The drawing off of water entirely from September until March is desirable because it encourages the growth of plankton, an essential feature in successful bass-culture, and also because it destroys the larvæ of the dragon-fly, and of water-beetles, the waterbeetles themselves and the crayfish, all destructive although furnishing food for the fishes. Finally, the periodical drawing off of water assists in keeping algæ in check,-one of the greatest nuisances known to fish-culturists.

Introduction of the Stock.-For some years it was universally believed that mature bass must, under all circumstances, be introduced from their wild habitat into the hatchery in the autumn, to insure their spawning the following spring. An impression prevailed that the fish required time to accustom themselves to their new environments, and to recover from the excitement or terror of capture and transportation.

Those who entertained this view may have acquired it from the knowledge that sometimes, after abortive efforts had been made to express eggs from a ripe female, she was un- 
able to perform that function herself. But the experiences of Dwight Lydell, and of the late Frank N. Clark, two authorities on the culture of small-mouthed bass, and the observations of others, seem to show conclusively that neither terror nor excitement can be taken as an explanation. Moreover, the same authorities demonstrated that small-mouthed bass may be introduced into hatchery ponds in the spring and spawn the same season only when introduced not earlier than ten days before the regular spawning period. It is therefore a hazardous procedure to depart from the practice of autumn introduction in the case of the smallmouth. The spawning habits of the largemouths, on the contrary, do not seem to be affected or disturbed in any manner by the time of their capture. Whether caught in autumn, early spring, or when ripe, seems to them a matter of indifference, for when the breeding season arrives they follow the instincts of their nature and fulfil the function of reproduction.

A cautious bass man will put off securing his supply of mature fish in the fall as long as he 


\section{POND-CULTURE OF BLACK BASS 19.}

can safely do so. If he captures them while the water is yet warm he is likely to lose many. of his best specimens through fungus. Besides that, he does not want to begin taking care of a lot of fish and providing food for them until he has to do so. If the fish are introduced in the fall, as it is impossible at that time to distinguish sex, it is better to have more than needed. The trouble and cost of caring for any surplus during the winter is trifling. When spring arrives, and the fish develop to the point where the sex can be determined, sorting must begin and continue until the requisite number of males and females is secured.

Feeding Mature Bass.-For a day or two after wild mature bass have been placed in a breeding-pond it is not worth while to attempt to feed them. It is better to allow them a little time to grow accustomed to their new quarters, and also to become quite hungry. One of the difficult tasks to accomplish is to induce small-mouthed bass to take other than live food, especially when there are no domesticated fish already in the pond; if bass are 
already there the work is greatly simplified, because the new comers, seeing the "oldsters" rush forward to the meal, are more likely to do likewise, if only to gratify their natural instinct to keep their fellows from getting anything they can possess for themselves.

Bass-culturists naturally resort to beef lungs and liver if live food cannot be furnished. Some believe it essential to cut these into slices about the bigness of one's little finger, so as to make the pieces somewhat resemble worms or fishes, and give them a wriggling motion as they sink, deceiving the bass into thinking that they are alive. The experience of others shows that the energy expended in doing this is unnecessary, for small-mouthed bass can be induced to take lungs and liver cut in an ordinary meat chopper through the largest perforated plate, if time and patience are exercised. As soon as smallmouths have become used to this food, they will eat it as readily and eagerly as trout.

Bass, even in ponds, do not school as closely or move with the same speed as trout, therefore artificial food must not be thrown at them 


\section{POND-CULTURE OF BLACK BASS 21}

as rapidly or in the same manner as when feeding trout. At the outset, when teaching bass to take lungs and liver, only a piece or two at a time should be cast into the water, and then by the hand and not by means of a dipper or spoon. If the pieces can be thrown so as to cause them to skip a little, the chances of the fish taking them will be greatly increased. When feeding the first few times, mixing with it a few minnows will induce the fish to take the artificial food more readily. The best plan is to throw two or three little strips of lung, then a minnow or two, and immediately after a few more pieces of meat.

Mature bass may become accustomed to the artificial food in a week or two, but the culturist need not lose heart if at the end of five or six weeks they have not yet brought themselves to feed upon it. Efforts must be continued, for sooner or later, success will be achieved. It will be a great aid if the feeder makes a practice of casting the food upon the water daily from the same spot on the bank of the pond, for fish soon become accustomed to their attendant and his ways, and if they are 
hungry hasten to the customary spot when he appears in the hope of getting something to eat. One fish-culturist never passes his feeding-place without throwing some small objects into the water, even if it is only a handful of pebbles. The consequence is that whenever he appears there is a rush of fish after him and they will almost take liver from his fingers.

Minnows.-Small-mouthed bass grow sleek and healthy on liver and lungs, although it is admitted that minnows and crayfish, if they can be secured, are the best food that can be given. It is surprising what a quantity of minnows a few bass can devour and digest in a very short space of time. One hundred mature bass can readily dispose of 800 of the small fishes without any trouble whatever in an hour, when fed to them two or three at a time. It is not advisable to furnish so many, however, for if the bass average two apiece, per day, they will not starve. Neither is it well to feed them in such a way that by the time the assistant is through all the minnows have disappeared. Some advocate feeding one half the number allotted for a meal, two and 


\section{POND-CULTURE OF BLACK BASS 23}

three at a time, and then casting in the remainder at once. It is argued that by this method many of the minnows will escape for the time being, and keep the bass busy for half a day or more hunting them. This searching for the food some men declare to be beneficial.

There is one important exception to this rule, however, namely, that just before the spawning time the minnows must be thrown in one at a time and eaten before another is tossed in. It is inevitable that some nests will be stolen and some may escape observation. When this is the case, if there are any number of minnows at large in the pond, they will have the time of their lives when they come upon the young bass. They know their opportunity and will seize it. They are much larger than the bass-fry, and a hundred or two healthy minnows can easily devour several thousand fry in two or three days; hence there must be no minnows alive and free in the breedingpond at spawning time. 


\section{CHAPTER II}

\section{SPAWNING OF BLACK BASS AND CARE OF FRY}

HaviNG considered the character of the pond, the quality and volume of the water-supply and its disposition, the next important point for presentation is that of the nests and their adjuncts. Bass nests in a hatchery are of two kinds: those provided by the culturist, and those which the bass themselves make.

Artificial nests consist of a box containing coarse gravel. The size of the box is sometimes determined by the size of the fish in the breeding-pond, but ordinarily it is two feet square, with two sides open. The bottom is fitted with two strips, three to six inches wide. The thicker the strips, the deeper the bed of gravel. The top of the box is provided with a board to strengthen it, and on which to place a weight to keep the apparatus steady in the 

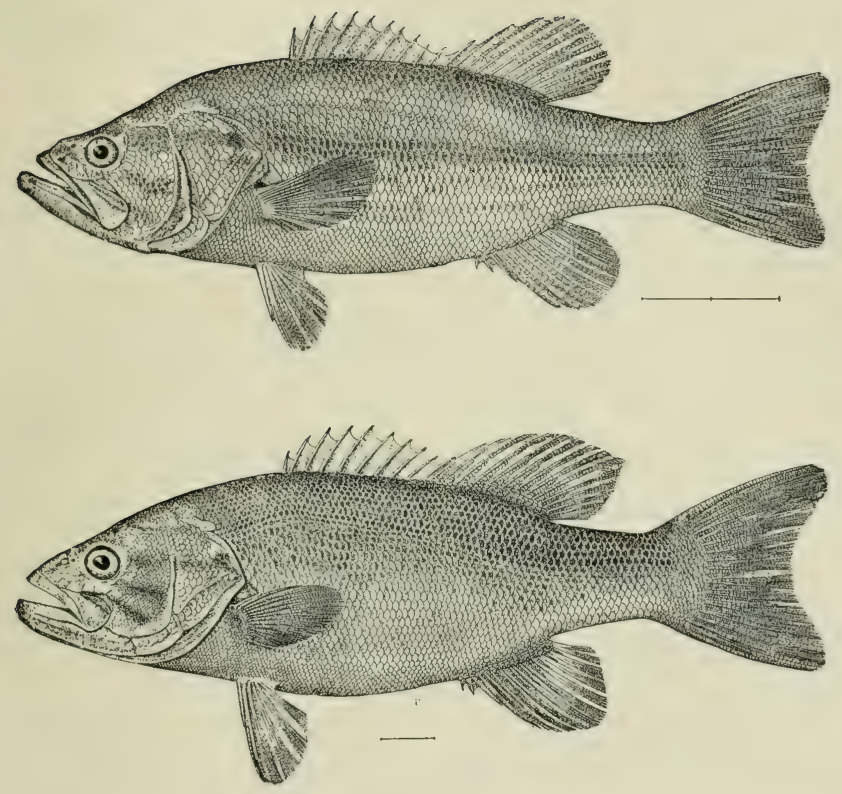

LARGE-MOUTHED BLACK BASS (Micropterus Salmoides).

SMALL-MOUTHED BLACK BASS (Micropterus Dolomieu). 

water, as well as to act as a sunshade to the fish. A spot several inches deep and two feet square is excavated in the pond, the box is placed therein, and the hole filled with gravel, varying from the size of a goose-egg to that of a marble, to the top-level of the strips. It is policy to place some of the large stones in the centre, as a bass would do if it were constructing the nest.

It is the male that selects the site for the nest and gets it ready for use. He does this before he has even looked about him for a mate. If he has started early in the season, say the latter part of May, while he is yet unripe or "hard," he sometimes digs for days before the nest is completed to his satisfaction.

Construction of the Natural Nest.-The nest-building season begins usually about the middle or latter part of May and sometimes does not end until after the first week in July. As a rule the site for a nest is selected with great care and with close attention to surrounding conditions. Bottoms with small loose stones, or with gravel or clean sand, are invariably preferred. Places with large rocks 


\section{FISH CULTURE}

or immovable stones are generally avoided. Early in the spring nests are located in shallows where the water is likely to catch the warming rays of the sun earliest and receive them the longest, but nests will often be located in places shaded throughout the day; and toward the close of the season they may be constructed in seven or more feet of water, doubtless because the shallows have become too warm for the proper hatching of the eggs. Wherever possible, a natural nest is placed in close proximity to a large stone, a sunken log or some other submerged object, which will protect it from being violently. washed by the water in stormy weather.

A site selected, the male bass clears away the mud and débris from a circular space, by exceedingly rapid fanning motions of the pectoral and ventral fins, and by slower sweeps of his tail. Leaves and sticks are carried outside the enclosure in his mouth. Stones and pebbles are pushed into place by means of his nose. Usually a slight concavity is noticed in the natural nest, and should be imitated in the artificial one. Sometimes a natural nest is 


\section{SPAWNING OF BLACK BASS}

found almost perfectly level, due it is believed to the rapid ripening of the male, which prevents his completion of the work. If he is nearly ripe, he is less likely to spend much time in construction, but devotes himself rather to thoroughly cleaning it and to working the larger gravel to the centre, the two most important considerations. The larger stones are centred in the nest because it is among them that the bulk of the eggs are to be deposited.

Courting the Female.-When his house is ready, the male bass seeks a female and pays court to the first that he meets. He does so without ascertaining whether or not she is ripe, reserving for himself the privilege of rejecting or divorcing her after she has been to the nest and proves unripe. On encountering a female he begins the most grotesque contortions. He will swim around her in erratic circles, will nip her gently on the cheeks and belly, rub against her and show himself off, in his way, just as proudly as a cock bird does when courting a hen. All the time he guides her steadily towards the nest. At times she appears to accompany him willingly; then 
again she displays indifference and even reluctance at accepting his advances. When at last he has succeeded in coaxing her to the nest, it seems as if the coquette regarded his work of nest-building with scorn or contempt. She is apt to swim languidly several times over the nest and then leave it, to the evident perturbation of the male, for he redoubles his antics and contortions, exhibiting as many as a negro in a "cake walk," and guides her back again to the nest.

This courting sometimes continues for two or three hours before the female consents to remain. Then if he finds she is hard, and the eggs cannot be expressed, he promptly drives her away and goes in search of another female, to whom he pays as assiduous court as he did to the first. Should she prove ripe, the function of spawning is begun. If much delay occurs in meeting a ripe female, he does not accept the fact philosophically, but "runs amuck." He darts hither and thither over the pond, and at the first nest in which he discovers a ripe female, there ensues at once a free fight. The raging bachelor dashes into the peaceful 
household, and does his best to thrash the male owner and appropriate his mate. It is a battle often to the death, a struggle in which no quarter is desired nor given, and in which the female is apparently an uninterested spectator, ready to accompany the victor. Whatever the outcome, the nest is nearly certain to be destroyed.

On account of the propensity of the male to go to war when unable to find a ripe female, it is considered best by some not to stock a breeding-pond with pairs, but to introduce females in the proportion of about five females to three males. The surplus is not lost, because it often happens that a male will nest a second time, if he comes upon a ripe female after he has hatched out the first lot of young and discards them. All fish-culturists, however, do not advocate or practice having the sexes in the proportion of five females to three males. On the contrary, the majority probably pair the fish evenly, and assert that no ill effects have ever followed doing so.

It is a curious fact that no matter how many nests there are in a pond every male is able to distinguish his own from his neighbour's. A male may be removed from the nest at one end of the pond, taken to the other and liberated, yet, even if the distance is a mile or more, it will not be long before he will be found 
back again on the nest he constructed. To prove this fact it is only necessary to catch a male, mark him and liberate him at once.

While the black bass is usually satisfied with one female, monogamy is not an invariable habit. It is said that sometimes a male, seeing a female passing the nest, although he already has a mate, will rush out and bring in the stranger, and add her to the household. It is also said that occasionally, for some reason or other, before the female has finished ejecting her eggs, the male will become dissatisfied with her, drive her away and bring in another mate to take her place. Again, if a female is not attracted by the particular male, he will sometimes have great difficulty in inducing her to remain. She will make efforts to escape while he is doing all in his power to keep her.

Sometimes she succeeds in getting away, and mates with another male, but rarely without a terrible battle in which she may lose one or more of her fins, or be otherwise injured. It is possible that when the female is dissatisfied, it may not be due to a lack of attraction on the part of the male, but that she is not suited with the nest, particularly if it is restricted by an artificial box.

Behaviour when Spawning.-The act of spawning and impregnation is exceedingly interesting. The male and female pass each other in opposite directions, pressing their 
bodies together, and thus assisting each other in voiding the eggs and milt which issue almost simultaneously, the eggs possibly an instant ahead of the milt. If the eggs do not come freely, the male will sometimes go to the length of pressing the abdomen of the female with his mouth, she working her tail rapidly as if to loosen the tissues; indeed, frequent and plainly visible tremors shake both male and female from head to tail throughout the entire process.

The female does not yield all her eggs at once. The larger the fish and the warmer the water the greater will be the number of eggs deposited at a single spawning. As a rule, one period of spawning covers about half an hour, but even then there is not an uninterrupted flow of eggs; they issue in little spurts or jets, from 30 to 60 seconds apart. There may be, also, intervals from three to five minutes, during which the pair swim around the nest, coquetting with one another. At the end of half an hour there is a cessation of egg-laying, of indeterminate length, depending on the temperature of the water and upon the condition of the female. As a rule, two or three 


\section{FISH CULTURE}

days elapse before all the eggs are deposited. As soon as all the eggs are laid, the male drives the female away and assumes full charge of caring for the eggs and hatching them. He moves slowly back and forth a few inches above the nest, with intervals for rest of perhaps a minute, keeping his pectoral fins moving all the time, so as to fan away all dirt or sediment, and often raising his body to an acute angle so as to bring the fanning tail-fin closer to the eggs. Every few minutes he will carefully scrutinise all parts of the nest, to make sure there is no dirt anywhere; and will make short excursions to see that no enemies nor curious fish are approaching too near.

During this period he exhibits marked savagery,--seems to have lost nearly all sense of fear. At such times a bass has been known to rush fiercely at a man's hand thrust into the water, and bite it with all his might. After the eggs have hatched, and when the culturist is dipping the advanced fry from the nest, it is not uncommon to have the old male rush at the net and sometimes tear it. It is unsafe for any fish to approach a nest while it is occupied 
by eggs or fry, for a bass will not hesitate to attack a fish three or four times its own size, and will invariably succeed in driving it away, unless, as before described, it is another black bass, one on a rampage for a mate. A bass of one and a half pounds will put to flight two or three carp of twenty to twenty-five pounds' weight.

Bass which have been kept in breeding-ponds lose to some extent, in course of time, the viciousness they display in a wild state when spawning. Seeing mankind as often as they do, and receiving food from their keepers regularly, the fish become domesticated, and the regular attendant, if he moves quietly, can go around the pond and attend to his work without disturbing them. Still, it is always better at spawning time to approach a nest only when necessary, and then in the quietest and most inconspicuous manner possible. Domestication of bass never extends to a point where the male views a disturbance of his nest with resignation. While not always as vicious as when in a wild state, he will often display strong anger and bite a man's bare legs if he 
wades into the water, or strike at his hands or at the net when the nest is being tampered with.

During all the time of building the nest and watching the eggs, and until long after the little fish are hatched, the male bass does not usually take any food. If food be dropped into the nest he will pick it up and throw it outside. It is said to be a fact that if a fish has been killed, or for some reason driven from the nest while the eggs are still unhatched, and another male comes along and takes possession, instead of assuming charge and hatching the eggs as he finds them he will simply treat the eggs as dirt, clean the nest, and bring in a female to deposit a new stock.

Another curiosity of the spawning period is the frequency with which a male will select for his mate a female much larger than himself. Out of forty-seven nests which I examined in one natural pond, two-thirds of the males were much smaller than the females; and, as a rule, a female bass is larger than a male of the same age. Except for a short time before spawning actually begins it is extremely difficult to dis- 


\section{SPAWNING OF BLACK BASS}

tinguish the male from the female,-indeed most fish-culturists say it is impossible to do so, in spite of the contrary belief among fishermen. Just before spawning time the females are rounder in outline than the males.

Barrenness occurs to a greater or less extent among all fresh-water fishes, but this does not imply that a female will be barren throughout her life. Some may be barren one year and never again until there comes what may be called a "change of life"; or barren for two or even three successive years, and then produce good eggs. Intermittent barrenness is more common among introduced fishes in captivity than among wild indigenous species. One of the most conspicuous examples in the eastern United States is the rainbow trout, of which half of the females in a single pond have been barren in one year, and at the same time half of the males were either without milt, or yielded infertile milt. This, however, is merely an illustration of a well known law of nature, that changed environment is likely to produce sterility in animal life.

Preference for Natural Nests.-Many men urge that artificial bass-nests should not be placed nearer together than ten to fifteen feet; and that the boxes ought to be so arranged that the fish on one nest cannot see the fish on an- 
other; yet in particular cases, where it was necessary for the nests actually to face each other, no trouble was experienced. Moreover, a number of bass have built natural nests immediately outside and against the boxes of some of the occupied artificial nests, and were not disturbed. Several other fish built natural nests close together and appeared to get along well. This becomes more significant from the fact that these bass were not domesticated in any way, but were wild fish caught during the spring in Lake Erie, and introduced into the breeding-ponds, where they built nests and spawned a few days after their arrival.

In every pond fish will be found which absolutely refuse to make use of nests prepared for them, however carefully constructed, but will build their own, sometimes of inferior construction. Some bass have, on occasions, carried their apparently obstinate rejection of an artificial nest so far as to scoop out a hole in the muddy bottom, in which unfavourable situation eggs were deposited and hatched.

Often the natural nests are larger and contain more eggs than those which are artificially 


\section{SPAWNING OF BLACK BASS}

built. A skilled bass-culturist in commenting on this peculiarity said:

"In the use of the artificial or box nests, it is possible that the female selected by the male may be an extraordinary fish. In their maneuvres back and forth on the nest, it is my opinion that the female sometimes becomes tired of her confinement, refuses all persuasion of the male, and will not remain on the nest until all of her eggs are cast. I noticed particularly in one season, that the larger fish nearly always occupied the natural nests, and it would naturally follow that there would be found the largest number of eggs. Of course this idea will not prevent an increase in the size of the artificial box, but even then, in my opinion, they are sometimes cramped for room."

There is reason to believe that this opinion is nearly correct, and it leads to the thought that whenever the size and the character of the bottom of a pond will permit it, natural nests will be productive of more eggs and fish than the same ponds with only artificial nests. The bass-culturist quoted above, an ardent believer in natural nests, said further:

"Where ponds are small in area, it is perhaps necessary that artificial nests of some character be used, 
so as to provide more or less seclusion. From my observation and experience, I should prefer, where conditions permitted, to build no nests, but prepare for the spawning season by arranging the pond as follows: I should construct the edges or shores of the pond in irregular shape, allowing a point to project here and there, creating small bays, somewhat like one or two of the ponds at the Drayton Plains Hatchery, Michigan. Then instead of using the artificial or box-nest, I should simply provide a sunshade, set upon props or sticks, leaving all sides free and open to the unrestricted movements of the fish. In a pond of large area, I am satisfied that this is ample shelter. It is only needed to protect the fish, while hovering over the nest, from the direct rays of the sun. The size and area of the pond would furnish the same seclusion that is given in a pond of smaller size by the box or Lydell nest."

Bass-fry and their Care.-When the young small-mouthed bass issue from the eggs they are exceedingly small and almost transparent; but in from 24 to 48 hours, depending on the temperature of the water, they change to dark brown and then to black, and resemble a newly hatched tadpole. There is no such quick change of colour with the large-mouthed bass, in which the early stages of development of the 


\section{SPAWNING OF BLACK BASS}

fry proceed much more slowly than in the case of the smallmouth.

During the sac stage the fry of the smallmouth huddle close among the stones in the nest, a quivering and almost solid black mass. In this period they cling so closely to the stones that it is impossible to remove them without injuring and killing large numbers. As the fish approach the advanced-fry stage they begin slowly to rise. When the metamorphosis is completed they approach close to the surface, provided the water-temperature is right. If when they are rising the temperature falls the little fish will drop at once to the bottom. The ascent from the nest to the surface is not sudden but gradual, and by a series of upward and downward movements, covering a period of about three days. A rise of a few inches is the limit for the first day, and about a foot or more the second, if the water-conditions are favourable, or if there is that much depth. The shallower the water the more rapid will be the ascent, which means of course, a more rapid development of the fry, on account of a higher water-temperature. The third rise is usually 
to within a few inches of the surface, regardless of the depth of the water.

Each day, as night approaches, the fry sink back to the nest, due to the fact that the water becomes cooler. After the lapse of a few days, if the advanced fry are not confined in cribs, the male parent crowds them toward the shore and abandons them. The period from the time of hatching to the time of abandonment, is from seven to ten days, under ordinarily favourable conditions.

For about twenty-four hours after this, the little fish swim together in detached schools, gradually separating until they finally become almost solitary in their habits. They then exhibit pronounced cannibalistic habits, pursuing and devouring each other, or attempting to do so. In a wild state however, the young bass at this period of their lives do not terrorise other forms of fish-life. On the contrary, small yellow perch, shiners and even minnows, regard them as tidbits, and for days the young bass are kept busy escaping the maw of those who a few months later will in turn scurry to places of safety on their approach. 


\section{SPAWNING OF BLACK BASS}

Cannibalism of Bass.-Of all fresh-water fish, the small-mouthed bass from infancy, and the largemouth from a year old, are the most inveterate cannibals. Were it not for their high qualities as food and game, their introduction into any water could only be regarded as a misfortune. Cannibalism with the smallmouth begins within a day or two after they have become advanced fry, increases in intensity as they grow older, and continues until death overtakes the fish. It is this craving for the flesh of their own kind that makes it diffcult to rear bass to maturity in large numbers in captivity.

When, with rare devotion, the male parent watches the eggs, cares for the fry and advanced fry to the point of driving them to shore, preparatory to abandoning them, there is no indication whatever of his cannibalistic habits; but no sooner has he driven them into shelter among the weeds where he leaves them, than his appetite returns, not only with full force, but whetted by his abstinence of two or three weeks when a housekeeper. At this critical moment, he will devour as many of his progeny. 
as he can catch. The young bass that escape have learned in a rude school what to expect from older fish, and, their instinct suddenly developed by the object-lesson they have had, proceed at once to imitate their parent by trying to devour each other. Very rapidly the smaller and weaker succumb to the superior strength and speed of the larger. It is a struggle for existence and the survival of the strongest.

No amount of food given is sufficient to entirely conquer this instinct of cannibalism. On one occasion 20,000 fingerlings were placed in a pond in July, to be retained there until October. They were fed six times a day, with ground fish, which they ate ravenously, and it was estimated that each day there was given about three times their aggregate weight in food; yet despite the quantity of food given and the oversight exercised, when they were counted the 20,000 fish in July had dwindled to 11,000 in October. Those which survived had grown wonderfully. None was less than four inches in length, and some were over seven inches. 


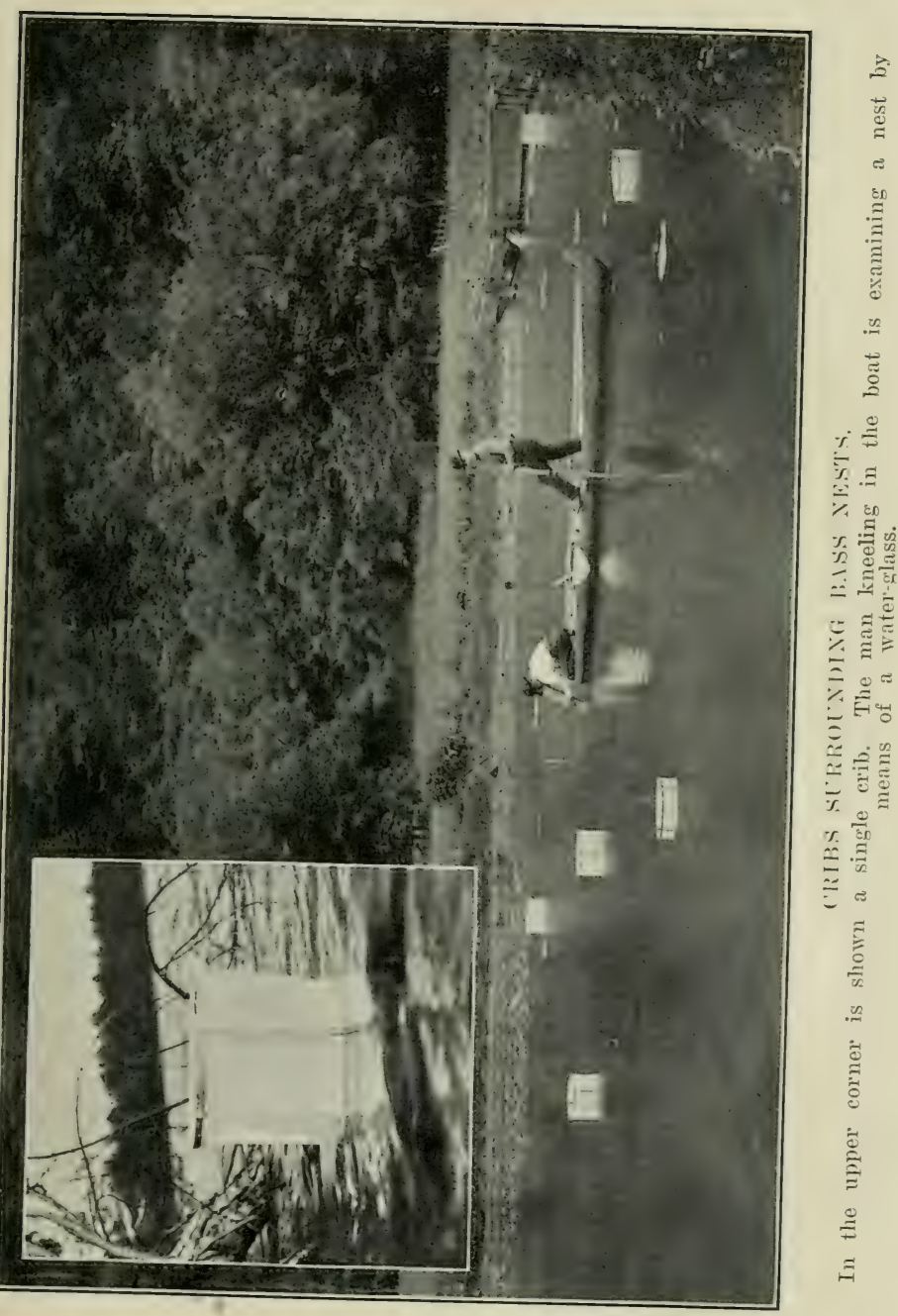



Cribs and Nest-boxes.-When the eggs in the hatchery have all hatched in any one nest, a crib or screen is usually placed around it to confine the young fish until the time arrives to transfer them to the fry-pond. The nests vary much in size as well as in the number of eggs which are deposited therein; consequently it is important that if a crib be used to surround the fry it should be of large diameter (usually $2 \mathrm{ft} .6$ inches). A crib is a circular framework of heavy band-iron, with the sides covered with cheese-cloth or thin muslin of good quality. The top and bottom are left open. As it is important that the top of a crib be at least six inches above the surface of the water, the depth will determine its height, which should not be less than four feet. Yet it is not a serious matter if a crib be of less size than the nest, because the male will keep the young outside of it close to the crib; when these outsiders begin to rise, the attendants can gather them up with a scap-net, but under such circumstances it is impossible to prevent a few small bass from escaping, and the work of saving the advanced fry is very much increased. Those who have 
had experience in gathering fry from around cribs have noticed that with each succeeding attempt to gather in the little fish, they become wilder and harder to catch. If the crib be of sufficient size to completely surround the largest nest, all this work is easily avoided.

The crib is slipped around the wooden nest, and as soon as it is finally settled, so that the lower rim is well imbedded in the bottom of the pond, the wooden nest is carefully lifted out. It is exceedingly important that the bottom of the crib be firmly planted in the floor of the pond, so as to obviate the possibility of any of the little fish escaping. It may be held in place by a board laid across the top and a stone placed upon it, but this is rarely necessary excepting in localities exposed to very high winds. If the nest is a natural or stolen one, of course the only thing to do is to set the crib about it, for there is nothing to remove. Some bass-breeders, instead of employing a circular crib of iron, make use of a square crib with wooden frame having the same diameter, held in place by anchoring it with cords to stones or to stakes. 
Nourishing Fry.-The general practice is to allow the fry to remain in the cribs until the sac is entirely absorbed, and the fish rise to the surface. It is important that the advanced fry be removed from the crib the moment they begin to swim freely, for the reason that in the confined space they will dart at each other, often nipping off the pectoral or anal fins.

Experiments made in feeding fry in cribs before transferring them to the fry-ponds have shown satisfactory results. A bunch of chara moss was suspended by a string from the board on top of the crib about midway from the bottom, and the little fish immediately attacked the small crustaceans (daphnia and cyclops) which swarmed therein. The little fish thus fed were held ten days in the crib after they had swum to the surface, making the total age of the fish fourteen or fifteen days when they were finally transferred to the fry-ponds. They were more than double the size of the fish which had not been fed in the crib, and there seemed to be a perceptibly smaller amount of cannibalism. It is believed to be advantageous to feed the ifish before putting them in the fry-ponds, both 


\section{FISH CULTURE}

as a possible diversion from their cannibalistic instincts, and because it promotes growth.

Every pond should be abundantly supplied with such aquatic plants as are particularly affected by such plankton as daphnia and cyclops, as it has been found that this food causes a more rapid growth among the advanced fry than any artificial food which can be given them. The best aquatic plant for this purpose is chara moss. The potamogeton is also recommended very highly, but it is not so satisfactory as the chara moss, especially for smallmouthed bass, which most fish-culturists now try to rear, and which are the most difficult with which to succeed. The chara moss forms a thick mat over the bottom of the pond; so thick, indeed, that unless frequently thinned too great a quantity will form and smother the young fish. It is most important that there always be kept a clear space of water, about a foot in width, on all sides of the ponds.

By heavy feeding, both with natural and artificial food, and with a favourable water-temperature, smallmouth fry should be brought to 
a length of one and a half to two inches at the end of thirty-five days. It is doubtful whether they could be retained much longer without a heavy loss through cannibalism, since up to this point it has taken continuous labour and the utmost vigilance to rear a satisfactory number.

Cultivating the Large-mouthed Bass.-For large-mouthed bass the principal requirements are a large pond, similar to that already described, and the same water, with the shelf well covered with chara moss or coarse grass. The largemouth will clear up spots in this moss or grass, deposit the eggs thereon and hatch them. No artificial nests are necessary. The natural nests may be surrounded by cribs in the same way as for the small-mouthed bass, and at the proper time the young may be removed to the fry-ponds.

The large-mouthed bass are much slower in turning a dark colour than the smallmouths. During the fry stage, they are not quite as cannibalistic, although after they are placed in the fry-pond, and begin to feed freely, there is 
48

\section{FISH CULTURE}

little difference in this respect. They can be carried, hatched, and reared in a much lower grade of water than can be used for the smallmouth, and hence the chances for success with them are increased. 


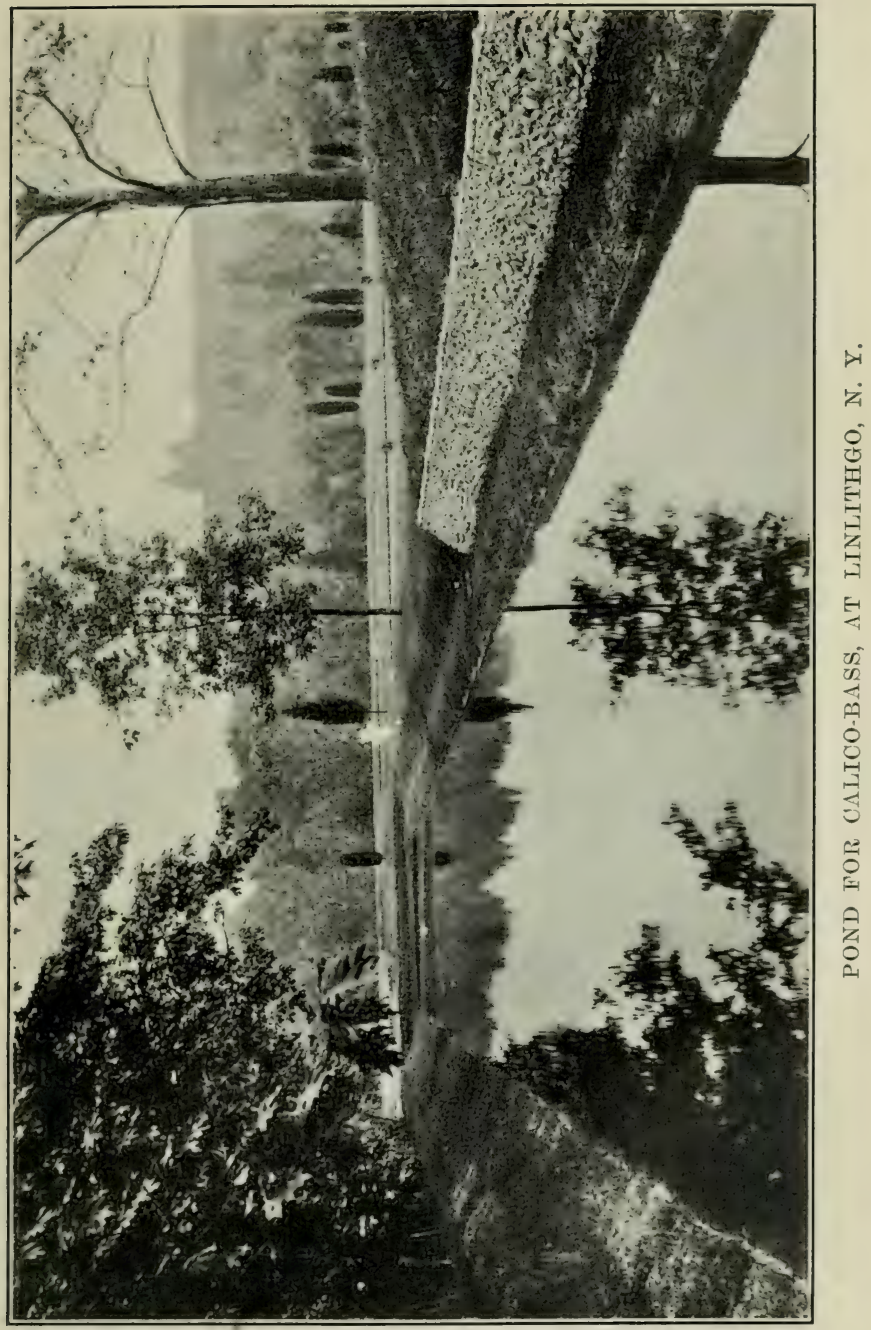





\section{CHAPTER III}

\section{ROCK-BASS, CALICO-BASS, AND SUN- FISHES}

Aцtнобян among the smaller fishes, the rockbass, calico-bass (or grass-bass), and two or three of the sun-fishes, are well worth attention by fish-culturists. They afford excellent food, and their game qualities are not to be despised by anglers. Of the sun-fishes the bluegill, or Lake Erie sun-fish, attains a size suitable for the market, and has a distinct commercial value. Its flesh is firm, sweet, and of high grade. It rises readily to an artificial fly, takes bait with avidity, and gives the angler a short but brisk fight.

The eggs of the sun-fish can be taken and fertilised artificially, and a gratifying percentage hatched; but it is found to be easier, cheaper, less troublesome, and quite as satisfactory, to allow the fish to spawn naturally, 
and care for the fry themselves. It is even possible to leave the young in the same ponds with the adults, until, through growth, overcrowding is evident. Some cannibalism will naturally follow this method, but usually not to a serious extent. It is confined almost wholly to the older fish. This is true especially of the long-eared and bluegill sun-fishes. However, as the sun-fish is so prolific, and the proportion of eggs naturally fertilised so very large, some may be spared to supply the maws of the parents, and yet leave enough to make a good showing for the fish-culturist.

The habits of rock-bass, calico-bass and sunfishes, just before breeding time, during this period and after it, are very similar to those of the black bass, with the exception that the sun-fish is more inclined to polygamy; and that none of the three named has as strongly developed cannibalistic habits as the black bass. The rock-bass is more apt to devour its young, and these young are more likely to eat each other, than are any of the sun-fishes. The calico-bass seems to hanker the least for the flesh of its kind. A pisciculturist may there- 


\section{SMALL BASS AND SUN-FISH 51}

fore, with some degree of confidence, have either rock-bass and calico-bass, or calico-bass and sun-fish, breeding in the same pond.

Nesting Habits.-Rock-bass and sun-fish are decidedly gregarious during the spawning season, and their nests are often found closely: mingled. The whole of the bottom, or both sides of a pond, have been observed so thickly; covered with sun-fish and rock-bass nests that they almost touched each other, the occupants apparently dwelling in amity. The same type of pond may be constructed for the three species as for black-bass breeders. It is unnecessary to build artificial nests unless the bottom be more than usually muddy, although these three species prefer sandy or gravelly: places on which to deposit their eggs. They desire from one to three feet of water in which to spawn. It is a curious fact that in Pennsylvania the four principal species instinctively choose, when they have the opportunity, different degrees of depths. Calico-bass will often build nests in six feet of water. The common "pumpkin-seed" selects a very shoal spot, and begins nest-building a few days earlier than its 
cousin, the common or long-eared. The bluegill follows a few days later. The common long-eared sun-fish usually locates a little deeper than the pumpkin-seed, while the bluegill seeks the deepest water of them all.

Spawning Time.-The sun-fishes and the rock-bass do not begin spawning quite as early: as the black bass. In fact they rarely begin nest-building until the latter have almost finished hatching their eggs. It is seldom, when the bass begins spawning the latter part of May or the first of June, that sun-fish have started to clean up their nests. It is not until the end of the first week, or the beginning of the second week in June that sun-fish activity begins, but when a start is made, there are found to be specimens to continue it until the middle or the latter part of August. There appear to be two distinct periods when there is a more pronounced industry and a greater number of fish on the spawning beds. The first period is from the beginning of June until the early part of July; the second is from about the first to the tenth or fifteenth of $\mathrm{Aa}$ gust. 
Nest-making of the Sun-fish.-Sun-fishes are small in body, but ambitious when it comes to nest construction. The house-building aims of the sun-fishes remind one of the frog, which, in the fable, endeavoured to emulate the proportions of the bull. Happily, unlike the frog, which is said to have burst in its efforts, the sun-fish achieves success in his ambitions to outclass his huge cousin, the black bass, in the size, symmetry, design, and even artistic character of his house.

A sun-fish's nest can, in nine cases out of ten, be distinguished at a glance from that of the small-mouthed bass, even where both have located on the same kind of bottom. The former, is, in the majority of instances, from two to three times as large as that of the bass, and when he can select a sandy place where there is some coarse gravel the nest is almost invariably a nearly perfect circle surrounded by a symmetrical rim of sand, several inches high. Thus the gravel is arranged in the center of a decidedly bowl-like depression, with almost mosaic exactness of design. This domicile, while fit in every respect for the accommoda- 
tion of the female during the period of spawning, is manifestly too large for her needs. Perhaps the size is due to the polygamous instincts of the male. Be this as it may, it is not an uncommon thing to see the male surrounded by two, three, or even as many as five, females when on the nest, sometimes fertilising the eggs of one after the other, and occasionally of two simultaneously.

The sun-fish seems to be very sensitive to observation during the process of spawning. Every few minutes the operation will be suspended while the male darts suddenly from the nest and encircles it a few feet distant; if any other fish happens to be near he will attack it savagely, drive it away, and return with a jaunty air to his mate or mates.

Hour by hour and day by day the spawning is continued, until all the eggs of one or more females are deposited, and the bottom of the nest seems to be literally covered with small grains of coarse, translucent sand. In the majority of cases the females leave to the male the task of keeping these eggs clean until they 

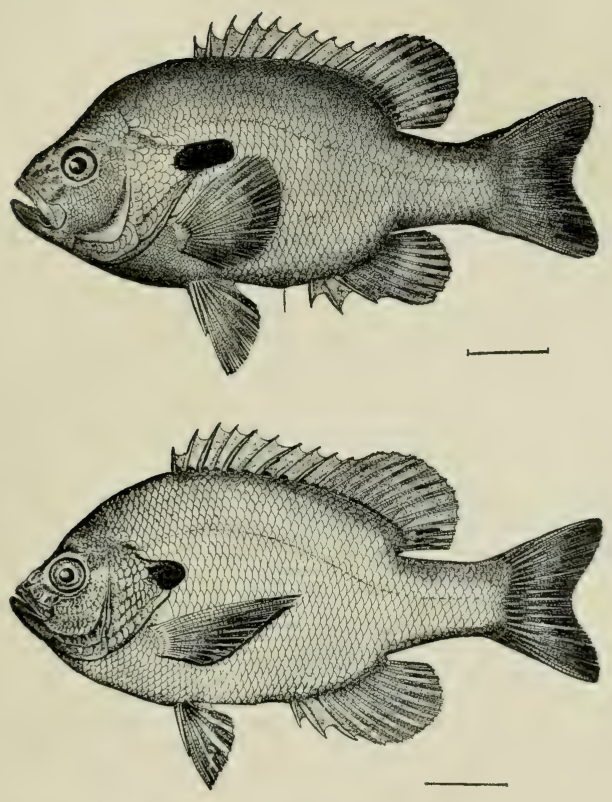

PUMPKIN-SEED OR SUN-FISH (Lepomis gibbosus). LONG-EARED SUN-FISH (Lepomis auritus). 



\section{SMALL BASS AND SUN-FISH 55}

hatch them; but there have been instances where females assisted the male in the cares of parenthood.

Care of Sun-fish Young.-When first hatched, the fry behave very much like those of the bass; but when they reach an advanced stage and rise towards the surface, they are not looked after with the same solicitude by the parent fish, but are discarded almost as soon as they have absorbed the yolk-sac. The male sun-fish is an interesting creature at this period of his life, reminding one of a bantam cock; he is as quick to take offence, attack and fight, regardless of the size of his antagonist. A single male will frequently attack a mature bass or a huge carp, with as much ferocity and confidence as a black bass would chase a sun-fish were he the householder.

Within a brief time after they have been deserted by the parent, the young of the black bass scatter, each going its solitary way; but the sunfish cling together in schools, sometimes for two or three weeks; and in fact they may be found during the entire summer in groups of vary- 
ing numbers. The young fish grow very rapidly, and by September it is a joy to behold them in their shimmering opal coats.

Artificial Rearing of Sun-fish Fry.-Unless a culturist wishes to be very particular and save every possible fish, it will not be found necessary to surround a nest of sun-fish fry with a crib or pound, but he may allow them to scatter and dwell in the same pond with the old fish until ready to be disposed of. This method has one disadvantage in that the culturist can scarcely give more than a wild guess as to how many fish he is rearing. If he impounds fry, and removes the advanced fry to ponds by themselves, he may make a reasonable estimate of what he has.

Fish so removed will grow more rapidly than when left in the breeding-ponds, especially if the fry-ponds have a good supply of aquatic plants which invite abundant plankton. In the early days of sun-fish life, the common, longeared species seems to grow more rapidly than the bluegill. It is not until after it is about three months old that the bluegill starts, and then it speedily surpasses its more bril- 

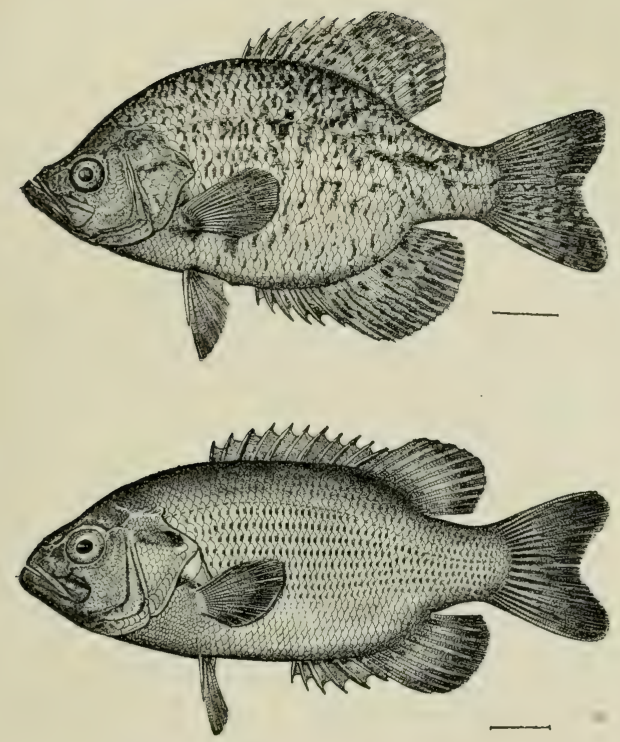

CALICO- OR GRASS-BASS (Pomoxys sparoides). ROCK-BASS (Ambloplites rupestris). 

liantly coloured cousin in size. An additional reason for removal is that rapidity of growth is gained when the young do not have to spend half their time in evading the attempts of the mature fish to devour them. It would be a waste of time and money to put in any such an artificial nest as is used for black bass. It would be cheaper to strip the fish and hatch the eggs.

Rock-Bass.-The nest of a rock-bass, while usually as large as that of a sun-fish, is sometimes quite small, less in size than that of a small-mouthed bass, and no larger than that of an Oswego, or large-mouthed bass. Like the largemouth, the "goggle-eyes" will readily clean up a nest on masses of aquatic moss or chara. Polygamy has not been reported by any authority. The male guards its young more sedulously than does the sun-fish, and falls little behind the small-mouthed bass in this kindly duty.

Calico-Bass.-Calico-bass (grass-bass) prefer water that is quite deep for nesting purposes. For this reason it is most difficult to observe their habits during the spawning season. Why 
they select water so much deeper than the rockbass and the sun-fishes can only be explained by the possibility that they prefer semi-darkness while spawning, an idea strengthened by the fact that a nearly related fish, the crappie, will spawn successfully only in cloudy water. 


\section{CHAPTER IV}

\section{CAT-FISH CULTURE}

Ir is possible to take eggs from the cat-fish, but there is no necessity for doing so. Natural fertilisation is so nearly perfect, the care given by the parent to incubation and to the young is so faithful and unremitting, that it is needless for the fish-culturist to increase his stock by the artificial expression of eggs. Moreover, on account of the spiny rays on the pectoral and dorsal fins, the operation of stripping is unpleasant, and likely to be very painful, to the man who attempts it.

Spotted Cat-fish.-There is one species, the spotted cat-fish, which has thus far defied every effort made to handle it successfully, even by pond-culture. Hitherto the greatest experts in the United States have been forced to acknowledge complete defeat. Spotted cat-fish, 
when transferred to hatchery ponds, absolutely, refuse to breed, and show no signs nor indications of spawning; for this reason it is attracting considerable attention. At one of the meetings of the American Fisheries Society, it was suggested that possibly success might be achieved if the fish were placed in running water instead of in ponds. Here is an unbroken field, but one of great value, since the " spotted cat" has few equals among fish for delicacy of flavour. Its successful introduction into waters which do not now contain it would mean very much for the public.

The bullhead and yellow cat-fish offer no difficulties whatever, and the white cat-fish comparatively few, for artificial or natural breeding. In the matter of their propagation in ponds, the only unhappy feature is the large percentage of mature fish which are apt to die about the spawning period. The act of spawning appears to be nearly as hard on white and yellow cat-fish, and even on bullheads, as on the shad or eel. One need not be surprised if he finds after the spawning period is concluded that he has lost nearly half of his stock. The 


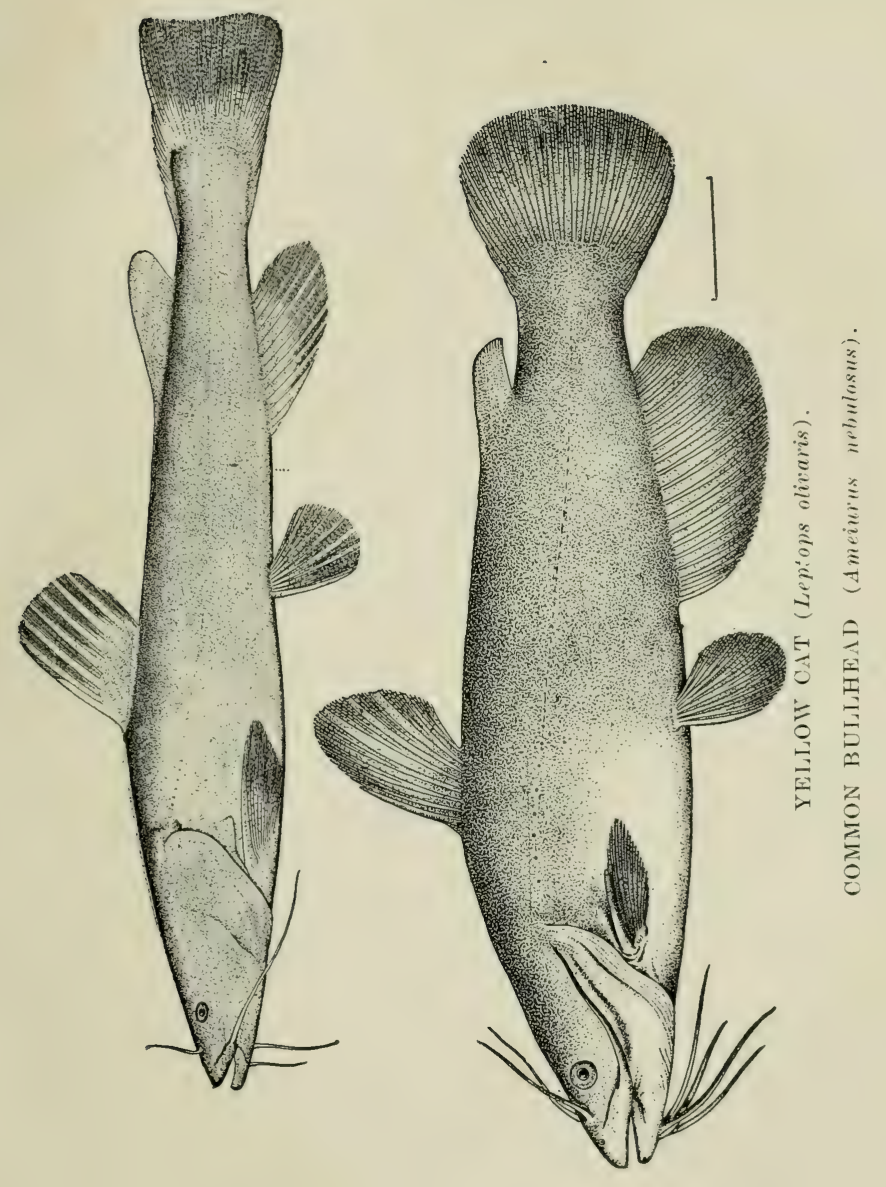



fish at that time contract fungus more readily, than some scaled fishes.

White and Yellow Cat-fishes.-The white and yellow cat-fishes, when transplanted from rivers like the Delaware and the Hudson into interior waters in the same latitude, develop a flavour excelled by very few species. The yellow one takes very kindly to being transferred from its native environment, and land-locked, while the white cat-fish accommodates itself to changes nearly as well. Hence the culture of both these species can be profitably carried on for market purposes in towns removed some distance from sea-port cities, since the prices for them in city markets are very encouraging.

One man in Pennsylvania had a number of artificial ponds, each covering a considerable area of ground. One or more of them had formerly been mill-dams. At a certain period of the year he drew down the water, thinned out his stock of young bullheads by netting them out and throwing away the smallest, returning to the water only the largest and best appearing, as he said that unless such thinning took place the entire stock would be stunted and their market value depreciated.

The Commonwealth of Pennsylvania has for sev- 
eral years been engaged in the propagation of white and yellow cat-fish on a large scale. It has, however, been giving very little attention to pond-construction for this species of fish, simply using types of ponds already built. The only uniform features have been natural clay banks and clay bottoms without any gravel coverings. The most pretentious ponds as far as size and general utility are concerned are at Torresdale Station, in Philadelphia. One is 150 feet square; another is 275 feet long and 90 feet wide; others are about 100 feet by 30 feet. The largest is about six feet deep in the kettle, with an average depth of a foot and a half all over the shelf. It was formerly used for propagating sun-fish and bass. It is excavated throughout and is fed by a small stream. The first-mentioned pond is supplied by water pumped into it from the Delaware River. White and yellow eat-fish do equally well in both ponds, and in 1908 the square pond yielded very nearly 200,000 eat-fish from about 300 brood fish of both sexes.

Spawning and Care of Young.-The spawning habits of the white and yellow cat-fish are interesting. Although a nest-builder, the location of the home and the habits of each are notably different from those of the black bass. Instead of selecting a stony or gravelly spot as a small-mouthed bass would do, or a sandy. 
place like the sun-fish, or a moss-grown bottom like the large-mouthed bass, it chooses one of the banks of the pond or a sharp depression in the bottom. Here is excavated a tunnel or cave, sometimes equal in length to the fish itself, and several times larger in circumference.

The eggs, and there are many of them, are deposited thickly on the bottom of the excavation and fertilised, one of the parents taking a position over them with only its head projecting from the cavern. Here it remains almost motionless, rarely leaving for any purpose except to drive away an intruder, or when stirred out by a stick. Left alone, it will almost immediately return to its household cares. The catfish is a solemn and forbidding-looking creature about the head, even under favourable circumstances, but there is something almost savage in its aspect when guarding a nest. The cavern, the position which the fish takes, with head only projecting, and the warlike look in its eyes, together with its capacious mouth, bring to mind some fabled monster.

Under favourable water-conditions in Pennsylvania, both the white and yellow cat-fishes 
begin spawning about the latter part of June. The period of incubation is about two weeks. As soon as the young have absorbed their sacs and are ready to swim up to the surface, they are coaxed from their cavern to the water just outside its entrance. Here they remain for a day or two, being driven back daily into the cave when the sun has gone down, or when enemies approach. Little by little, however, they are led away, though kept closely herded, until they appear on the surface of the water like a big quivering black ball. In this manner they work slowly back and forth over the pond. As they move, the old fish swims slowly around them, driving back into the mass any which may stray. At this stage of their development the fish-culturist steps in, and with one sweep of his long-handled scoop-net gathers in the entire school and transfers them to one of his small ponds, where they can very quickly be taught to eat ground liver, and, later, pieces of bread. The fish grow quickly, and by the first of September are an inch or more long.

Profit in Pond-culture of the Cat-fish.-Few fishes offer greater possibilities than some of 


\section{CAT-FISH CULTURE}

the cat-fish, notably the common bullhead and the yellow cat-fish. Their cultivation is peculiarly to be recommended to farmers. Almost every man engaged in agriculture possesses a piece of low wet land with a spring-run or a small stream flowing through it. This land is perhaps not extensive enough for ponds of a sufficient size for commercial value, but it would have to be less than half an acre to be too small to be converted into two or three cat-fish ponds large enough for an unfailing supply for table use.

Mature fish in confinement will readily take almost any food which may be given them. They eat living minnows, dry bread, or chopped lungs, with equal gusto, and in taking any floating food make a sucking noise nearly as loud, and remarkably similar to, that made by ill-bred men when eating soup or drinking coffee.

Under favourable circumstances cat-fish will be ready for the market when nearly two years old, and certainly at the age of three. Their remarkable tenacity of life should make them particularly valuable for the market, since there is a very large element among consumers who in- 
sist on purchasing alive the fish they want for their table, and living fish bring a much higher price than those which are sent to the market dead.

Preparation of Cat-fish Ponds.-Construct one pond which will occupy about half the land available, and three others which will occupy the other half. The large one will be used for breeding, and for the maintenance of fish more than one year old; while the smaller ponds are for the rearing of young fish up to the age of one year. The sorting may all be done into these three ponds. Two or three ponds about 300 feet long and 100 feet wide each, and ten or twelve smaller ponds, would yield many hundred thousand healthy fingerlings and yearlings to be sold for stocking purposes. If, however, it is designed to raise cat-fish for food and for market there must be a decided increase in the size and number of the larger ponds. It would not be advisable to increase the size of the ponds designed for keeping those less than a year old, because they could not be easily and quickly worked; but it might be desirable to increase the number in order to permit sorting into three 
or more sizes at least three times in the first twelve months.

Sorting fish into sizes several times during the year is a very important duty of the fish-culturist. This is true even when the young are not pronouncedly cannibalistic. It is a well known fact that very young fish of the same age vary considerably in size. When allowed to remain unsorted, the larger annoy the smaller, will not allow them to eat until they themselves are gorged, and chase them around the pond between meals. As a result, the smaller fishes do not grow, at least at the same rate as the larger. When sorting is practised, the majority of the smaller, if they are in good health, rapidly overtake the larger, and there is not much difference in size when they reach the yearling stage. At that age, the smallest, or cullings, can be disposed of, leaving the others in fine shape for rearing to market age. Where the species are cannibalistic, sorting is imperative, if it is not desired to lose more than fifty per cent. of the young stock.

The larger the volume of water the more rapidly the fish will grow. The quicker the growth the sooner the fish will be ready for the market. Ponds from three quarters to one acre in area each are advised, with a length much greater than their width. Very wide ponds are 
to be avoided, because of the difficulty in handling the nets when fish are to be removed, unless it is possible to draw off all the water for that purpose.

The character of the sides and bottoms of the ponds for cat-fish culture is important. When ponds are built for most types of fishes the bottoms are gravelled, and in some instancestrout-culture for example-the sides are walled with boards, stone or concrete; but ponds for cat-fish must have the banks and bottoms of clay,-at least those portions where the fish spawn. The kettle, or deep portion, if not of clay, may be of heavy mud, but not too deep.

There are two reasons for this : first, the clay banks and bottoms are essential as nest-building and spawning places; second, during the winter months cat-fishes burrow to a greater or less extent. They cannot do this where the bottom is gravelly.

Two feet is a sufficient depth for the shelf, although two and one-half or even three feet is more desirable. The kettle should be from five to six feet deep. Cat-fish do better where the water is not too shallow, and for this reason 


\section{CAT-FISH CULTURE}

the greater depth of the shelf is advised. The shelf, a shoal part, had better comprise the greater part of the pond, as it gives a larger spawning-surface. The kettle naturally will be located at the outlet end. Arrangements for the inflow and outflow are the same as for bass or any other warm-water fish-ponds-that is, provide an inflow pipe, and for the outflow concrete gate-frames with splash-boards and screens. About the same amount of water is ordinarily used as for black bass, although catfish can get along on a smaller supply. Too little water breeds the dangerous fungus. 


\section{CHAPTER V \\ CARP CULTURE}

$\mathrm{H}_{\mathrm{AD}}$ it not been for over-enthusiasm carp farming would probably now be a very large and valuable industry in the United States, and the fish generally regarded with friendly eyes. Instead, it is undoubtedly the most execrated and unjustly accused fish swimming in American waters.

The introducers of the German carp have been likened to Benedict Arnold. Many men have advocated laws putting a bounty on the death of the fish with a view to its extermination. Pennsylvania, in order to prevent its increase, carried in its statute books for a time a law imposing a heavy fine on any person who planted carp in any of the waters of that state.

There is not a fish-crime on the calendar that has not been charged against the German carp; some rightly, many more wrongly. It is accused of being 


\section{CARP CULTURE}

a spawn-eater, probably with justice; also of destroying water-plants, which are almost as necessary to the well being of fish-life as the water itself. This charge is undoubtedly true. Wherever there has been a decrease in game fishes it has been accounted responsible. There is little if any truth in this last statement. In many instances where carp have been pronounced the offenders, the decrease has been traced to other agencies, chief among them man. The most widespread condemnation is that it is unfit to eat, as its flesh has a strong muddy flavour due to its habit of rooting in the bottom of a pond or stream.

The bad reputation of the carp was gained through over enthusiasm on the part of its friends, and misapprehension regarding the requirements of its successful pond-culture, when first introduced into the United States. As a matter of fact, while the carp is undoubtedly very inferior in table qualities to many native food-fishes, it is not an unpalatable fish when reared in a suitable environment. It cannot be so, since it is found on the bills of fare, at one dollar a portion, of high-class restaurants in New York and elsewhere. Without doubt, many persons who have condemned the carp most severely, have eaten it under the impres- 
sion that they were being served with something else. Mr. John W. Titcomb, formerly the head of the Division of Fish Hatching of the United States Bureau of Fisheries, relates that in January, 1902, 224 members and guests of the North American Fish and Game Protective Association were served with carp at a banquet, ate it and pronounced it "good," under the impression that it was baked red snapper.

Bad Reputation Due to Improper Culture.When the carp was first introduced into America the authorities very properly stated that it was a highly esteemed fish in Germany and other parts of Europe; that it was very prolific, easily cared for, suitable for warm sluggish waters, and specially adapted to pond culture. There was an instant and widespread demand for the new importation. Farmers who had duckponds, built perhaps three quarters of a century before and never cleaned, stocked them with carp. Others built for their reception dams across streams on their bog-lands, without taking the trouble to clear away the mud. Almost any muck-hole containing a few hundred gallons of water was considered fit to be utilised. 


\section{CARP CULTURE}

The craze, for such only can it be called, spread rapidly without any pretence of method or intelligence until "almost every farmer had a carp pond in his front yard, back yard, barn yard, or somewhere." The crash came when the fish were large enough to be killed. As might be expected they were inedible. Their flesh fairly reeked with a smell and a taste of filth. The disgusted farmers tore down their dams and liberated the fish with blackened characters into the public waters.

Unquestionably the carp is inferior to almost every other fish native to waters like those of Pennsylvania, but it is equally certain that if, when it was first introduced into this country, fish-culture had been advanced as far as it is to-day, carp-farming would probably be a recognised industry, yielding in the aggregate a huge sum of money annually. As it is, a revulsion of sentiment is slowly but surely taking place in favour of this importation as a food-fish.

Market Value.-The carp undisputably holds an important place in the market. It is worth several hundred thousand dollars a year to the state of Illinois. Over 40,000 pounds, two- 
thirds of which come from other states, are sold weekly in the markets of Philadelphia, while $5,000,000$ pounds are disposed of yearly in New York. A five-pound live carp will sometimes bring more in Philadelphia or New York than a Delaware River roe-shad of the same weight. Almost the entire industry in America to-day depends on the carp caught from the rivers and lakes, although a large proportion are held in temporary ponds and pens before being sent to market.

There is reason to believe that if states now condemning this fish would recognise its market value, would give encouragement to its citizens and would instruct them in the proper methods of culture, capital would speedily be invested and carp-farming become a profitable industry, as it is to-day in Germany. It should become profitable, because the demand for carp in the large cities is generally greater than the supply, and because in the smaller cities a demand car likely be made for the fish. As carp-farming is not generally carried on in this country, it is impossible to say how large a tract would be necessary to insure very profitable returns, but 
probably any reasonable amount would yield fully as much, acre for acre, as land devoted to vegetable produce. This is important, since a carp-farm can be established on land which ordinarily yields little or nothing.

Ponds.-Hatching-houses and expensive apparatus are unnecessary. The entire business may be conducted by pond-culture. Mr. Leon J. Cole, who prepared a bulletin for the United States Bureau of Fisheries in 1905, entitled "German Carp in the United States," says :

"A well appointed carp-cultural establishment has at least three kinds of ponds, each adapted for a particular phase of industry.

"1. Spawning ponds.-Shallow ponds in which the water is easily warmed by the sun and suitable for the spawning fish.

"2. Raising ponds.-Ponds usually of medium size, to which the fry are transferred and where they are retained, isolated from the larger fish, until they are a year or two old.

"3. Stock ponds.-Large ponds in which the fish are kept until they have reached a marketable size; this is usually considered to be when they have reached a weight of two and three-quarters pounds to two and a half pounds." 
To these Mr. Cole adds a fourth type, namely winter ponds, located in sheltered spots, which should have a depth of six to eight feet. Winter ponds are only necessary where the stock or raising ponds are not suitable for carrying fish from autumn to spring, that is to say, where the water would freeze to or nearly to the bottom.

Generally, it is not wise to build any ponds for the cultivation of carp by damming a stream unless there is no possibility of a freshet. Should it be found cheaper, and otherwise good policy, to build in this manner, an artificial ditch should be built the whole length of the pond, at one side, to carry off surplus water. If a dam built across a pond were to break out, or an overflow to occur of any considerable depth, an almost total loss of fish would result. This is peculiarly the case with carp, for that fish more than most follows currents and changes in depths. If surrounding land becomes submerged, for instance, nearly every carp will swim from the pond to the submerged lands.

The third type, described by Mr. Cole as the 
"stock-pond," should be as large in area as possible; it may properly be two or more acres in extent. Conditions which call for restricted areas for other species of fish do not obtain with carp, on account of its proneness to follow currents, so that there need be hardly any restriction placed upon the size. It is only important that, apart from the wintering quarters or kettle, there should be at the lower end splash-boards or gates which can be opened easily to permit the water to be drawn off rapidly along a race or ditch into a pool known as a "fish-pit," into which the carp will go and where they can be netted out.

If desired, and this is recommended by $\mathrm{Mr}$. Cole, the fish-pit can be in the pond itself at the place of outlet. Ditches from various parts of the pond lead into other ditches which are deeper, and these finally lead into the fish-pit itself whence they can be taken out with dipnets.

Care of Carp.-There ought to be at least two stock-ponds so that one can be annually drained, cleansed of sediment, and purified by the action of air and weather. To insure the best results 
there should be a large number of spawningponds of small size, each large enough to hold not more than five fish, three females and two males. They must also be very shallow so that the water may be warmed rapidly by the sun. Such ponds need not be more than 20 feet long, and eight or ten feet wide. Raising-ponds for advanced fry, fingerlings and yearlings, must of necessity be much larger, and somewhat deeper than spawning-ponds. They should not, however, be of so great an area that they can not be easily seined, and the fish handled quickly and thoroughly; but they must be large enough to carry safely a number for at least one year, preferably two.

To facilitate growth, the water should be moderately warm, mostly shallow, and the ponds supplied with an abundance of aquatic vegetation. A large volume of water is not essential, but enough to insure proper aeration and to prevent too high a temperature is necessary. Contrary to widespread belief there can be an excessive water-temperature, even for carp.

Rudolph Hessel, in his work "The Carp and Its Culture in Rivers and Lakes and Its Intro- 
duction into America," says that the inflow of water into the pond should never be allowed to be direct; as, for instance, a brook falling into it. "This often causes the water to rise at an inopportune time, carrying into the pond other fishes, especially the rapacious pike. The carp also has the disposition to swim towards the inflowing water, by which means it is drawn away from its proper feeding place." If this is correct, and from the investigation of Mr. Cole it appears to be, then the inflow should be so arranged as not unduly to attract the fish to the spot.

Kinds of Carp.-There are three well defined species of introduced carp more or less common in American waters; namely the leather, mirror, and scale carp. The leather carp is distinguished by its having no scales, or only a few on its back, but, instead, a thick soft skin, velvety to the touch. The mirror has three or four rows of very large scales on its sides, the rows being separated by a scaleless skin. The scale carp is completely covered with scales, and is neither more nor less than a developed form of the original species. All three are rapid 
growers, attaining heavy weights and having the reputation of great longevity. Specimens weighing from 20 to 25 pounds are not uncommon, and occasionally there are found some, particularly of the mirror carp, which will turn the scales at 40 pounds. In water of ordinary temperature carp will acquire a weight of from three to three and a half pounds when three years old, and where the water is warmer they sometimes reach it in a year or two.

Spawning Habits.-In the warmer parts of the United States carp begin spawning as early as April, but in the Middle States not until May and June. Under ordinary circumstances they require three years to reach maturity; but it is said that under very favourable circumstances they sometimes spawn when only two years old. According to Robert A. Poppe, carp have been known to spawn when nine months old. Whatever the age, fish first spawning are from three to four pounds in weight, with a length of from 15 to 18 inches. The eggs are very small, but the number to each female is exceedingly large, a female weighing from four to five pounds yielding from 40,000 to 50,000 
eggs. A fish of $16 \frac{1}{2}$ pounds may have over $2,000,000$.

The carp is not a nest-building fish. The egg's are deposited carelessly about in shallow water, and then abandoned. As they are strongly adhesive they become firmly attached to the roots of grasses on the bottom wherever they happen to fall. They develop rapidly in water having a temperature of 69 degrees, and hatch in five or six days, but in the Middle States, under ordinary conditions and favourable temperature, they require only about twelve days.

On account of the great number of eggs produced many breeders are not required. Into each spawning-pond should be placed either two females and one male, or three females and two males, constituting a "spawning party." According to Cole, the spawning is not confined to any particular time of the day, though it apparently takes place during the morning hours, probably about daylight. Mr. Hessel says: "The female drops only about from 400 to 500 eggs at a time, and it will require days and weeks before she has given up the last egg. 
There is some doubt also as to whether the eggs are extruded while the fish is in motion, or, as is the case with the shad, whether the function takes place while the fish is not moving." Instances have been known, however, where several thousand eggs were deposited at one time. A female carp weighing 16 pounds, in the Fairmount Park Aquarium, Philadelphia, deposited in a single night, on one occasion, eggs estimated to number 20,000 or more.

Mr. Cole, in writing of the spawning habits of the carp, makes the following assertion:-

"I was unable to tell at what moment the actual spawning took place, though I observed at times that one of the males would work forward near the female until they were swimming nearly side by side, when he would turn somewhat on his side, and bring his ventral fin closer under the female. At such a time the body of the male usually shook with a sort of quick vibrating movement (though this was not always observed to be the case) and it was then, too, that the most violent splashing of water occurred. It is probably at this time that the eggs were laid and fertilized." Fish-culturists agree that during the actual spawning time the operation is accompanied by considerable splashing. 
The spawning-ponds should all have a moderately hard bottom, and if it is intended that the eggs are to remain for hatching where they are deposited, then there should be a thick growth of aquatic plants to which the spawn can adhere. One experienced carp-culturist, however, kept his spawning-ponds entirely clear of plantlife. Instead, he had sheets of bagging material on which he fastened thickly bunches of grass and plants, and to each corner of the sheet he affixed a weighted pole. This contrivance he placed in the pond and then introduced his spawning fish. Every day he removed the apparatus to a pond containing no fish, so that the eggs adhering to it could hatch without any danger of their being devoured. Fresh sheets were then placed in the ponds with the spawners.

Precautions.-There ought to be no difficulty in taking the eggs from the female and impregnating them artificially, in which case time and labour would be saved. Under some circumstances these eggs could be treated the same as goldfish's eggs when taken artificially, that is, placed upon sheeting and submerged. 
After the sacs of the fish have been absorbed, or after they have reached a size which will not permit of their being retained in the spawning-ponds longer, they must be transferred to the rearing-ponds. By autumn they will be from three to four inches long, and the following spring they can be sorted and placed in different rearing-ponds according to size. Although not a carnivorous fish, strictly speaking, sorting into sizes is still desirable, as, when all are kept together in one pond, growth is not rapid.

The rearing-pond should be supplied not only with water plants but also with large quantities of small crustaceans, a favourite food of the carp. They are especially fond of daphnia, hence the growth of this minute creature should be encouraged. But the carp is an omnivorous feeder, and may be given almost anything which comes to hand. They will eagerly devour bread, partly boiled potatoes, turnips, grain, or even chopped young corn-leaves. They will not disdain flesh, as they will eat both lungs and liver.

When shipping to the market, if the distance 


\section{CARP CULTURE}

is not too great they may be carried alive by laying them on wet grass and covering them with it. It is only necessary, it is said, to keep the body and gills wet. If the distance be too great to carry them in this manner then they may be transported in shallow tanks of water. 


\section{CHAPTER VI}

\section{WATER FOR TROUT CULTURE}

IN selecting a site for a hatchery for the cultivation of trout, two conditions are to be observed-one, that there be a slope to the ground, and the other a spring of proper quality and volume, or, in lieu of the spring, a good stream of cold, rapidly running and clean water, and free from frequent flooding. The best supply is derived from a deep spring, since such springs seldom run dry, or change materially in volume or temperature.

Quality of Water.-Some men suppose that a very large volume of water is required to successfully carry on a trout-hatchery, but this is a mistake. A moderate, steady supply of water of even temperature, thoroughly aerated, will produce as satisfactory results as a large body, if skillfully utilised. Nevertheless he is a fortunate man who owns a spring that fur- 


\section{WATER FOR TROUT CULTURE 87.}

nishes more water than he thinks he can possibly use. Where a spring is of small volume the hatchery supply may be augmented under certain conditions by water from a stream. When this course is pursued it is better that the flow from the stream be used for the ponds entirely, and that from the spring first for the hatching and nursery troughs, and then for ponds where the two may be mingled if found most convenient. It is held, indeed, by many. fish-culturists, that while spring water is best for hatching trout eggs, stream water is better for rearing fish after they are four months old. Artesian or other very deep wells may be used for the increased supply of water.

I am one who holds that trout-stream water of good volume, which can be flowed through ponds without causing an undue rise in temperature in summer, is better under some circumstances than an outflow directly from a spring. Creek water possesses both aeration and animal life, and is usually a little higher in temperature during the best growing period of the trout, a very desirable feature, especially when the fish are in the fingerling and yearling 


\section{8}

\section{FISH CULTURE}

stages. Water which is at times slightly impregnated with mud of a certain character appears to be harmless, and often is actually beneficial. Spring water, however, is preferable to creek water for hatching purposes. If, however, it is necessary to depend on stream water for hatching purposes, it would be well to arrange some device by which it can be filtered before its entry into the hatching-house.

Water-Supply Most Important.-Prospective fish-culturists should give the greatest attention to the character of the water-supply, because on it depends primarily success or failure. To be sure of its excellence is more important than the location of the hatchery, a heavy pitch in the land, or proximity to a town or a railroad station. An artificial pitch in the land can usually be created. Ponds can all, or most of them, be built above the ground when necessary. to insure a proper flow and aeration throughout; horses or motors can in time reach the nearest railroad station or town; but if the water falls below requirements either in steady quantity or quality, the place is useless for a trout hatchery. 


\section{WATER FOR TROUT CULTURE 89}

As an axiom, a fish-culturist should bear in mind that if losses occur they are almost sure to be wholesale and not retail, so to speak. Trifling changes in the character or conditions of the water-supply may mean the loss of every fish. In 1889, the Pennsylvania Fish Commission lost over 2,000,000 advanced fry, partly because, during a thaw after a severe snow-storm, a vast quantity of surface water flowed into the spring which supplied the hatching troughs, and so diminished the supply of oxygen that there was not sufficient to sustain the lives of the little creatures. Hence, when a station is located, it is advisable to so guard and wall in the spring that little or no snow, or in fact, surface water of any kind, can flow into it. What is of equal importance, drainage from barnyards, tanneries, or any industrial establishments, must be carefully excluded from all water used, for pollution of that character is fatal to trout. Such pollution, indeed, is to be guarded against in all pisciculture.

It is not absolutely necessary that water be very cold to raise trout successfully. Nor is it essential, as before stated, that it be of an even 
temperature the year round, but it ought to be well aerated. Aeration must be more thorough and more carefully attended to the farther the water progresses towards the lower end of the hatchery grounds. Trout will live and grow and remain comparatively healthy, it is said, in ponds where the temperature rises on occasions to a little above seventy degrees-some writers say eighty degrees, provided there is abundant aeration; but water of such high temperature is not to be desired.

The warmer the water the shorter the period of incubation. The shorter the time of incubation, below a certain point, the more danger there is of weak fish being produced. The best temperature for hatching trout eggs is between 45 and 50 degrees. This will make the period of incubation from 45 to 60 days. A temperature between 50 and 60 degrees is good for young and mature trout in the ponds. A lower temperature is not injurious, but when it falls close to the freezing point incubation is retarded sometimes from 100 to 120 days. While this is not injurious it is apt to give the fish- 


\section{WATER FOR TROUT CULTURE 91}

culturist more work, for if the water at the end of that time warms appreciably, the eggs are apt to hatch almost simultaneously.

Limestone, otherwise called hard water, is as good for trout-breeding as soft, although, in some circumstances, more prone to encourage fungus, unless it should, as sometimes happens, contain an overplus of organic matter. A little iron in the water will not prove harmful, but some mineral substances are undesirable, and in large quantities fatal; for example, a sulphur impregnation is likely to prove hurtful, as also is very much iron.

A limestone spring may prove dangerous apart from its mineral qualities for a reason unsuspected by those who have not had experience with one of that type and its possible vagaries. This danger is the liability of the underground stream which feeds the spring to suddenly change its course, abandon its outlet and seek another. A change of this kind may occur as the result of an attempt to raise the body of the spring by damming it, thus increasing the weight and pressure on the channel 
92

\section{FISH CULTURE}

which the subterranean stream has dissolved out of the limestone beneath until it breaks through some thin partition and flows elsewhere. 


\section{CHAPTER VII}

\section{TROUT PONDS AND HOW TO BUILD THEM}

ONE vital requirement in selecting a site for a trout-breeding establishment is that water can be carried into the hatching-house at such a height as to permit a flow through the troughs, allow drainage from the building and at the same time supply the ponds. There must therefore be some fall of land away from the spring or intake.

The degree of fall needed depends on how the troughs are to be set in the hatching-house, and the manner of building the ponds. If only one row of troughs is to be used, a decided pitch is immaterial because they may be placed upon the floor, in which case a fall of two feet will be sufficient; for troughs in two tiers, $31 / 2$ feet from the flow will meet the requirements; if the water is to be used three times, by employing 
three tiers, the fall must be nearly five feet. It is now considered immaterial whether the ponds are below or above the natural surface, so long as the water can be successfully brought into the first set of ponds and from thence in a well aerated condition to those below. The more quickly the water can be passed through the better, provided a proper volume be not exceeded, particularly where fingerlings are being: held.

Planning an E'stablishment.-There must be at least five ponds for the smallest establishment; one for the advanced fry or fingerlings, on their removal from the nursery troughs, a second in which to place fingerlings after they have been sorted in the summer; a third for yearlings; a fourth for two-year-olds and a fifth for three-year-olds and over, providing such fish are to be retained. If the plant is to be of any considerable size, the location and type of the whole series of ponds ought to be well considered and planned, even though there be no intention of building some of them for several years. They should be as carefully considered and planned as a house. 


\section{TROUT PONDS}

Unless the supply of water is to all intents and purposes unlimited, the water should never be "split," or divided into more series of ponds than can possibly be avoided. If with a limited supply splitting is unavoidable it is important that the water be reunited into a single series of ponds in the shortest distance, even though splitting again be required, because any appreciable diminution of the volume of flow is likely to cause a rise in temperature and consequent loss in the "life" of the water.

Shape and Size.-The shape of ponds should be such that the current may flow through in such a manner as to leave the least amount of dead water; and also it is desirable to adopt a shape which will permit of easy netting. A rectangular pond, whether square or oblong, is not the best, therefore, for fulfilment of both requirements, yet it is the one most easily and cheaply built; the ground space is best utilised; and this is unquestionably the best form when a "nest," or series, of ponds is to be built at the same time or in the near future. Oblong ponds with rounded ends are even better.

Ponds constructed in nests or groups and fed 
from a common open race or sluice are most desirable for many reasons. They are more easily worked and attended and, what is much to be desired, a simple drainage system can be more easily provided. In this way also there can be more ponds, with a less amount of water per minute than when built separately. Always, in laying out ponds, care should be taken to make them suitable for various sizes and ages of trout, and to arrange them with a view not only to their being worked conveniently but also for the advantageous growth of fish.

Ponds for trout which have arrived at full maturity can be built nearest the spring or where the water is coldest, because, having attained their growth, warmer water is no longer desired, and also because fish three or more years old naturally spawn before the two-yearolds, and cold water has a tendency to retard the ripening of their eggs. The longer this function can be delayed within reason, the better are the chances for hatching healthy young.

It is advisable to construct ponds for twoyear-olds next; those for yearlings still farther away; and those for fingerlings and nursery 


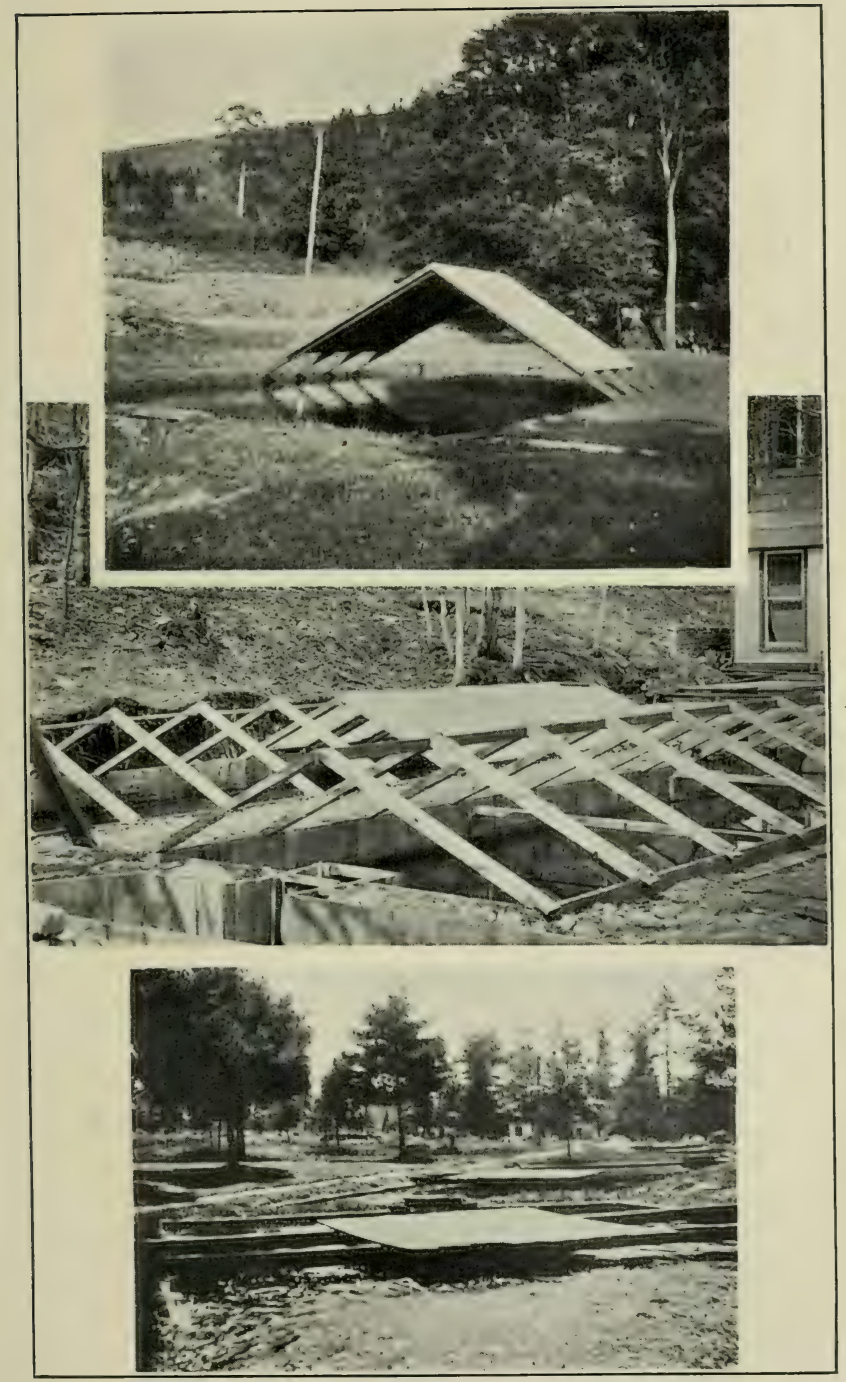

ME'THOHOA OF' SHADING TROL'T PONDS. 



\section{TROUT PONDS}

fish where the water is the warmest, so as to advance their growth as rapidly as possible. Ponds for fingerlings should be so constructed that the water-supply may be augmented and decreased at will. No pond, however, should be built at such a distance from the intake that the temperature of the water would be so high as to render necessary a very heavy volume, as that is not good for trout in the first year of their lives.

Shading.-There ought to be a generous space between at least every other pond so that trees may be planted. Trees not only keep the water cool in hot summer days, but also are useful in that they breed insects which fall into the water and furnish food for the fish. Willows are probably the best trees to plant for this purpose, because of their rapidity of growth, because their leaves do not make so much dirt in the ponds as most other trees, and because their long drooping branches and slender leaves act as a fan, thus producing a cool breeze on the hottest day in summer. The only objection to the willow is that the fine roots force their way in sponge-like masses 
through the banks of the ponds; but this does not occur when the sides are of concrete or of well kept boarding.

While, strictly speaking, appliances for shading ponds may seem to come in the chapter detailing methods of caring for fish out-doors, rather than in one of pond construction, I feel that it is well to mention it here. A common method is to lay 3-by-4 studding across a pond near the middle, about five feet apart, and nail inch-boards thereon. This method is doubtless as effective as any other but it is neither sightly nor durable, as such a structure speedily becomes rotten and is soon likely to break under weights of snow. The best shade-covers for ponds of ordinary size for mature fish are made by building a double pitched roof of lumber. Snow cannot break this down, and it is easier to work the net beneath it. Such a roof should cover the middle third of the pond at least; my experience has been that fingerlings in the nursery did much better when the entire pond was covered and the fish kept in nearly complete 'darkness.

Sides and Bottoms.-There is much discus- 
sion as to what it is best to do with the sides of the trout-ponds. Many fish-culturists advocate "going back to nature," as they express it,-that is to have natural banks without walls or stays of any kind. There are, however, obviously many objections to doing this, except where ponds are nearly if not quite half an acre in extent, among which are exposure to the ravages of the crayfish, muskrats and other burrowing creatures, and the danger of the earth sliding in early spring, when the frost comes out of the ground.

I cannot see that the advantages of natural sides are equal to the disadvantages. A very common practice is to construct the sides of inch-boards nailed to stays of 2-by-4 lumber and posts, and this does well if the lumber is given a good coating of tar when first built, renewed every two or three years. Tar is harmless to the fish when dried before the water is turned in, and is a foe to many fungoids. Sides made of lumber, however, are neither as sightly nor as enduring as walls made of cement, which is nearly as cheap as lumber and sometimes cheaper. Occasionally, where the soil affords a 
poor foundation, it is not feasible to use cement, in which case hollow building-tile is strongly recommended; blocks 24 inches long, 8 inches wide and 6 inches thick may be used successfully, and will form a wall as durable and attractive as cement. If a pond is only about two or three feet deep the tile can be set in concrete on edge, making a six-inch wall; when the water is deeper, and the sub-soil very mucky, the tile must be laid sidewise, making an eightinch wall. Stone is sometimes used for sides, but unless faced with cement it affords hiding places for crayfish, snakes, and other undesirable creatures, and also refuges for trout when netting a pond.

Now and then a fish-culturist will advocate covering the bottom of a pond with concrete or boards. I have seen both in hatcheries where fish-culture is conducted on the latest scientific principles. In some I have seen fish doing apparently well and in others I have seen them dying by the hundreds. I feel, therefore, that there is enough doubt to make it inadvisable to use either when it can be avoided. There are certain soils where artificial bottoms must be 
used to prevent an undue quantity of water from leeching through and escaping; and my advice is to cover the artificial bottoms in such cases with at least six inches of heavy gravel.

There may be rare instances, where, in digging ponds, an area of ooze-mud of considerable depth is encountered, greater than can be removed. In such a contingency, dig the pond a foot or two deeper, and then dump in many loads of coarse gravel, sufficient to make an even layer at least a foot thick. This will probably settle and bind in a few days, and make a fairly firm bottom. This, of course, need not be done where a bottom can be floored with concrete or boards.

Indeed, the bottoms of all ponds should be well graveled, but care must be exercised that none of the stones are larger, say, than a man's fist or projecting much above the ordinary level. There are two reasons for this, first, an irregular bottom is hard to draw, and second, with large projecting stones there is danger that after a severe thunderstorm the fish-culturist may find that he has lost a large number of his trout. 
'A number of years ago the Pennsylvania Fish Commission had over 300 rainbow and brown trout killed in its ponds in Allentown during a single thunderstorm. At no time did the lightning strike nearer than a quarter of a mile from the ponds. A former manager of the Penn Forest Brook Trout Company, a commercial establishment near Mauch Chunk, Pa., informed me that during a severe thunderstorm more than 400 pounds of trout were killed by lightning. As long as the trout are swimming free in the water no harm to them will result, but if any fish happens to be on the bottom touching larger stones, and lightning should strike the ground anywhere within a quarter of a mile or so, the fish would either be stunned or killed. The true trouts are more liable to injury from lightning than the brook-trout, because the former are more likely to rest on the bottom.

Size and Depth. - The size and depth of the ponds remain to be considered. These factors must depend mainly on the water-supply, and upon the purposes for which each pond is intended. I prefer ponds of moderate size, and believe for mature fish the deeper they are the better, so long as they are not too deep for handling. Those for advanced fry and fingerlings should be shallower. An ideal pond for advanced fry might be, say, 25 feet long, about 
6 feet wide, and of a depth to allow from 18 inches to two feet of water. A pond for yearlings and two-year-olds, may be about 40 to 50 feet long, 14 wide, and about three feet in depth. One for older fish might be from 50 to 100 feet long, from 15 to 20 feet wide, and about 4 feet deep, excepting in the circumstances stated later in this chapter. Where it is not desired to rear trout beyond the age of two years, the largest pond mentioned would be used for the oldest fish, and the second size for fish from six or eight months to one year old. Livingston Stone, a well-known authority on trout-culture, advised with sound sense that the smaller the water-supply the smaller should be the ponds. "If," says he, "your water-supply is small and liable to heat up, make the pond narrow and deep,-a deep ditch."

Where the trout-breeding establishment is for commercial purposes exclusively it is well to have one or more ponds half an acre or so in extent, sloping to a depth of eight to ten feet at the lower end. Such a pond will hold an almost incredible number of fish, and require less attention than smaller ponds. 
Raceways.-There has been a tendency in recent years for fish-culturists to abandon raceways, owing to a well grounded belief that ponds in nests or groups yield better results; but wherever ponds are built separately I would advise the making of raceways, even if they be not intended for the use of spawning fish, because thus the shallow, rapidly running water becomes well aerated before entering the pond. Where the supply of water is not scanty, the raceway might be from three to five feet wide, not less than 20 feet long, and with a depth of from six to eight inches. The bottom should be thickly covered with clean coarse gravel, both for aerating purposes and to attract the fish from the ponds when they are ripe enough to spawn. The sides must be of carefully set boards, concrete, or building-tile, and so arranged that the whole raceway can be covered from end to end in order to exclude the light during spawning season. At the upper end or entrance there must, of course, be a screen to prevent the fish from going past a certain point or into the pond above. At the bottom there should be a gate, kept open except when the 


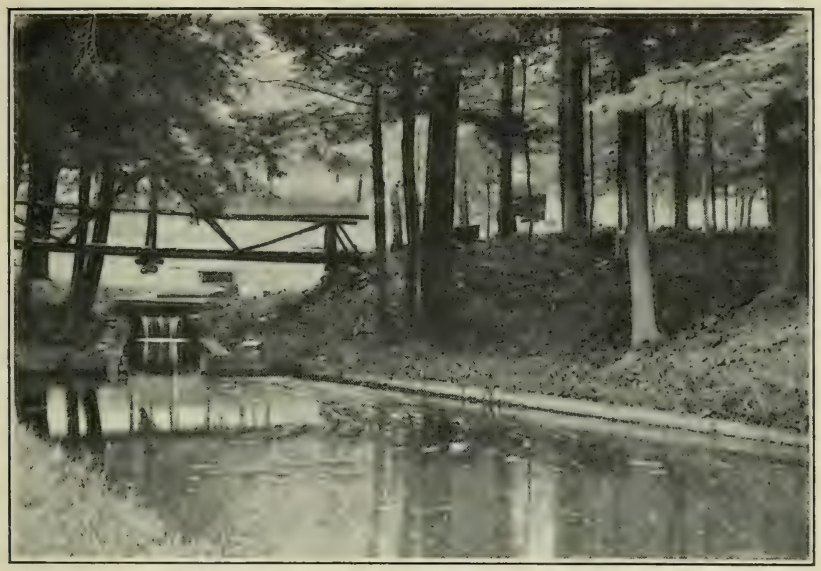

INT.IKE FOR A TROUT POND.

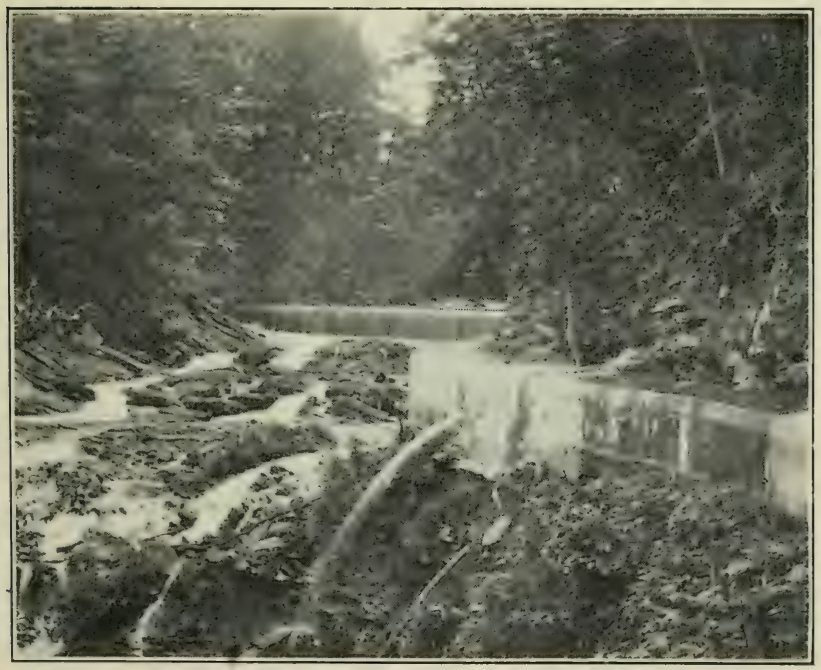

A DAM AND A COVERED RACEWAY. 

culturist is about to take out the fish which have gathered in the race for the purpose of expressing the eggs and milt. A raceway is especially good for the beginner in trout-culture, because few excepting ripe fish enter it at spawning time, hence he does not need to handle the stock in the pond so frequently in order to secure those fit for spawning.

When the spawning season is over the cover should be removed from the raceway and put away in the storage house until wanted again the next year, so that the raceway can have the full benefit of light and air in order to fulfil one of its functions, namely, that of aeration.

Implements needed at a Hatchery.-A well equipped trout-hatchery will possess all the usual implements for digging, hauling, and outside labour, including long-handled shovels, picks, scoops, wheelbarrows, wagons and carts, a roller, mason's implements, carpenter's tools, etc. An essential implement is a measuringboard, in order to get ground-levels. A 16-foot board, planed, trued, and provided with a spiritlevel, will be found a fair and cheap substitute for regular surveyor's instruments. Other 
tools and implements specially needed for hatchery work are an assortment of buckets, both wooden and tin, for carrying water, fish, thick milk, chopped meat, and so forth; also washtubs for carrying large fish from one pond to another, for holding spawning fish when first taken from the raceways or ponds, and for many other purposes.

I have found that the ordinary milk can with a round hole, about the size of a quarter of a dollar, will answer as well for shipping fish by railroad as any specially designed shippingcan. It would be well, however, to have the bottom changed to a convex form, as when the bottom is concave trout are apt to crowd into the centre, sometimes to their detriment. A long narrow can, similar to what is generally known as the combination Philadelphia and New York pattern, seems to be better than one short in height but large in circumference. It has the advantage of taking up less room in a car, which fact will appeal to any one who has many fish to send away by railroad. Cans containing twenty and thirty quarts each are the most desirable in size. For transporting 
larger fish oval cans specially made are the best.

As an accompaniment to shipping-cans, there must be a device which messengers can use for the aeration of the water while fish are being taken on the railroad journey. The national government and some of the states maintain fish-cars with complete aerating apparatus, but this is not feasible for a commercial establishment, and some other means of aeration must be utilized, the best of which is a tin dipper, with a bowl shaped like that of a milk dipper, with the opening covered with a finemesh wire netting, and with a straight handle.

What seems to be the best hand-aerating apparatus yet devised was recently invented by an assistant of Mr. Lydell, Superintendent of the Mill Creek (Michigan) State Hatchery. It consists of a cylinder of tin with removable perforated bottoms of different sizes. A valve worked by the finger allows the apparatus to be pressed to the bottom of the can where the valve is released and the cylinder filled with dead water. Another pressure of the finger closes the valve, the cylinder is lifted into the air, and the valve once more released, allowing the water to fall back through the 
perforations in the bottom. The principle is good, since it allows the water in the bottom, which is in the poorest condition, to be taken out and aerated. There is no patent on the apparatus and all who will may use it. Another useful device is a tin cylinder about two feet long, three inches in diameter, having a fixed handle at the top and the bottom pointed like a lead pencil. The pointed end is thickly perforated. To aerate with this, plunge the pointed end to the bottom, and then withdraw it, allowing the water to run back into the can through the perforations.

Thermometers are among the useful instruments needed, although messengers and men about the hatchery should be taught to guess closely the water-temperature by feeling with the hand. By dint of practice the average hatchery-man can estimate temperature very nearly.

A meat-grinder, for grinding liver and lungs for fish-food, is indispensable. It must, however, have a number of dises with perforations of varying diameters so as to cut meat of different degrees of coarseness. If the hatching establishment is of considerable size it will be almost necessary to operate the grinder by power. This can be done by erecting a small 


\section{TROUT PONDS}

building over the stream of waste water at the lower end of the property and setting up an undershot waterwheel. The same building could also be utilised as an icehouse and a refrigerator for meat.

In connection with the meat-grinder there should be an assortment of perforated tins for pressing liver through them to make a paste of requisite thinness for advanced fry. A liver-pulverising block is a part of this important contrivance. The block is made of wood, well sand-papered, just large enough to be held comfortably in both hands, and with the thick end bevelled so as easily to catch and crush liver through the perforated tin.

Pudding pans of tin or agate ware of different sizes, for holding eggs and liquid liverpaste for feeding the fry, must always be kept on hand. Also a soft-rubber bulb attached to a hard-rubber tube, for picking out dead eggs, and for feeding fry while in the troughs.

Some fish-culturists use wooden pickers exclusively for egg work, but in Pennsylvania the superintendents of the state hatcheries abandoned them years ago for a rubber bulb, which 
they believed to be the much more safely and just as easily manipulated. Such a bulb can be procured at any drug store by asking for an infant syringe, and a little practice will enable a man to pick up eggs with great rapidity and skill.

The bulb is undoubtedly far superior to a spoon or feather for feeding advanced fry, enabling the work to be done in half the time and more thoroughly. There must also be constantly about the place a bundle of turkey feathers for feathering eggs and fry in the troughs, besides small scap nets, fine-meshed seines, long-handled scoop-nets and other nets necessary for handling fish. There must also be a liberal supply of wire-mesh for egg-trays, which is tacked on wooden frames a trifle narrower than the interior width of the hatching trough. It is also necessary to keep on hand several bags of salt, and bags of cement for emergency work. Galvanised wire-netting of various sizes for screens, and a barrel of tar and brushes of several sizes and styles should be conveniently at hand. 


\section{CHAPTER VIII}

\section{CONSTRUCTION OF A TROUT-HATCH- ERY}

AN appropriate building for the hatching of eggs is necessary unless trout-propagation is to be conducted on such a scale as to be scarcely worthy the name.

Certain conditions must be observed to insure success-conditions as important as the location of the ponds or the character of the water. First and foremost the building must be located in such a manner that water can flow through the supply-trough so as to give a good head and flow freely into all the hatching troughs, and also so that there will be perfect drainage from the hatchery into the sewer or the ponds outside. It must not be so far away from the spring as to allow much change in the temperature of the water, or if it must be very far from the source of supply then the 
pipes leading to it should be so built or protected as to keep as nearly uniform a temperature as possible. The size of the house is of course conditioned upon the size of the plant, the character of the troughs, and whether it is intended to carry fish beyond the fry stage, and well into the advanced-fry stage, or even through it to the fingerling stage.

If the hatching-house is to be for a club that intends to propagate only sufficient fish to stock its holdings, or for an individual who wishes to do business on a moderate scale, chiefly for his own consumption, a building 20 feet long, 12 feet wide, 7 feet to the eaves, and with either a double-pitch or lean-to roof will answer the purpose. Such a building will hold two sets, or four troughs, each 14 feet long, and will have a capacity for 100,000 fry, which can be held in the building through the advanced-fry stage, and, indeed, until summer. It will also allow sufficient room for the meat-grinding machine, a table on which to pulverise liver and do other work, and a stove, besides a little additional room in which to move round.

If business is to be done on a large scale and 
it is not intended to hold fish much beyond the fry stage, in other words to get rid of them as soon as they have become advanced fry, either by planting, sale, or depositing in outside nursery-ponds, then the smallest house which can be considered will be 50 feet long, by 20 feet wide, using the same type of trough just described. This will accommodate, with outside trough attachments or nursery-ponds, between $2,000,000$ and $3,000,000$ fish of advanced-fry stage and the smaller sizes of fingerlings. Yet a house of this size is small for the work named, and entails a great deal of disagreeable outside work in February and March, so that it would be better if larger, so as to avoid having any outside troughs.

Construction of a Good House.-To my mind the ideal hatching-house for trout, taking into consideration compactness, no waste room, and a minimum amount of water, is one which is 100 feet long and 40 feet wide. Such a house will easily provide accommodations for 3,000 ,000 advanced fry and fingerlings to No. 2 size. If it is necessary, and the fish-culturist be skilled and bold, he can carry $5,000,000$ of advanced fry 
and No. 1 fingerlings, but the latter not very, long, and such a number would mean unremitting care, and attention from early morning until late at night. Such a house will hold 60 double or 120 single troughs if set in three tiers, and will require only 120 gallons of water. To build a house of this type there must be a fall from the spring or stream sufficient to permit of there being about five feet from the supplytrough to the floor of the house, certainly not less than four feet. It can be built of frame, with stone, concrete, or building-tile foundation, and completely equipped, at a cost of from $\$ 1,600$ to $\$ 2,400$, depending upon the price of materials.

A gambrel roof will be found cheaper than a double-pitch roof, and probably present a better appearance. The side walls should be not less than eight feet from the top of the foundation walls to the eaves, but a more imposing appearance will be given if the walls are ten or twelve feet to the eaves. There should be no inside pillars or posts, as they would be in the way of the workmen, consequently the roof must be supported by trusses. Five trusses will be sufficient for a house 100 feet long. The simplest and cheapest form is the single railroad truss. The bot- 
tom beams of the truss, which of course are 40 feet long, may be made of boards six inches wide, and one inch thick, of different lengths, spiked together so that when completed there will be a solid beam 40 feet long, six inches wide and six inches thick. This will often be found cheaper than a solid beam of that size, and just as effective. The top beam of the truss, which is of course very much shorter, may be made of the same material if desired. The stays, however, should be of solid timber, 6 by 8 , with two heavy iron stays or rods, bolted both above and below. The studding may be of 2-by-4 lumber, but for the other timbers forming the skeleton it would be best to consult a carpenter. The sides may be of what is called Dutch siding. I have found no urgent necessity for air spaces or paper or inside stripping.

Spring water, when run into a hatchinghouse, being warmer in the winter than the surrounding atmosphere, will very likely throw off a heavy mist, which will make work in the hatching house disagreeable; but the mist can be dissipated by having three or four ventilators in the apex of the roof. I would not advise ventilators the entire length of the building, since they allow snow to enter and keep the house uncomfortably cold.

The house should be liberally provided with 
broad windows so that the building can be well lighted in the daytime; but these should have either solid inside shutters or be provided with curtains, so that the interior of the building may be darkened when desired. Darkness, or rather gloom, is an important factor in the successful hatching of eggs and rearing of fry. It is well to have at each end of the building doors wide enough to permit even bulky objects to be taken in and out. Of course all the outside lumber should be planed so that the building can be painted. It is poor economy not to be liberal with paint, to say nothing of an unsightly appearance; and thought should be given to tasteful colors, avoiding white.

Arrangement of Troughs.-For a building of this size the troughs had better be set in three tiers if it is at all possible to do so, which will permit the use of 120 troughs and a maximum of 120 gallons of water per minute. If this method is adopted the water is conducted into the building at the upper end and on one side of the house, and flowed into either an iron supply-pipe or wooden supply-trough 12 inches wide and 14 inches deep, which extends the 

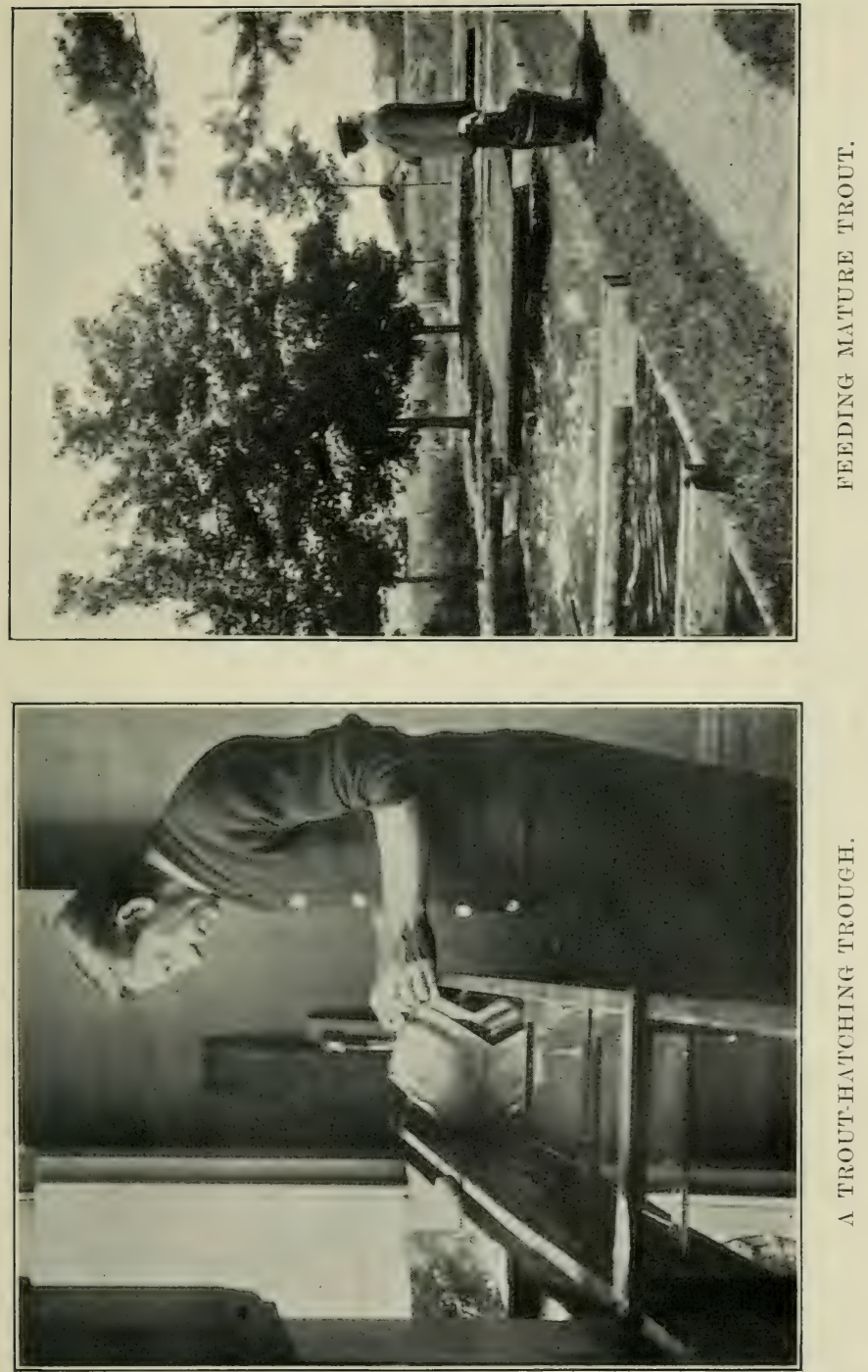

entire length of the one side of the house.

By three tiers of troughs is meant three sets one below the other, with the water flowing from the supply-trough into the upper end of the first set, from the lower end of the first set into the upper end of the second set, from the lower end of the second into the upper end of the third, and from the lower end of the third into the sewer or drain. By this method the water is used three times before it is discharged from the house, and each gallon of water will be equal to three gallons. In setting the tiers or sets, the upper end of the second should project a couple of inches under the lower end of the first and the upper end of the third a couple of inches under the lower end of the second tier.

It would also be well to set the second tier only about two inches below the lower end of the first tier and to set the third tier about an inch above the floor; then there will be a considerable fall from the outlet of the second tier into the third tier, and this will aerate the water. The troughs should not be set exactly on a level. The lower end ought to be from half 
an inch to an inch lower than the upper end; but the lower end of the supply-trough should be not more than an inch below the upper end or intake.

For a 40-feet-wide house equipped with three tiers, each set of troughs can only be 12 feet long; this will allow a four-foot walk the whole length of the opposite side of the house. The troughs are made in pairs and of lumber one inch thick when dressed, 33 inches wide outside measurement, with a one-inch division-board down the centre, making two troughs each 15 inches inside measurement. They are usually eight inches deep, but may be 10 inches to advantage.

At the lower end of each trough, if two or more tiers are used, there must be bored two holes, one in the centre and one at the side, each not less than one inch in diameter. One is to carry the water from one trough to the other; and the other to be used only when the trough is being cleaned, at all other times being kept plugged. Six inches from the end, and above the hole, two cleats are set on each side, three-fourths of an inch apart, and two others 
nailed across the bottom. In this is set a wire screen, 14 or 16 mesh to the inch, to keep small fish from passing through. Two inches below is fastened another set of cleats in which are placed pieces of wood, two inches wide, each to form a dam, and when in use to tighten it. The bottom and sides should be filled with stiff clay.

The water is carried from the supply-trough into the hatching-troughs by means of faucets, and a wooden spigot is not dependable. One of the various makes of cast-iron molassesfaucets should be selected and the most costly is the best. It is well to be particular about this, because while the idea is generally exploded that any more than a certain quantity of water will burst the egg or the sac of the fry, it is essential for many other reasons to be able to regulate the flow accurately and without danger of something happening to change the amount which has been set.

Before being used, the inside of all the troughs should be given a heavy coat of tar, in which a little litharge should be mixed to hasten the drying; and the outside should be 
painted. I have heard fish-culturists complain that tar is injurious and that it had killed their fish; but I am satisfied from my own experience, as well as that of most fish-culturists, that this is a mistake; indeed tar may be esteemed beneficial, since it is a germ destroyer. Black asphaltum paint, however, may be safely used, if tar is not easily available.

Surprise may be expressed by some persons that I have not advocated the use of heavier lumber than one inch for the construction of hatching-troughs of the type described. It has not been many years since it was claimed to be unsafe to use lumber less than two inches thick on account of jarring, but I have found no ill results following the use of one-inch lumber, and I have superintended the hatching and distributing annually of from 7,000,000 to $13,000,000$ trout; furthermore the average hatch from the eggs taken from the brood-fish in the hatcheries has been regularly over 90 per cent.

The ends of the trough may be flush, there being no necessity for dovetailing. The troughs can be made perfectly water-tight by making a scratch the whole length of the bot- 
tom board, stretching a piece of string dipped in white lead along it, and then nailing on the sides. Dovetailing is unnecessary and expensive.

The stands on which the troughs are set should be of heavy lumber not easily moved, and of the best quality, either white pine or cypress, rejecting any lumber where knots completely penetrate the board, for it will leak.

The floor of the hatching-house should be of concrete, and a ditch be made the whole length of the house, between the walk and lower end of the third tier of troughs, to carry the water into a sewer or a pipe conducting it to outside ponds. There should alsc be a slope of about an inch from the foundation wall on which the supply-trough rests to the ditch, and there should also be a slight concavity under each set of troughs for drainage to the ditch.

If the business is to be conducted on a huge scale, and a vast number of eggs are to be sold, then, besides the troughs described, it would be well to have an egg-hatching trough of the Clark, Clark-Williamson, or some similar pattern. The United States Bureau of Fisheries gives this description of the 


\section{FISH CULTURE}

Clark hatching box:- "A tank 15 feet long with a partition running its entire length and so placed that its lower end rests upon the upper end of a similar one 13 feet long, which differs from the upper one only in that it contains two boxes less. Nine partitions placed crosswise of the tank form, with the lengthwise partitions, a double row of compartments, each of which is $19 \frac{1}{2}$ inches long, and $15 \frac{1}{2}$ inches wide, and is provided with a waste-water channel or sluiceway leading into the next compartment. In these compartments are placed the hatching boxes."

The Clark box is 18 inches long, 14 inches wide, and $9 \frac{1}{2}$ inches deep, and is made from three-quarterinch dressed white-pine lumber. On its under side the box is provided with short feet to allow a free circulation of water under it and to prevent it from resting on any sediment or refuse that may be deposited on the bottom of the tank; and on the inside of each bottom corner is fastened a thin block to support the trays. Five small auger-holes permit the escape of water from the box. A slot is cut in one end of the box, so that the water from the compartment above cannot flow into the one below without falling into and passing through this box. Upon the feet or risers inside the box rest nine trays, made of perforated zinc, or fine wire netting, tacked upon a pine frame 16 inches long, and 12 inches wide. The trays are placed one upon the other, in the box, the 
end of which contains the slot fitting snugly against the upper end of the compartment in which is fitted a tin over-flow. The whole is held in place by a cross-bar or binder, which fits in grooves cut in both sides of the tank. The binder, which rests upon the box, keeps it from rising in the water, and is provided with feet so placed as to prevent the trays from floating in the box itself. Each tray is capable of holding 5,000 brook-trout eggs, the ninth or top tray being used only as a cover. There are several other types of purely egg-hatching troughs or boxes, the general principle of all being a series of dams, the water flowing alternately over and under. These troughs, however, are for hatching or eyeing eggs only, and are not suitable for carrying fry or advanced fry.

Suggestinns.-If the water-supply is from a deep spring, there will be no need for a stove or heating apparatus in the hatching-house, except to permit the men to warm their hands after having them in the cold water for some time, as the spring water, averaging say from 45 to 50 degrees of warmth, will keep the house fairly comfortable. If the water is creek water then it may be necessary to have a heating apparatus to give some warmth to the building; 
but it is not well to keep the temperature of the house very high, because it has a tendency. to raise the temperature of the water.

It will also be well to have a small building with plenty of shelving attached to the hatching-house as a sort of workshop and a place in which to keep the smaller implements and in which to make the liver paste. The wisdom of such a building will be apparent at once to any one who has had anything to do with rearing fish, or remembers how things will accumulate and get in the way of the workmen, or become lost, when there is no set place for them.

Absolute cleanliness in the hatching-house is very necessary. Carelessness in this respect may cause trouble and loss of fish. It must be remembered that impurities in the water are as fatal to trout as filth is to human beings.

It may in some cases be impracticable or not desirable to set the troughs in two or more tiers, in which case the hatching-house may be 32 feet wide with two sets of supply troughs, one on each side of the house, each trough being 14 feet long; or a house may be 20 feet wide, with one set of troughs each 16 feet long. The 


\section{TROUT-HATCHERIES}

walk ought to be four feet wide, and the width of the house and the length of the trough be made to conform thereto; but as lumber is cut in lengths of $8,10,12,14$ and 16 feet, one of these should be adopted to save waste. 


\section{CHAPTER IX}

\section{TAKING AND FERTILISING TROUT EGGS}

As, according to an old saw, "all roads lead to Rome," so in trout-culture all efforts are directed towards taking, fertilising, and hatching trout eggs. The fish begin to ripen in autumn, sometimes as early as the first of October, but often not until well in November, depending on water temperature and conditions. Weeks beforehand, both males and females show signs of restlessness. The under jaw of the male lengthens and becomes almost a hook at the tip, and he exhibits signs of pugnacity, which become more pronounced day by day. Fights of great ferocity are frequent, and fatal wounds are given and received, for the hook at the extremity of the lower jaw, has become an ugly weapon of offence. All battles are for the possession of females, and it sometimes happens that the latter, getting in the 
way, are fatally hurt. There are also other signs of the approaching spawning. Here and there fish will be seen clearing nests in the gravel, and females with swelling sides move more slowly and heavily through the water.

Spawning Habits of Trout.-From this period on the days of the fish-culturist are full of watchfulness and anxiety. He must use his nets frequently to make tests to discover ripeness. This is done by taking the fish as though for stripping, and gently pressing the finger along the abdomen. If the eggs flow freely. from the vent, the fish are ripe.

When ponds are provided with a raceway the work is simpler, because few excepting the nearly ripe males and females enter it, and it is then only necessary to close the entrance and examine the fish which may be there. Raceways attached to ponds should be covered with boards a couple of weeks before the spawning time, as darkness has a great attraction for gravid fish.

Ripeness is usually found first among fish of three years and older; the younger, or first spawners, not "coming in" until later in the 
season. A few days after the first ripe fish have been found, numbers of others will be ready, and after that eg'-taking proceeds daily, with growing rapidity, until the height of the season is reached. It is not expedient to draw all the ponds every day, partly because the number of the spawners found would scarcely pay, for the trouble, but chiefly because frequent handling is not good for the fish. Yet many days must not pass without every pond having been overhauled, or eggs will be lost.

Handling Ripe Fish.-The act of spawning, as well as the period immediately preceding and following it, is always a drain on the vitality of fish, and some are certain to die. Handling and artificial extruding are still harder ordeals, under which further loss may be expected; hence great care must be exercised not to bruise nor roughly treat the fish while they are sorted and stripped. Some men use wet gloves made of canvas or other material during this process, in order that the trout may not slip from their hands; but this practice cannot be condemned too strongly. The glove is a deathdealing apparatus. Neither ought a fish to be 
handled with dry hands, as fungus is certain to develop where the trout has been grasped.

When sorting his fish, three tubs are needed, a small-mesh seine, a long-handled scoop-net and a bucket. All the trout in the pond are drawn to one spot, as near as possible to the tubs, in each of which has been thrown a bucketful of water. Then a number of the fish are dipped out, transferred to one of the tubs, and the sorting begins. The ripe females are gently deposited in one tub, the ripe males in another, and the hard fish back in the pond.

After the sorting is completed, the fish are carried into the hatching-house and placed in tanks or hatching-troughs. The latter is preferable, as it saves one handling. The strippers, with the spawning-pan in front of them on a box only a foot high, are seated while working, so that if, by mischance, which is not infrequent, a trout slips from the hands and falls to the floor, it is not likely to meet with serious injury. This plan, to my mind, is infinitely better than the practice of standing at a bench or barrel, as some fish-culturists do, for then the accidental dropping of a trout is almost certain 
to result in its death. After observing many methods I am of the opinion that the best is to use one of the double hatching-troughs, so that if a fish slips, it will fall, not on the floor, but into the water.

Choosing, then, one of the hatching-troughs for spawning purposes, the females are placed in one section and the males in another, the dams in each section having been previously so set that there is about six inches depth of water. A hatching-screen is set endwise in each section and fastened about two feet from the lower part, so as to confine two or three dozen fish in that space. A spawning-pan is made ready and set on a board midway on the trough. If there are a very great number, one man is assigned to handle the females; a second, the males; and a third to care for and dispose of the fish after they have been stripped.

Before being placed on the board between the strippers, the spawning-pan is submerged for a moment or two in water, then allowed to drain off until only a few drops remain on the sides and bottom. This act seems trifling, but it is nevertheless important. If the eggs were 


\section{FERTILISING TROUT EGGS 131}

stripped into a dry pan many of them would stick to the sides and bottom, and most of those which so adhered would in a little while become affected by fungus and die. The remainder would not become fertilised and consequently would not hatch. The moist pan prevents adhesion.

Artificial Fertilisation.-All the preliminaries having been completed the men are now ready to "take" and impregnate eggs. The ovaries of the brook-trout are two membranous sacs lying along each side of the backbone of the female, in which the eggs are developed, growing larger until early in the fall, when, shortly before being voided, they attain their full size previous to being fertilised, and can be expressed easily from the fish by a slight pressure of the fingers on its belly. On both sides of the backbone of the males are the testes, in which are formed spermatozoa, or fertilising elements. They are pendant-shaped, with the points towards the vent. As the spawning time grows near, the pointed ends become soft, and there exudes a milky liquid called "milt," bearing thousands of spermatozoa. This milt may 
easily be expelled by means of a gentle pressure of the thumb or finger above the vent. When the female and the male are in this condition they are called ripe, and the mingling of the milt and spawn fertilises the eggs. Fishculturists generally now accomplish this end by the Russian or "dry" method discovered by Vrasski and announced about 1871. Instead of fertilising the eggs in water, as taught by Gehin and Remy, they are pressed from the fish into a moistened pan and fertilised before any. water is poured on them.

A careful man will not take fish from the water by any abrupt or rapid movement likely to frighten them. Having first thoroughly wet his hands he will gently seize a fish by the head with the left hand, and with the right hold it firmly by the tail, not bruising it, until all struggling ceases. It will become quiet in a minute or two. In grasping the fish, the man's left hand should be over its head with the thumb towards his body; the right hand should grasp the fish from the underside, with the thumb above and pointing away from his body. As soon as struggling ceases the fish is held over 
the pan so that the vent will be as close to the bottom as possible while the eggs or milt are being taken.

There are two methods of taking eggs, one known as the two-finger, or thumb-and-finger method, and the other the one-finger method. In the former a man gives a slight pressure with the thumb and forefinger of the right hand along each side of the belly, from below the head towards the vent. In the one-finger method-probably the better-the thumb is gently pressed along the bottom of the belly towards the vent and the forefinger aids only in the final stripping of the last few eggs. By either method the eggs are easily expressed and flow in a steady stream into the pan. The advocates of the one-finger method hold that there is less liability of injury to the fish than by the two-finger method. Probably they are right.

Some men believe in stripping every egg from the female; others that it is best to allow a few to remain. The former hold that it is better for the fish, as there is a liability that the eggs which remain will not be voided naturally by the female afterwards, but that they will harden. 
and perhaps kill her. They also claim that despite all care an occasional male will be thrown into the tub containing the stripped females, and after being placed in the ponds there will inevitably be a fight with possible fatalities. I am inclined to think that the weight of the argument is in favour of clean stripping.

As soon as the eggs have been taken from the female the milt is expressed from the male in the same manner as the eggs from the female. The eggs and milt are then thoroughly mixed. Some fish-culturists stir the two together with a feather, but my experience is that no implement for this purpose excels the tail of the male, the operator still holding the fish and stirring with it.

The eggs, when first extracted, are about onethird smaller than they become after they have been fertilised. A fish's egg, like an orange, is slightly flattened, and in the top there is a minute hole called a micropyle, surrounded by a glutinous substance. Fertilisation is accomplished by an atom of milt (a spermatozoon) passing through the hole into the interior. It is a marvellous provision of nature that the 
atoms of milt almost unerringly find this minute opening. Even where the eggs and milt are naturally deposited in a stream, and where there is originally a distance of many inches, they: reach the proper point for fertilisation of the ovum.

It is also an exceedingly curious fact that the milt cannot retain its properties in water for more than a few minutes, generally less than three. It is this fact which made the discovery, of Vrasski's "dry method" of fertilising eggs, of such great value to fish-culture.

The operator squeezes females and males alternately until he has a sufficient number of fertilised eggs in the pan. It then becomes necessary to wash them, in order to remove surplus milt and any dirt or blood which might have been pressed from the fish. This should be done after a lapse of from three to five minutes. The eggs are then covered with clean water and allowed to stand not less than 15 or 20 minutes, so that they soak in water and attain the proper size of fertilised ova. After being covered with water the eggs soon adhere to each other and to the bottom of the pan. It is very 
necessary that the eggs be now left absolutely, quiet, as any disturbance during the process of water-soaking, sufficient to cause them to break apart, would almost inevitably cause the loss of nearly if not all the eggs in the pan. Little by little the eggs swell until the micropyle becomes closed and is hermetically sealed by the glutinous substance which surrounded it, and it remains so sealed throughout the entire period of incubation. At the end of from 15 to 30 minutes adhesion ceases, the enlarged eggs separate and are now ready to be placed on trays for hatching.

The ordinary method is to pour the eggs from several spawning-pans into a dish-pan, previously filled with clean cold water, until a sufficient quantity has been taken to fill one or more trays. From the dish-pan the eggs are poured into a graduated glass so that the exact number of eggs may be ascertained, and then are poured gently on to trays until the latter, according to size, contain from 10,000 to 25,000 eggs. The eggs are then carefully spread two deep, by means of a feather, although there are circumstances in which they may be placed, 


\section{FERTILISING TROUT EGGS}

for eyeing purposes, four or five deep, or even to the rim of the trays. The safety of doing this depends on the character of the troughs and the circulation of the water, for which no specific instruction or rule can be laid down. The knowledge thereof can only be acquired by experience.

After the fish have been stripped they are placed in buckets, males in one, females in another, given a mild salt bath as a preventive against possible infection by fungus, and put back into their pond. 


\section{CHAPTER $\mathrm{X}$}

\section{HATCHING TROUT AND CARE OF THE FRY}

THene are differences of opinion as to how much water should be sent through the troughs containing trout-eggs. Some fish-culturists believe that if a certain quantity be exceeded, it will result in what is call "bursted" eggs, or the destruction of the germ and also of the sac attached to the young fish; but I can find no evidence that mere volume can produce such disastrous results. I have seen water pouring forcibly from two one-inch pipes into a trough containing eggs; and in the same house a similar supply in a trough containing fry, yet without the slightest injury to either.

The fish-culturist must determine for himself how much water he may safely use without danger. It may be said as a general rule, that the more air there is in the water the smaller the flow required, and as there is usually more 
air in hard water than in soft, ordinarily a greater volume of the latter may be turned on than of the former. But this cannot be taken as a hard and fast rule. I know of a case where three gallons of hard water per minute can be flowed over the eggs and fry without harm to either; in a second case, also having hard water, two gallons is about the limit. In a third hatchery, where the water is soft, three gallons can be used without disturbing the eggs, and in another, of similar water, two gallons is ample. It is important for a fish-culturist, no matter how long he may have been in the business, to study thoroughly all about the water he uses in his plant, and also not to get it into his head that because he has been successful in rearing fish at one place, he must necessarily at once have the same good fortune on another property.

Placing Trays.-The trays on which the eggs are placed should be submerged very close to the bottom of the trough, or in such a position as to provide the greatest amount of current or aeration consistent with not moving the eggs. As the trays are slightly narrower than the 
troughs they must be held in place by some means. To do this several methods are employed. One quite common is a V-shaped wedge of wood, inserted between the troughs and one side of the tray. Another is to make the trays of material so light that the weight of the eggs will keep them submerged; when this latter method is used it is necessary to fasten at the under corners screw-eyes, or blocks of wood, to keep the trays from settling entirely on the bottom, and thus run the risk of being covered with sediment and injured. Trays are sometimes weighted enough to keep them down, or are slipped beneath cleats on each side of the trough so as to slide in and out after the manner of drawers in a desk. This is perhaps the best way.

Care of the Eggs.-There is always a quantity of unfertilised eggs in every lot taken. Some of them are frequently detected as soon as the washing is finished. They are marble white, opaque, and sometimes show the micropyle in the form of a yellowish spot. Within 48 hours after the eggs have been placed upon the trays others which were not fertilised begin to show 


\section{HATCHING TROUT}

themselves, and must be removed. One notable and interesting form of unfertilised egg is the "ringer." Ringers seldom appear until from 15 to 20 days after they have been on the trays, and as they become opaque very slowly they may be found throughout the entire hatching. A ringer does not at first appear as a bad egg, and will deceive any but a practical fish-culturist into thinking that it is fertilised. It is translucent, like a good egg, but when held to the light nearly a perfect circle is discerned within the shell.

Another failure in fertilisation which sometimes deceives an inexperienced person is what may be called a "false" egg. The false egg is rather more translucent than a good egg; but when held to the light, its worthlessness is easily detected, for it is seen to be simply a ball of watery albuminous material. Ringers are found in eggs from mature fish of all ages, but false eggs are seldom taken from fish less than three years old.

What causes ringers and false eggs is a question that most fish-culturists would like answered. Why one unfertilised egg should become opaque within fif- 
teen minutes or forty-eight hours; why a ringer may remain translucent until after good eggs are hatched; why false eggs may remain superficially as clean and translucent as good eggs for three or four weeks, are enigmas as bewildering as anything the Sphinx could propound. Although it is claimed that ringers are more abundant among fish which have been over-fed, I have never heard any one offer a solution for the appearance of them which seemed to me to be even plausible. I have heard only one explanation of the cause of a false egg which seemed at all enlightening. As a false egg is seldom found in fish younger than three years, it has been suggested that they are eggs which have been soaked prematurely in the ovaries when, as it sometimes happens, the female took water. On several occasions I have found ripe four-year-old females in July. I stripped them and found them all carrying water, and the eggs were as thoroughly soaked as they would have been after impregnation and washing. These experiences indicate the plausibility of the theory that a false egg is caused by being soaked while in the ovaries. It is claimed also, by some men, that a water-soaked egg is often carried by the female over the year, or until the next spawning.

Dead Eggs.-It is of course necessary that all dead eggs be removed from the trays before they develop fungus; hence, picking should begin not later than the day after the laden trays 


\section{HATCHING TROUT}

have been submerged in the troughs. Daily picking is desirable, but not always imperative. The temperature of the water, and the fishculturist's knowledge of its liability to produce fungus, must help him to decide this matter. In very cold water fungus develops very slowly, but in rising temperature more rapidly; it is also more likely to appear in abundance in hard water than in soft water of the same temperature. The appearance of dead eggs does not always mean that they were not fertilised. Their death may have been caused by careless handling, by being jarred or bruised, notably by instruments used in picking. It is to reduce the possibility of injury by picking, that the use of the rubber bulb is advocated instead of the old-fashioned picker employed in many hatcheries.

When trout eggs are carefully fertilised, and water conditions remain normal, there is not likely to be a very heavy loss. Occasionally something that cannot be foreseen nor prevented happens which results in an abnormal death rate among the eggs, sometimes forcing the employment of extra labour in order to clean 
the trays before fungus appears. As egg-picking under such circumstances is often costly, fish-culturists would be glad if some method could be discovered which would rapidly and inexpensively separate the good from the bad eggs without injuring the former. At one time it was hoped that a salt solution might be effectively employed.

I remember that at a meeting of the American Fisheries Society, held at White Sulphur Springs, W. Va., in 1905, Mr. Henry O'Mally, of Baker, Washington, announced the successful separation of good and bad salmon eggs of several species without injury to the former, by the use of first a solution of equal parts of salt and water, and afterwards one part salt to nine parts water. Under this treatment the good eggs slowly separated and settled to the bottom while the bad eggs floated to the surface and could be skimmed off. This discovery led to experiments being made with trout and other eggs, but the results as far as published do not appear to be very satisfactory. It is hoped that further experiments with brook-trout and laketrout eggs may show a better outcome. 
Egg Development.-After a lapse of from ten to twelve hours, a perfectly fertilised brook trout egg, when held to the light, shows what appears to be several globules not unlike air bubbles crowded about the micropyle. They are so small that only the sharp eyes of an expert can detect them, a microscope being necessary to aid the sight of the unskilled. In addition, the egg has a delicately coloured, clear, translucent appearance. After a lapse of three or four days these globules become elongated, and otherwise change to somewhat the form of the spreading roots of a tree. About a week or ten days later, the globules have disappeared and in their place there is a very indistinct outline of a little fish.

Growth of the Embryo.-Day by day the outlines grow more definite, yet only to be detected by a sharp and practised eye, until, when the egg is from eighteen days to three weeks old, two intensely black spots set close together are plainly visible. These are fish's eyes,-the first unmistakable view of the embryo observable.

Next is sharply outlined a jetty $V$, the two points of which touch the eyes. These converg- 
ing lines represent the contour of the skull. A little later a curving black line is attached to the bottom of the $V$ and a perfect $Y$ is the result. The tail of the $Y$ is the backbone. With succeeding days the rude outline of the skull and backbone develops, until at length a perfectly formed fish is visible, wrapped almost completely around an oval ball (the yolk-sac).

Active life is then apparent. At first it is manifested at short irregular intervals by occasional tremors through the little fish; then, in sudden, convulsive, jerky movements which increase in frequency until just before it emerges from the shell. As soon as the little fish has acquired sufficient strength it breaks the shell and begins to emerge, tail first. It works vigorously for a short time, then rests, then resumes activity and so, alternately struggling and resting, it finally frees itself wholly from the membranous envelope in which it began existence. To break through the shell of the egg tail first, is nature's method of bringing a perfectly healthy fish into the world.

Why does a healthy fish always issue from the egg tail first? A plausible answer is that by so doing 
the little fish is enabled to keep more easily his gillcovers open and breathe. In fact the shell, dragging at the edge of the gill-covers, pulls them open and thus gives assistance to a safe delivery. If the little creatures were to emerge head first the shell would most likely press itself against the gill-covers, close them, and either smother the fish or leave it so weak that death would surely follow in a little while. Be this as it may, it is nevertheless a fact that the issuance of a fish in any other manner than tail foremost is indicative of premature or improper hatching, with early death as a result.

As the fry emerge, they fall through the long meshes in the trays to the bottom of the trough which at this time contains no gravel or sand. They are then gathered daily, or oftener, by means of a feather and scap-net, placed in pans of water and transferred to troughs previously made ready for them, the bottoms of which are covered with fine, well washed gravel. It is important that the gravel be not sharp, but water-worn and smooth, so that the delicate covering of the yolk-sac cannot be injured by the wrigglings of the little fish. When a sufficient supply of good gravel is secured, it should be carefully preserved from year to 
year; because the oftener it is used, the better adapted it becomes to its purpose.

Provided they are disturbed as little as possible, and there is a proper water-supply, the care of good eggs to the period of "eyeing" is called a very simple matter by many people. Nevertheless from the third day after fertilisation to the appearance of the eyes is a period, which, if not critical, is at least one which will require unremitting watchfulness and care.

Moving eggs about before the eyeing period may or may not be seriously injurious according to local conditions. In some fish hatcheries it would be considered fatal to the bulk of the eggs at least, to disturb them in any manner whatever, until they showed the eyes. In other establishments it is declared that the eggs may be handled with perfect freedom and safety, if the work be done carefully; and feathered, cleaned or salted. A capable superintendent of one of the Pennsylvania stations declared emphatically and truthfully that he had a less percentage of loss from trays which he removed during this period from one trough to another for the purpose of salting when fungus ap- 


\section{HATCHING TROUT}

peared, than he had among eggs which he did not disturb.

On the other hand, at another station, a superintendent equally capable and truthful, asserted that in his hatchery such treatment would be fatal to every egg. From this it may be gathered that to what extent eggs may be handled, feathered and salted, before they are eyed, depends more or less on the water conditions in the hatchery; and in a measure must be left to the judgment of the fish-culturist to determine. On general principles, however, it is wiser to leave the eggs undisturbed except in so far as picking is concerned.

It is greater wisdom to take the chance of eggs smothering from a muddy deposit than to wash them by removing the trays to troughs or tubs of clean water and moving them gently up and down; or even cleaning the eggs by means of a feather without removing the trays. This is particularly true where the eggs are cared for in troughs of the Pennsylvania patterns. There is much less danger of smothering in troughs when the circulation of water is up and down through the trays, as it is in the troughs 
of the Clark make or those of similar pattern. Of course if it becomes plainly evident that eggs in the troughs of the Pennsylvania pattern are certain to smother if the mud which surrounds them is not cleaned, then the risk of clearing must be taken if there is the slightest chance that even a part of them may be saved. After eyeing, eggs can be handled freely and cleansed at will without danger.

One very important thing is to avoid any jarring of the troughs and trays during the entire period of incubation. It is very disastrous to green and young eggs, and productive of monstrosities at the eyeing period. Double fishes, that is, two fishes to one yolk, are not produced in this manner, but through more than one atom of milt having entered the micropyle when the egg was fertilised.

Feathering.-Frequent mention has been made of feathering eggs. The operation consists simply in taking a feather, preferably a turkey feather, and gently waving it along the eggs or the fry, or among or over them. Feathering only begins after the eyes show, and ought to be repeated frequently thereafter. It is done 
to aid in the aeration of the water about the eggs, as after eyeing they should come into contact with plenty of free oxygen in the water which flows over them. The frequency of feathering will therefore depend on the amount of oxygen there is in the water. Feathering also assists in the prevention of the growth of fungus, and in other particulars appears to be an aid in successful hatching.

Care During the Yolk-sac Period.-The number of fry placed in a trough is a matter of discretion and ability to care for them. Almost as soon as transferred from the screens the fry will "huddle," as it is termed; that is, gather together thickly in different parts of the trough, usually in the corners and along the sides. Huddling is regarded as a sign of health. If the fry do not do this within a reasonable time after hatching, and continue to do so until the sac is partially absorbed, they are not thoroughly strong and healthy. It is possible of course for the little creatures to huddle in too great numbers in some particular parts of the trough, so it is advisable to set low partitions in the bottom, near the head and at the centre. 
These will invariably attract some of the fry and so distribute the groups more evenly throughout the troughs, thus preventing what might otherwise result in smothering. While the sac remains, the fry will take no food, except that which is furnished by the contents of the sac. This is absorbed.

The period of absorption depends largely upon the temperature of the water. In most spring water the period is from 35 to 45 days. In creek waters it is from 60 to 120 days. The lower the temperature the longer the time required for the absorption. Under favourable conditions the growth of fry during this period is very rapid. After the sac is partially absorbed the huddling is less persistent, and as the days pass there is an increasing inclination on the part of the fry to scatter. Just before the sac has entirely disappeared the little fish begin to rise towards the surface and scatter freely over the bottom of the troughs; and when the absorption of the sac is complete the little fish start to take food which is prepared for them.

The care of the fry during the absorption of 
the sac is a work that should receive close attention. Troughs must be kept clear of fungus, which quickly develops whenever any of the young fish die, or when filth is allowed to accumulate; hence not only should dead fish be picked from the troughs as quickly as possible, but the troughs feathered often to remove the sediment or other dirt which invariably gathers when feeding begins.

After the sac is absorbed and the little fish arise, a strip of wood an inch wide should be added to the lower end of the troughs, so as to increase the depth of the water to about three inches. This will enable them to swim up more freely and render the task of feeding easier.

After feeding is begun the advanced fry, as they are now called, require very close attention to prevent the breaking out or spread of disease, especially fungus and "sore throat." The latter is caused generally by the fish becoming weakened through an insufficient supply of oxygen, especially when the troughs are crowded. Should more than a normal mortality be noticed at anj time, the young fish must be given a salt 
bath, and perhaps the number in each trough be reduced. In fact, after the fish have been feeding well, there should be a thinning out before any sign of disease or undue uneasiness develops. A trough filled with fry will be greatly overcrowded by advanced fry after a fortnight. The extent of the thinning will depend of course on the number of fry that were first put in the troughs. This must be left wholly to the judgment or experience of the fish-culturist. It might be said that where close attention is paid to the health of the advanced fry a much larger number can be carried in a trough than some people suppose.

Not many years ago the average fish-culturist would hesitate to carry more than 15,000 advanced fry in a trough in which the same man to-day would not hesitate to carry over 30,000 , or if driven to it, 40,000 , and bring them through successfully. While this is true, it is not advisable to carry more than 15,000 or 20,000 advanced fry in a twelve-foot trough, nor is it advisable to go far below the smaller number mentioned, because there is less likelihood of all the food that is given out being devoured, 
and uneaten food is a developer of fungus.

Dangers to the Fry. - With a marked increase over 15,000, there is proportionately a greater amount of care and attention required and greater danger of disaster. Troughs containing only about 15,000 will requireattention about once a day in addition to the three daily meals. A trough containing 30,000 will require care at least three or four times daily, exclusive of feeding, and must be carefully scanned the first thing in the morning and the last thing at night.

If trouble breaks out in a heavily stocked. trough the danger of a total loss is much greater than where there is only a normal quantity. Naturally the number must be governed somewhat by the temperature of the water and the character of the troughs. It would be perfectly. safe to carry 20,000 to 25,000 for two or three months after the sacs have been absorbed in troughs of the Pennsylvania pattern. After a couple of months there must be further thinning. The higher the temperature the smaller the number of fish that can be carried safely, for the reason that with the higher tempera- 
tures there is more rapid breathing and therefore a greater amount of oxygen consumed.

Salt-Baths.-Mention has been made of the use of salt. It is both important and necessary in successful trout work. Salt is to the fishculturist what calomel or quinine is to the doctor of human patients, a sort of preliminary cure-all. On the other hand it should also be said, by way of caution, that salt is to a fish what strychnine is to mankind-death, when administered in too heavy doses, a powerful stimulant when used under proper conditions and in due proportions. Salt is also useful as a cleanser of troughs and ponds. The discovery of the valuable medical and hygienic qualities of salt in fish-cultural work was made in 1872 by Livingston Stone.

Salt baths for fry are advisable, as they act as preventives of gill troubles. They should be administered in varying degrees of strength regulated by needs of the different stages of disease that may present themselves. In very mild cases, or when there is slight indication of sickness among the fry, the salt can be placed at the head of a trough where the water from 
the faucet can fall on it. This will make a very. weak solution which will run through every part of the trough. If the disease be more pronounced, and a more effective dose be necessary, the salt can be scattered over the bottom of the trough and then thoroughly dissolved by the hand, leaving the water running during the saturation. As the fish grow older it is sometimes well to put salt in the water, even when there is no pronounced indication of disease. There are two very good methods of administering a salt bath to advanced fry and fingerlings while yet in the hatching-house. The most successful is to cut off the water-supply and distribute salt as evenly as possible throughout the trough; then by a gentle motion of the hand back and forth through the gravel, dissolve it. The other method is first to dissolve the salt in a pailful of water, and then, after turning off the water-supply as in the other method, distribute the brine as evenly as possible over the trough by means of a small sprinkling-can or watering-pot. Should it happen that the disease is widespread, and heroic measures are necessary, the amount of salt 
must be increased and the fish kept in the brine until they all exhibit great distress. When some of the fish begin to turn over, the fresh water must be turned on at once and the salt water washed out as quickly as possible. Under this heroic treatment some fish may die, but this need cause no alarm, for they would have died in any event. When a large amount of fungus develops daily among eyed eggs, good results may be obtained by taking the trays carefully out of the troughs and sprinkling them by means of a sprinkling-pot with a solution of salt and water.

Another word of caution is necessary concerning the use of salt. Under no circumstances must what is commonly called "table salt" be used. There is something in the process of refining for table purposes that is highly injurious to fish. Almost any form of coarse salt can be employed, except pulverised rock salt.

Reference has been made to cleaning troughs by means of a scap-net. The process is both simple and interesting. First the water-supply is turned off at the faucet, and the upper strip 
of wood which forms the dam at the lower end of the trough is removed, first making sure that the screen above the dam is secure and clean. When the water has fallen to about an inch in depth, the operator feathers from one end of the trough to the other. Then he takes the seapnet and, beginning at the upper end, works it gradually to the lower in very short sweeps, picking up the dirt and also very weak fish, which if allowed to remain would undoubtedly. die. A spawning-pan containing water is kept close at hand and into it is emptied the contents of the scap-net, to be finally thrown away. 


\section{CHAPTER XI \\ REARING YOUNG TROUT}

THE successful care of trout in ponds from the fingerling* stage to maturity, and until they are disposed of, depends upon having sufficient water, clean ponds and proper food. Fingerlings which are designed for breeding purposes should be transferred to outside ponds as soon as possible after they have reached that stage, or in the advanced-fry stage soon after they have begun to feed.

The most difficult period for carrying trout is the first summer. Unless every precaution is taken, the utmost diligence observed, and the best skill exerted, it will likely be found in October, when the transfer of fish from the hatch-

* Fry,-Fish freshly hatched, still carrying the yolk-sac; Advanced fry,-Fish with the sac absorbed, but less than 1 inch long; Fingerlings,-Fry less than 1 year old; No. 1 fingerlings, are from 1 to $2 \mathrm{in}$. long, No. 2, from 2 to $3 \mathrm{in}$. long. Yearlings,-Fish from 1 year old and over. 
ing-house to the ponds is made, that the number has been much reduced. I have known the loss to be half during the first summer of an establishment.

One method, usually safe, of reducing the death-rate during the advanced-fry and fingerling stages is to furnish plenty of shade. At one of the stations in Pennsylvania the annual death-rate was from 50 to 75 per cent., until the nursery-ponds were completely covered, between March and October, whereupon the death-rate fell from 10 to 15 per cent.

Automatic Feeders.-Rapidity of growth, which is important when rearing for the market, can best be stimulated during the first six or eight months after the sac is absorbed by the use of one of the forms of automatic feeding apparatus. It is then possible for one man to care easily for almost any number of ponds holding from 5,000 to 10,000 fish each. Young trout should be given all the food they can consume, but no more, since more will be a waste, and will foul the ponds. The reservoir of the feeder should be replenished at regular intervals with an amount that will become exhausted 
in about an hour. It is also essential to the successful operation of an automatic feeder that the food remain of uniform consistency. If the liquid liver paste or the milk becomes thickened beyond a certain point it cannot be drawn into the water by the piston system or properly cast by the revolving-spoon device.

Some men object to the automatic feeder chiefly on the ground that the strongest fingerlings will get all the food and the weakest none or very little; at the end of a few months, they say, there will be a few very large fish and a great number of half-starved and little ones. My experience and that of others is that this does not occur, especially when the trout are sorted at the proper time. Even if it were true that the largest and strongest get nearly all the food and the weakest very little, the condition would hardly be worse than when fed by hand. I may add that after observing a continual use of automatic feeders for a long time I find that the average size of all fish fed in this manner is at least a third larger than those fed by hand. This is also much the cheaper way. In hand feeding, one man can care for 
only half the number of fingerling-ponds that can be managed when the automatic feeder is in use.

There are several designs of automatic feeders more or less in use, two of which seem to be most generally favoured. Both are operated by means of a small waterwheel, and are usually set at the head of the nursery-pond. One supplies the food by drawing it from the reservoir by means of a piston rod, which works back and forth through a hole bored in the side close to the bottom. A good reservoir may be made from a stoneware marmalade jar with a hole bored in the side close to the bottom. The other throws the food over the surface of the pond by three or four wooden spoons or slightly hollowed paddles set like the spokes of a wheel in a hub. I prefer the first, because it supplies the food more regularly, more evenly, and much more slowly than the second. The last point is of decided merit, for until the supply of food in the reservoir is exhausted, there are fingerlings waiting eagerly for each grain that falls.

Food for Fingerlings.-Fingerlings or advanced fry, having been placed in the nurseryponds, should be given food not less than three times a day. Experience has taught us that there are two kinds of food that yield the best 
results. One is liver, prepared by rubbing it through perforated tins so as to reduce it to the consistency of a pulp or paste; the other is thick milk. The liver paste should be mixed with water until it is thin enough to be drawn through the automatic feeder drop by drop, at such a rate as will enable the fish to feed steadily from an hour to an hour and a half before the reservoir is exhausted. If it is made too thin, it will be dropped into the ponds faster than it can be eaten. When the feeding is to be done by hand the liver paste may be made a little thinner than when prepared for the automatic apparatus.

In the preparation of milk-food the best results are obtained by using skimmed milk which has been allowed to curdle and thicken naturally. The thickening ought not to be forced by scalding or boiling, which gives a toughness to the curds that is undesirable, and which is not so easily digested as the soft particles of naturally thickened milk. It should be placed in the automatic feeders in the same quantities as the liver. A little salt, occasionally, in both the milk and liver paste, has been found to be 
beneficial to the fingerlings, but so little should be used that the salinity would not be perceptible to our taste. Most fish-culturists use thick milk only as a change of diet, and in proportion of one meal to three. Very few offer it exclusively or as often as the liver paste. I have never heard a good reason for this, and have found that young trout, at least until they were six or seven months old, lived and thrived on thick milk exclusively, with care as to overfeeding, so that no surplus shall accumulate on the bottom of the ponds and ferment.

Hand feeding is done by means of a rubber bulb or a spoon. I prefer the bulb, for with it the fingerlings can be fed more rapidly, more effectively, and the food scattered more evenly over the surface of the water. Whether using a spoon or a bulb it is expedient to teach the young fish to come to a certain spot in the pond for their food, by patiently and persistently feeding them at the same place every day. It saves time and labour, and is amusing.

A curious fact may be noted here, illustrating the ease with which habits may be acquired by young trout, and the trouble which may ensue when it is 
desired to change them. A natural habit of wild trout is to rise towards the surface for food, and to ignore anything excepting living creatures on the bottom. The initial food for young trout in captivity, as I have said, is liver and thick milk, both of which sink rapidly to the bottom. When they begin to feed, the advanced fry seize the liver or milk as it sinks, and soon learn to pick it up from the gravel. They keep this up after being transferred to the ponds. After the lapse of several months the young trout, having reached the dignity of fingerlings, have their food changed to chopped lungs. Now lungs are lighter than water, and therefore float. When first introduced to this food the young trout pay little attention to it, not coming freely to the surface for it, but apparently waiting for it to sink; and it sometimes requires two or three weeks of very patient work to teach the youngsters to rise to the surface for their food.

After the young fish have remained in the nursery ponds or races until their size has appreciably increased, it is important that they be sorted according to size, and transferred to the rearing-ponds where they must be fed by hand, and regularly given as much food as they will consume, but no more.

Feeding Yearlings.-When the trout reach 
the yearling stage the food is changed from liver paste and thick milk to chopped lungs and hearts and liver, cut in small pieces, but not mashed into a paste. In some establishments certain artificial foods are furnished from time to time as a change of diet, and in one commercial establishment the principal food for trout over six months old is flour cooked into a mush, while trout of younger age, after the advanced-fry stage, are fed a mush of half flour and half liver paste.

Meat Food.-Meat food is ground by a sausage-grinder through perforations of a size convenient for the fish to swallow, and scattered over the surface of the pond so that every fish will have a chance to get its share, and all will be consumed. The different kinds of meat foods usually given the older fish are the livers of beef, or the lungs and livers of a hog, or the heart, lungs and livers of sheep. The last is best for advanced fry and fingerlings because it is more easily prepared. There is an unpleasant sliminess about hog liver that renders it undesirable for trout young or old. Many men engaged in rearing trout use blood for 
feeding advanced fry and fingerlings, and no more excellent nourishment can be recommended. To prepare it for use the blood from a slaughtered animal, while still warm, is run directly into a barrel and stirred vigorously until it is smoothly thick. Blood allowed to thicken without stirring is clotted, stringy, and unfit for feeding purposes.

Cleanliness Required.-Clean ponds are as important factors towards success as the character and quantity of the food. Dead fish should be removed at once. In every hatchery there ought to be a standing rule that every pond must be gone over the first thing each morning, and any fish which may have died during the previous 24 hours taken out. Filth of any kind and certain forms of algæ must not be allowed to accumulate, and the ponds therefore need to be cleaned at regular intervals. It is as necessary for the health of the fish that the ponds be kept clean, as it is for the well being of a man that the house in which he lives be kept free from filth; in both cases dirt breeds disease.

Ponds with concrete, or building-tile sides 


\section{REARING YOUNG TROUT}

are naturally the easiest to cleanse, and those with natural banks the hardest. To clean concrete or tile ponds the water-supply is first shut off and nearly all the water is allowed to run away. Before the drawing, a quantity of salt should be dissolved and the brine thrown into the water, so as to loosen slime and other refuse that may be deposited on the bottom and sides. The salt will at the same time act as a health bath for the fish. When the water has been drawn off as far as safety will permit, the sides of the pond are thoroughly swabbed with a brush and the dirt and refuse worked to the lower end to the outlet, where the current will carry it away when again turned on. To clean large ponds containing mature fish draw the water down, clean the sides with a brush, and then allow the full current of water to run through the ponds.

Sorting.-Trout, like other carnivorous fishes, are cannibals, and in a wild state the deathrate from this cause is large. Partly for this reason the trout in the ponds ought to be sorted into sizes as soon as possible. When first introduced into the nursery-ponds as advanced 
fry or fingerlings they are too small to sort, but through the agency of heavy feeding there will be a sufficient growth to warrant the work being done for the first time about the middle of June. There should be a second sorting in August and a third not later than the middle of October.

In ordinary circumstances the fish can be divided, in June, into three classes, or at most four, and it is probable that the same number of grades can be maintained both in August and October. The nursery-ponds will continue to be the abiding place of the fish after both the June and August sortings. After this work in October they are not returned to the nurseryponds, but transferred to the yearling-ponds, where they remain until after they reach the age of 20 months, or until the spawning period. After having the spawn taken from them the fish are transferred to their final home in the largest adult-ponds.

During the two or three months immediately following the recovery of the fish from the labour of spawning, or the ordeal of being stripped, trout grow faster 
than at any other period in the year; consequently, as soon as they have begun to recover, they should be given all the food they will eat in order to assist and foster the growth. This is perhaps the most important advice that can be given with respect to feeding. Delay in feeding regularly at other times is not as serious as a failure to furnish them a full and regular supply during the two or three months just mentioned.

After the lapse of two or three months, if the hatchery is one in which the main object is the propagation of the fry and fingerlings for breeding or distribution and not for the market, it would be well to decrease slightly the amount of food given daily, as a growth beyond the normal for their age is likely sometimes to cause a deterioration in the quality of the eggs. In my experience the proportion of "ringers" in eggs is frequently increased where fish are over-fed to increase their size.

If, however, the propagation of fry and fingerlings for stocking purposes is secondary to the rearing of fish for market, then the food question assumes another aspect. Naturally. 
the aim of those who rear for commercial purposes is to produce as rapid a growth as possible so that the fish will be marketable at an early date. In those circumstances the fish should be given daily, throughout the year, as much as they can gorge. In commercial establishments feeding occurs rarely less than three times a day, and in some of them as many as five times daily.

It is said that ordinarily a trout will eat daily, if given the opportunity, about onetwentieth its own weight. In one establishment, where fish are raised for the market, food to about one fourth the estimated total weight of fish is given regularly and there is much disease among the fish. In another, the average amount of food is about one fifth the estimated weight of fish in the ponds. In this instance there is no disease and very little fouling of ponds is perceptible. The ponds are very large, covering about half an acre each with a depth of from eight to fifteen feet in the kettle, and supplied by a large volume of creek water, consequently it cannot be laid down as a hard and fast rule that over feeding is sure 


\section{REARING YOUNG TROUT}

to breed disease. By feeding to the utmost limit of their capacity, trout at the age of 20 months will equal in size the normal growth of a three-year-old fish, a size which finds the readiest sale in the market. 


\section{CHAPTER XII \\ THE ATLANTIC SALMON}

SALMON-CULTURE is carried on almost entirely by the United States government, and on the Atlantic is maintained for sentimental reasons rather than for any great practical results. Nearly all the large streams in New England were once abundantly supplied with salmon, but now only the Kennebec and the Penobscot in Maine contain it in any numbers. The United States Bureau of Fisheries supports a hatchery in that state, but the cost of operating it is nearly or quite equal to the value of the catch of fish.

Numerous stations are maintained by the government on the Columbia River and in Alaska for the propagation of the various species of the Pacific salmon, and with great success. Efforts have been made from time to time to transplant the quinnat salmon to the 
Atlantic coast, but always without good fortune, apparently because its natural spawning-grounds are in a much higher latitude than Maine.

Attempts were also made to introduce the silversides, a fish that spawns in about the same latitude as the Atlantic salmon; the young thrived in the hatching-ponds at East Orland, Maine, and in the state breeding-ponds in Pennsylvania, to within one year of breeding age, when the experiment was abandoned. Fish a year old had attained an average length of seven or eight inches; they fed greedily and maintained vigorous health. That initial plantings in the tributaries of the Delaware River were successful is evinced by the fact that in July, 1908, three young silversides were caught in the Lackawaxen Creek, Wayne County, Pa.

Repeated but unsuccessful attempts have been made at the United States hatchery of East Orland, Maine, and at the Wayne and Bellefonte hatcheries in Pennsylvania, to domesticate Atlantic salmon in numbers sufficient to establish breeding-ponds. Mr. Atkins, Su- 
perintendent of the East Orland station, succeeded in raising a few from the eggs to maturity, and in securing eggs therefrom. The superintendent of the Bellefonte hatchery reared six to spawning age. Unfortunately they were all females, and each was stunted. At the age of four years the largest was scarcely 15 inches long, and at five years they had hardly added another inch to their length.

The Pennsylvania superintendents found almost insuperable difficulties in inducing the young fish to take food. Nothing seemed to tame them. They were so wild that whenever any one approached the pond they scattered in all directions hiding wherever they could. The superintendent of the Bellfonte station was unable to make them take any food while in the fingerling stage, excepting a half dozen which afterward reached maturity; he achieved success with these only by placing them in a pond containing brook-trout of the same size. The superintendent of the Wayne station managed to induce his first stock of fingerlings to eat a small quantity of food by hiding himself in a small reservoir at the head of the pond, and allowing food to be carried to the fish by means of the intake pipe. A second lot took food more freely when it was supplied by means of an automatic feeder, and when with the food a very small 


\section{THE ATLANTIC SALMON}

quantity of salt was mixed. Unless better success is achieved in some manner it seems certain that the Atlantic salmon is doomed in the United States.

The eggs may be hatched in the same manner as those of the brook-trout, although the meshes of the hatching-trays must be much larger, or the trays replaced by wire baskets. 


\section{CHAPTER XIII}

\section{HATCHING FISHES' EGGS IN JARS}

THE national and state institutions hatch in glass jars the bulk of the hundreds of millions of fish which they plant every year. The eggs of nearly all fresh-water and anadromous fishes, excepting the trouts and salmons, are incubated in this manner. No discovery yet made in fish-culture has equalled that of the hatching-jar. It has made possible fish-culture in such huge proportions that the work to-day is bounded only by the size of the hatchingplants and the amount of money available to secure eggs; and it has enabled national and state governments to take up "field work" on a scale commensurate with its importance, and through it to save and hatch the almost countless millions of eggs of ripe fishes caught in nets by the commercial fishermen which pre- 
HATCHING FISHES' EGGS IN JARS 179

viously were nearly all lost or wasted. It has also rendered possible the gathering and hatching of eggs which, through their being unprotected after being deposited by the parent fish, would have been nearly all devoured by spawneaters. In some instances valuable kinds of fishes which had become very scarce have been restored in such numbers as to make their catching a profitable industry.

The hatching of fish by the jar method is at present useful chiefly to governments for public work, or to fishing clubs that own lakes which they desire to stock very heavily, or for persons who desire to hatch useful fishes which they intend to sell as soon as hatched. There are at least five different hatching-jars prominently in use in the United States: the Chase, McDonald, Downing Improved, Meehan, and Clark. All have their staunch supporters, and all are effective egg-workers and incubators. A choice would depend upon local or individual circumstances and intentions.

Water for Jars.-In projecting a site for a station for jar work the water question is as important as in hatching trout, but fortunately. 
there is a greater latitude of choice. The best water is that taken from a natural lake having no floating sediment; but that from a stream will answer admirably, provided it is unpolluted by industrial establishments, or is not muddied by storms for too long at a time. Some eggs are quickly harmed by mud, while others will survive in turbid waters almost throughout the period of incubation. When the hatchery is for general work, it is not advisable to use water directly from a spring or which is piped directly from one. It is possible that fresh spring water may not be harmful to the eggs of some species of fish but for others it is often sure death.

When the water is introduced by gravity, there should be enough at all times in the year to fill a six-inch pipe, unless only one battery is operated. Under pressure, however, a fourinch pipe will supply two batteries with seven troughs, each 30 feet long and containing 350 jars. A six-inch pipe, under pressure, will supply with a safe surplus three such batteries. To bring the water into the hatching-house by gravity is naturally very desirable, because it 


\section{HATCHING FISHES' EGGS IN JARS 181}

involves no cost of maintenance; when a fall of land is not sufficient for this economical method, power must be brought into play. The best and cheapest pumping machine is a ram. In case the instalment of a ram is not feasible, the next best means of pumping is by a waterwheel. Failing this a pump must be installed with some sort of a heat-engine, unless city water-usually good enough-may be used.

For eggs which require a long period to eye, like whitefish or lake herring, or those which yield to fungus easily, like wall-eyed pike, uniformly clean water is important. For shad eggs it is not of such great concern, although desirable, and for yellow perch it is a matter of little or no moment, except that it makes more work.

Batteries.-Two distinct types of batteries are in operation, one very complicated in construction and the other almost the perfection of simplicity.

The first has both supply and waste troughs, one system set lengthwise and the other crosswise. The latter are arranged like a flight of steps, with an overflow in the centre, for the purpose of enabling 
the operator to see that a full supply of water is in the battery and carrying the fry, when they are hatched, to the fry-tanks on the floor. Screens are set in the cross tanks so that the fry must take a definite route to the fry tanks. The hatching-jars are fed from the troughs set lengthwise which are fitted with ball-cocks to regulate automatically the water-supply in the tubes and pipes. A battery of this type is very expensive to build, requires much water to operate it, and is now rarely seen.

The second style of jar-battery is commonly called the Alpena pattern, on account of its having been built first in the United States FishHatchery at Alpena, Mich.

The Alpena battery is so simple in design that any intelligent carpenter can build one, and is also thoroughly efficient and by no means costly. An Alpena battery, with a capacity of 350 jars can be built easily for $\$ 150$. Its only weak point is that the egg-shells and fry are carried to the fry-tanks through the troughs which supply the jars with water, and may. sometimes clog the faucets.

An Alpena battery is simply a number of troughs, all but one being 14 inches wide, 12 inches deep and as long as desired, set one 
HATCHING FISHES' EGGS IN JARS 183

above the other from the floor to the eaves of the hatching-house, with a space of $51 / 2$ inches between each. The exceptional trough is six inches deep instead of twelve, is placed upon or near the floor, and is used as a hospital. The troughs are not set on a perfect level, but with a slight slant so that the water will flow better. The top trough slopes a trifle from the inflow-tank or supplying pipe; the one beneath slightly towards it, and so on to the bottom or hospital trough.

There are two outflows; one in the trough immediately above the top of the fry-tanks, which is placed at the end of the building farthest from the supplying tank or pipe; the other into the sewer from the hospital trough. Arms or brackets, made of wood and shaped like a flat dumb-bell with very long handles, are fastened at regular intervals across the top of each trough excepting the uppermost one. On these brackets the jars are set on each side of the battery. The water is flowed into the jars by means of faucets and tubes from the trough above; and from them by means of the outflowlip into the trough against which they are set. 
The water is flowed into one end of the top trough, thence through those below and the jars, until it emerges into the fry-tanks or the sewer. Thus the water is used over and over again not only for the hatching of the eggs but for holding of the fry.

When brought into the house the water may be run directly into the top trough by means of a pipe, or first flowed into a supplying tank or trough and thence by pipe into the battery. Each trough of the battery must be of the same length, although the ends must not line from the bottom to the top, but be staggered endwise, the top trough being short at the end farthest from the supply-pipe. The purpose of the staggering is to allow the water to fall from one trough to the other. To facilitate the fall, the top of each end of the trough is cut for the depth of an inch, to which is set nearly perpendicularly a japanned tin lip. The staggering need be only just enough to allow the water to fall from one trough to another without spilling on the floor.

The troughs are held in place by standards, three inches by four, reaching from the floor 
to the girders of the building. To these are fastened cross-pieces on which the troughs rest. One-and-one-eighth-inch dressed lumber is proper for the troughs and the ends may be set flush and not mortised. To facilitate cleaning, a two-inch hole is bored in the bottom of each trough at the projecting end. Before being used the entire battery inside and out should be given a good coat of asphaltum. When made of lumber, only the finest quality of white pine, cypress, or some similar type of wood entirely free from knots, can be used safely; but a battery may be made of galvanised iron, if it is well asphalted before being used, or of concrete.

Ordinarily when eggs handled in jars begin to hatch, the proceedings are marked with great expedition and the attendants are kept busy. Hundreds of thousands of fry issue simultaneously; hence it is important to have plenty of tank-room to receive them. I have found the most convenient fry-tank to be 16 feet long, three feet wide, and four feet deep. With a battery built as outlined, the eggs of only one species of fish can be cared for at a time; but, 
by the addition of a simple device in the shape of a trough of tin or zinc, about the width of a rainwater gutter, set in the trough at one side and connecting the ends, two species can be handled at one battery simultaneously and the fry kept separate. By this means the water from all the jars on one side of the battery above the fry-tanks flows into the gutter instead of into the trough itself. The tin trough will also be found very convenient when two or more fishes spawn at the same time. It would be advisable when building the battery to provide for the possible contingency of hatching two species of fish at the same time, by dividing each trough lengthwise by a partition, giving each an outflow-lip.

Suitable Buildings.-A building 60 feet long and 32 feet wide, will furnish room for three batteries with an aggregate capacity of 1050 jars, and six fry-tanks. Occasionally there may yet be found a hatching-house for jar-work in which the table system, with closed McDonald jars, is still in vogue for temporary services, but this method of hatching fish is rapidly passing away. The battery marks as great an 
HATCHING FISHES' EGGS IN JARS 187

advance over the table system, as the jar over the old floating-box. It enables at least a fivefold increase in the annual output of fry, with the additional advantage that it requires no more water. For example, a building holding two tables with a total capacity of 120 jars would allow the setting up of two batteries of the Alpena pattern, holding altogether 550 jars and exactly the same amount of water. The table is about $31 / 2$ feet from the floor, about five feet wide, with a tank about eight inches deep set in the centre, the whole length, and having an outflow-pipe at one end into the fry-tanks. The jars are arranged in rows along the line of the tank with a long rubber hose leading therein from the outflow or siphon tube. The water-supply is received through a two-inch pipe suspended about three feet above the table and tapped every six inches by quarterinch pet-cocks. The pet-cocks and the intake glass tubes of the jar are connected by means of rubber hose. 


\section{CHAPTER XIV \\ CULTURE OF YELLOW PERCH}

For several years there has been a steadily. increasing demand for yellow perch, which is now regarded as one of the staple market fishes, as its flesh is not only very palatable but firm and flaky in character. This fact, together with rather a tough skin, and heavy, tenaciously clinging scales, makes it good to keep and ship.

A number of years ago the United States Fish Commission demonstrated the fact that yellowperch eggs could be artificially hatched, but it was in Pennsylvania that the work was first begun on a large scale. Eggs may be taken from the female with almost the same ease as from trout, and the milt will flow from the male at the slightest pressure of the finger; but experience shows that artificial expression and 


\section{CULTURE OF YELLOW PERCH 189}

impregnation is not as satisfactory in results as raising eggs naturally deposited and fertilised. Ordinarily a larger percentage of eggs can be fertilised by artificial impregnation than by natural, but this has not proven so in this case.

Care of the Fish.-Yellow perch can be retained and cared for in hatchery-ponds as easily and numerously as brook-trout. For food they take very kindly to cut lungs and liver, and will not even disdain bread. They require less artificial food than trout because there is for them a wider range of natural food. While yellow perch may be retained successfully in ponds of almost any size, they thrive better in those of large area, and should have ponds as large as those provided for the black bass.

It is no trouble whatever to induce yellow perch to take artificial food during the spring, summer and early autumn; but after they have gone into the kettle in the late autumn it is not so easy to feed them successfully. Yet they must be induced to eat it, because hatcheryponds contain a minimum amount of natural food, and otherwise on the arrival of spring 


\section{FISH CULTURE}

they will not have the proper vitality to properly perform the function of spawning. An apparatus has been devised by means of which it is possible for the fish to feed as successfully and certainly when the pond is covered with ice as in the summer. It is a basket about one foot square, made of quarter-inch wire netting, which is filled with cut liver and lowered through a hole in the ice until it is about one foot above the bottom of the kettle, sustained by two wire hangers wrapped around strips of wood laid across the hole. In a few minutes the perch discover the basket and attack the food eagerly, devouring it all in a very little while.

It is important that ponds for yellow perch have natural sides, and that they shoal to a general depth of not more than two feet, with not less than one foot at the sides, with a kettle at the outlet deep enough to permit the fish to hibernate safely. Water lilies for shade and shelter are important, but the grasses are undesirable on account of their unsightly appearance. In natural waters grasses are almost a necessity, as they form excellent means of at- 


\section{CULTURE OF YELLOW PERCH 191}

tachment for the strings of eggs; but they are not needed in hatchery-ponds for yellow perch because equally good if not better material for holding spawn can be provided. Brush fastened to the banks around the sides is generally used.

Spawning Habits.-Considering the average small size of the yellow perch, the number of eggs which a female will deposit is prodigious, and the length of the fertilised string is truly marvellous. A medium-sized female will give from 30,000 to 50,000 eggs, and there is reason to believe that one at her best will furnish more than one hundred thousand. Each string is invariably several times longer than the fish which deposited it, and after fertilisation and hardening is usually more than double the weight. It is possible for a fish 18 to 20 inches long, perhaps smaller, and less than two pounds in weight, to deposit a string of eggs over seven feet in length, which will weigh nearly or quite three pounds, and will almost fill a four-quart measure. The eggs are held together by a jelly-like substance, and the ribbon-like string appears to be crumpled, so that the eggs dotted 
thickly along it give the whole the appearance of a piece of yellowish white, accordion-plaited, lace. The string is round and consists of a series of concave disks fastened at the centre by a thin gelatinous material, so that it much resembles a string of winkle eggs.

The spawning period of a perch varies from February to May, depending on the locality and temperature of the water. In the lakes of north-eastern Pennsylvania the period begins about the latter part of April and in the lower Delaware between the first and fifth of that month. The egg's seem to be deposited most abundantly when the water is between 52 and $54^{\circ} \mathrm{F}$. About two weeks before the spawning period in the hatchery, thick brush is set firmly all around the edges of the ponds, so placed that the brush is completely submerged. Each piece should be from four to six feet long and the more numerous the branches the better. No part of the pond must be neglected, because the yellow perch is capricious and what would be the spawning-spot one year might not be the next. The first egg will most certainly be hung on the brush in the warmest water. 
Spawn is deposited most abundantly a little before daylight, but as the season advances fish will be found at work at all hours. The strings of eggs are laid among the branches of the brush, usually one or two feet below the surface, and occasionally underneath them, on the bottom of the pond. They are found very frequently on the surface, or so near to it that a portion of the string is not submerged and dies.

Gathering the Eggs.-After spawning begins the pond is to be visited every morning and the strings removed, either with the hand or by a small, shallow scap-net. The strings, as gathered, are put in a bucket containing about a quart of water. When the bucket is full, or the work done, the eggs are taken to the hatchery and placed in the jars for incubation.

If the eggs are gathered from ponds where naturally deposited by wild fish, in addition to the bucket and egg-nets a boat, an egg-stick, and floating-boxes, are needed. The egg-stick is simply a small wand cut from a bush, and at its tip must be left the stumps of a couple of branches, so as to form a very small fork. 
The floating-box should be about six feet long, one foot deep and three feet wide, with bottom and ends of wire mesh, about sixteen wires to the inch. A long piece of scantling is nailed to each side of the box at the top, so as to maintain a balance and make it float more buoyantly. This box is anchored in the lake in about ten feet of water.

There should be at least two spawn-gatherers in the field, and as each man's pail is filled the eggs are emptied into the floating-boxes where they remain two or three days, if not too far advanced towards incubation. They may be carried to the hatchery in the ordinary eggcases, or in shipping-cans. The cans should first be half filled with water, and not more than ten or twelve quarts of eggs placed in any one of them unless for a very short distance, say ten or twelve miles; even then the number ought not to exceed 15 quarts, as more is likely to result in many of the eggs being smothered.

There is nothing in fish-culture so easy to handle as yellow-perch eggs. Almost any ordinary bright young man who has been working in a hatching-house a few weeks can care for the eggs during the entire 
CULTURE OF YELLOW PERCH 195

period of incubation. There are no eggs which will stand as much rough handling. If they become covered with mud they may safely be taken from the jars and washed in tubs of water. If any portion of the string should die it may be cut or broken away without any harm whatever to the parts which are alive. The one feature of first importance is constant attention day and night. The jars may be nearly filled with eggs, and although they seem to be resting in a heavy mass there need be no apprehension of smothering. Only a very slight flow of water is required, but little more in fact than is needed to fill the tubes, preventing air becoming mixed with it, and to flutter or oscillate slightly the mass.

As the eggs are semibuoyant, and at times actually buoyant just before hatching, it is important that a screen of mosquito-wire be set completely around the inside of the top of the jar. The change from semibuoyancy to buoyancy is very sudden, and occurs usually just as the eggs are beginning to eye. At this period the gelatinous material, which is tough and strong when the eggs are first deposited, softens, or as it is termed "rots," the string breaking into pieces and rising to the surface. Were it not for the screen described above, the 


\section{6}

\section{FISH CULTURE}

eggs would flow over the top of the jar to the floor. A mass of eggs will sometimes rise for more than an inch above the top of the jar. It is chiefly on account of this proclivity, nay certainty, of the eggs to rise that it is necessary to have some one in attendance both day and night. Another reason for constant supervision is the necessity for closely watching the water-flow; as, owing to the small quantity used, any slight obstruction in the faucet will completely stop it. Sometimes, owing to changes in the specific gravity of the eggs, the flow must be increased or diminished. It often happens that during the period of incubation every faucet in a hatchery will have to be changed within twelve hours. When a rise in perch eggs occurs, the attendant must stop the flow of water immediately, and with his hand or a feather gently push the mass to the bottom, where, after about five minutes, the eggs will settle quietly. Then the water can be turned on again slowly and cautiously. It may be half an hour or more before a rise will occur again, if at all. 
CULTURE OF YELLOW PERCH 197

The average spawning-period of the yellow perch is from twelve to fifteen days, although, as with the eggs of all other fish, the time may be shortened or lengthened according to the rising or lowering of the temperature of the water.

Yellow-perch Fry.-Newly hatched yellow perch are minute and almost colourless, and can scarcely be seen in the water. Their yolk-sac is not heavy, so that they swim freely almost from the moment they emerge from the egg. On account of the tiny size of the newly hatched fry the out-flow of the tank into which they are carried from the battery must be screened with some very finely meshed material, as coppergauze wire or cheese-cloth.

The absorption of the yolk-sac and early growth of the yellow perch are very rapid, and by the end of a month the fry will be a sturdy youngster nearly an inch long and schooling with thousands of his kind in shoal water; and by the end of the year under favourable conditions he will be four or five inches long. After that the growth, as with most other 
fishes, is much slower, nature devoting herself to giving the fish girth and weight rather than length.

Death is always busy among young fish hatched in huge quantities from the eggs of a single parent. Loss from other causes than death is also great among minute fry, in the majority of cases at least 90 per cent. This would be appalling and discouraging, were not the spawn furnished by the female yellow perch almost limitless in amount. A string of 50,000 eggs will yield after all losses about 5,000 fish a year old, probably three times the yield in nature. A single hatching-jar would hold in the neighbourhood of $600,000 \mathrm{eggs}$, so that one jar alone would yield about 60,000 yearlings.

Owing to the great loss during the first few weeks after hatching, it is necessary to stock very heavily a pond intended for rearing purposes. The amount of yellow-perch fry introduced should be at least sixty or seventy times the number of yearlings which it would comfortably carry. This is an important point because it is not necessary to do any sorting the first year. Although a carnivorous fish, the 


\section{CULTURE OF YELLOW PERCH 199}

growth is more nearly even in yellow perch than in its distant relative the black bass, and the loss from cannibalism is therefore not as great. 


\section{CHAPTER XV}

\section{REARING PICKEREL AND MUSCAL- LONGE}

THE pike family is represented in Europe, Asia and America, and the species vary in weight at maturity from half a pound to nearly 150 pounds. The heaviest American species are called muscallonge* ; certain other members are called pike, and others pickerel. The word "pickerel" means little pike, and North America possesses two or three species, one of which is the "chain pickerel," a favourite food and game fish, distinguished by the chain-like reticulations of colour which cover the sides of its body. All the other pickerels and pikes have bands or bars.

The pikes prefer large bodies of water or deep and very sluggish streams having many

* The spelling of this Indian word is not generally agreed upon. The Standard Dictionary prefers maskinonge. 


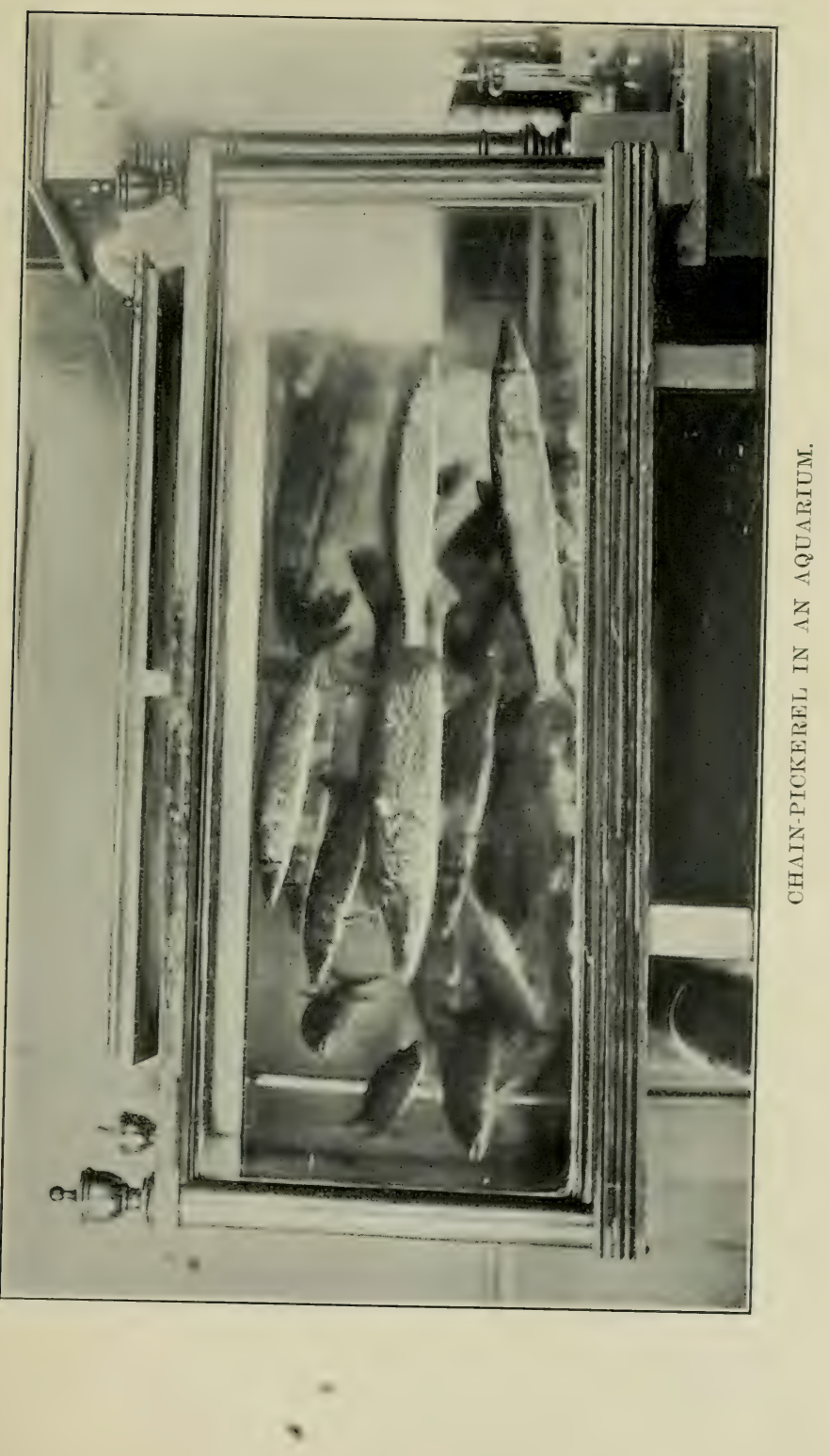



PICKEREL AND MUSCALLONGE 201

submerged logs, stumps, and aquatic plants. Among these, the pike, solitary in its habits, rests perfectly motionless, waiting for the coming of its prey. When within a few feet, the pike, galvanised into life, darts forth with lightning-like rapidity, seizes its victim and returns to its lair. There, often, it will play with its captive as a cat does with a mouse, and wait some time before swallowing it.

Some anglers regard the pickerel as a highclass game-fish. Others place it on a very much lower level. In food-quality the chain pickerel, despite the many small sharp bones in its chest, holds a very respectable place in the market, and meets with ready sale. The flesh of the muscallonge ranks high, and both it and the chain pickerel deserve greater attention than they receive from fish-culturists. New York State alone propagates the muscallonge, but no public hatchery exists for pickerel, yet its propagation is very easy.

Propagation of Pickerel.-Eggs may be pressed from the female without any trouble whatever; the eggs however, are glutinous, and have to be thoroughly rubbed and cleaned after 
fertilising, and before being placed in the hatching-jars, where the treatment should be the same as that for whitefish or shad. It is possible to gather eggs of the pickerel naturally deposited, but it is better to keep the fish in captivity and take the eggs from them by expression. A pond of three-fourths of an acre or an acre will contain many hundreds of pickerel in good health and condition if they are liberally fed with live food, for the pickerel will take only a moving life-like object.

Spawning begins very early in the year, soon after the ice disappears; but the spawning season is very short, and the hatching period is about two weeks. As the pickerel is strongly a carnivorous fish, it is important that the fry be not placed in the same ponds with mature specimens, but kept in smaller ponds, as would be done with any other carnivorous species. Growth is very rapid, and cannibalism, even among the young, strongly developed, hence persons desiring to rear their stock to maturity must expect heavy loss from this quarter.

Among the members of the pike family are four which attain large proportions and weight. 
PICKEREL AND MUSCALLONGE 203

The muscallonge (Esox masquinongy) is the largest of these, and attains a length of eight feet and sometimes a weight of more than 100 pounds. Its habitat is the Great Lakes, the upper St. Lawrence River and Canada. A second species (Esox lucius) is a native of New York State and the Ohio River basin northward. a Third (Esox immaculatus) is rarely met except in the lakes of northern Wisconsin and Minnesota. A fourth species is Esox ohiensis, most abundant in Chautauqua Lake, New York, because persistently propagated there. The three last named each reach a weight of from 40 to 50 pounds and a length of four or five feet. All rank high as game fishes and the flesh of each is greatly esteemed.

The fishery authorities of New York State were the first to undertake to propagate muscallonge artificially, which began at Chautauqua Lake in 1888, under the care of $\mathrm{E}$. W. Irwin and Jonathan Mason; but very primitive methods were pursued until superseded a few years ago by the hatching-jar.

Cultivating Muscallonge.-For the greater part of the year the muscallonge lives in deep 
water, usually in the vicinity of aquatic plants. As soon as the ice leaves the lake in the spring the fish make ready for spawning and by the latter part of April this function is concluded. The eggs are deposited in water usually less than 10 feet deep, and sometimes as shallow as six feet, preferably in muddy bays. The males are usually smaller than females of the same age, and very little milt suffices to fertilise a large number of eggs. The species is very prolific. A fish weighing 35 pounds will yield 265,000 eggs, each about an eleventh of an inch in diameter, 74,000 filling a quart-measure.

Muscallonge eggs are separate, nonadhesive, and semibuoyant, and under favourable circumstances 97 per cent. have been hatched. At $55^{\circ} \mathrm{F}$. they will hatch in 15 days; and the yolk sac is absorbed in about 15 days more. When first hatched the fry is so heavy that it is unable to swim from the jars into the battery trough. The eggs, therefore, should be transferred, when the fry are about ready to emerge from the shell, to trays set in boxes placed in the troughs. The boxes are fitted with wire at each end to insure a direct and uninterrupted. 


\section{PICKEREL AND MUSCALLONGE 205}

flow of water, and to prevent the banking of the fry at the lower end.

When in a wild state the black bass is probably one of the greatest cannibals that swims in fresh water; but in confinement it cannot match the cannibalism of young muscallonge. A few years ago the superintendent of the Corry, Pa., hatchery placed 5000 fry in a pond about fifty by twenty feet, and at the end of three months there was one muscallonge left, and that was eaten by a water-bird. It is therefore essential to plant the young fish before, or as soon as, the yolk-sac has been absorbed.

Gloves are used in taking the eggs of the muscallonge so that the fish can be held more firmly and be less liable to injury; sometimes two men are necessary to hold a large fish and express the eggs and milt. Muscallonge eggs may be hatched on trays the same as trout, in water with a temperature of $46^{\circ} \mathrm{F}$.; the incubation period is sixty days.

The culture of pickerel and muscallonge presents no difficulties when the eggs can be obtained from wild fish, and there is no difficulty. 
206

\section{FISH CULTURE}

in retaining the brood-fish in hatching-ponds, where they will live safely for an indefinite period provided the ponds are large and deep enough. I have kept several of the Chautauqua Lake muscallonge for more than a year in a pond 100 feet long and 30 feet wide, with a water-depth of from three to five feet. These fish ripened both eggs and milt. 


\section{CHAPTER XVT}

\section{WHITE PERCH, STRIPED BASS, SMELTS AND SUCKERS}

Striped bass and white perch represent two extremes of size and weight in the family to which they belong; the first is a fierce and powerful fish, the second is no larger than some minnows, and quiet and unobtrusive. Widely separated as they are in regard to size, character and habits, they are held in equally high esteem as game and food. In the fury and vigour of its rushes when hooked, the first resembles the black bass; the second the brooktrout, in its dainty, delicate struggles. In many places the striped bass and white perch are diminishing in numbers, and both have given the fish-culturist some trouble in their propagation.

A failure on the part of some states to give the striped bass "proper protection when entering the 
rivers to spawn, particularly the "mammy rock," or striped bass of 20 pounds or over, is responsible for much of the diminishing supply. Loose methods of fishing have had something to do with lessening the number of white perch in many places, but as great a factor is the unsuspicious character of the fish. Like its cousin, the yellow perch, it is greedy. All the members of a school will continue to bite at the baited hook during the entire feeding period, unafraid, and regardless of the disappearance of their companions. Hence, although the white perch is a prolific breeder, it is not a difficult matter to deplete waters in which they should be abundant.

Compared to the numbers which were there a quarter of a century ago, white perch are scarce in the Delaware River to-day, and they are also decreasing in the Chesapeake Bay. There are signs of improvement in the latter waters through the artificial propagation conducted by the national government, and, for a short period, by Maryland. This good work has been hampered in the Delaware River by difficulty in getting ripe fish in sufficient numbers to make it worth while to operate a hatchery during the spawning season.

White Perch.-White perch ripen about April. Spawn-takers in the Chesapeake strip the fish, caught in nets for the market, by the dry method. When first taken the eggs aver- 


\section{WHITE PERCH, SMELTS, ETC. 209}

age 29 to the linear inch, and after they have been water-hardened the number is only decreased by one; they are among the very smallest known, a quart containing about 1,600,000. White-perch eggs are very adhesive, and when stripped into an ordinary tin pan are extremely difficult to handle; therefore porcelain-lined pans should be used, and the eggs stirred constantly with the tail of the fish while the milt is being applied. If this is not done, the chances are that a large percentage of the eggs will fail to fertilise.

After the eggs have been fertilised, washed, and hardened, they are placed in jars at a battery, and cared for the same as shad's eggs.

A peculiarity of the white-perch eggs is that while yet undeveloped they are white and hard, almost opaque, so that it is extremely difficult to distinguish good eggs from bad. It is therefore unsafe, until after the eyes have developed, to clean up any portion of a jar or throw away its contents excepting where there are signs of fungus, as it is not unusual for a large percentage of eggs, all presumably bad, to suddenly eye and hatch. Fortunately for the 


\section{FISH CULTURE}

nerves of the culturist, the days of suspense are not long. When the water temperature is about 60 degrees, the eggs will hatch in from 48 to 52 hours. If the temperature is from 68 to 70 degrees, the little fish will emerge from the shell in about twenty-four hours in the McDonald closed-top jars, after they have been held from six to twelve hours in jars without tops or caps.

Every one who has had experience in hatching pike-perch dreads the deadly fungus during the period of incubation, and those who have the care of white-perch eggs declare that they are equally liable to be similarly attacked. It is not surprising that this should be the case, because of their adhesive character, together with the higher water temperatures, both of which are favourable to the appearance and spread of fungus. On this account it is advisable to carry. only a small quantity in each jar.

Striped Bass.-Personally I have no experience in the propagation of striped bass. The United States Bureau of Fisheries has been experimenting with the problem for some years, and in 1904 Mr. S. G. Worth, one of its superin- 
WHITE PERCH, SMELTS, ETC. 211

tendents, presented a paper on the subject to the American Fisheries Society of which the following is a synopsis:

The operations were conducted at Weldon, North Carolina, and occupied twenty-three days, beginning with May 2nd. The water temperature of the river ranged from 60 to 70 degrees. The smallest ripe fish weighed three pounds and the largest 50 pounds. The smallest fish gave 14,000 eggs, the largest 3,220,000, green in colour when fresh. Jars were used in hatching; but a number of floating boxes were needed in addition, since the eggs of one fish weighing 50 pounds would fill over 300 jars. Fully 69 per cent. was hatched. When the fry were about four hours old they were approximately three-sixteenths of an inch long, and at four days they averaged one-fourth of an inch in length; at four weeks they had reached a length of nearly half an inch with the fins easily discernible, and on close inspection the stripes on the sides were visible. With the water temperature between 60 and 70 degrees, the eggs hatch quickly. The period of incubation is only about four days.

Since the publication of his paper Mr. Worth has made a number of additional reports to the Bureau of Fisheries, in whose publications they may be consulted by any one interested. The special weakness of the earlier work, the hatch- 
ing of the eggs was corrected in the following manner, quoting Mr. Worth's account:

"A better per cent. in hatching could have been gained by the earlier adoption of the pitcher-mouthed tops of the Universal hatching-jars, which were experimented with, for the first time, during the season covered by this report. I had already been aware that losses of fry, already hatched and delivered into aquaria, were excessively large at times, and I am of the fixed opinion that the cause was to be found in having the fry struggle through outlet tubes of the Universal jar. . . It is necessary to supply an auxiliary of canvas to the lipped jar-top, in order to let the fish down gradually into the aquarium. Hatched and handled in this way, the results are all that could be desired, for every good egg developed and all the fry lived. It would be a waste of time and material to undertake the hatching of striped bass in the McDonald tidal box, as the separation of bad and good eggs would be impracticable, and there is a percentage of bad eggs in every lot."

The Smelt.-Like the striped bass, the smelt is an anadromous fish, entering fresh water from the sea early in the spring for reproductive purposes. It prefers rapidly running streams with stony or gravelly bottoms, on which the female deposits in vast quantities 


\section{WHITE PERCH, SMELTS, ETC. 213}

eggs so adhesive that they form a thick mat. They become so firmly attached to the bottom and to each other that it is difficult to remove them without damaging a great quantity and taking along stones and gravel. The fish enter the streams in such crowds that I have seen bottoms thickly covered by eggs almost from shore to shore, and for a distance of over 100 yards.

New York was the first state to undertake the propagation of the smelt, and its fishery authorities hatched from $50,000,000$ to $100,000,000$ annually. The smelts are caught in nets and transported to troughs on the hatchery grounds similar in construction to a trout-hatching trough, but without gravel of any kind. About eight inches of water is flowed through them, and the apparatus is kept covered by boards. Smelts do not seem to mind their capture and yield their spawn freely. The eggs are so minute that it requires nearly 500,000 to fill a quart-measure.

Every morning, the hatchery men shovel the eggs from the troughs into buckets partly filled with water. The thick masses of eggs are 
then sieved through wire trays of very fine mesh, care being taken that the work is done in the gloom of the hatching-house. The screen is held in a tub of water close to the surface, and as the eggs are rubbed through they fall to the bottom. The sieving is repeated two or three times until the eggs are entirely free from each other and do not adhere. They are then transferred to hatching-jars.

At Cold Spring Harbor, New York, where the bulk of this work is done, the McDonald automatic jar and the old table system is used; but the eggs can be hatched in the open Downing improved, or in the Meehan jar, quite as effectually. It has been found that excessive light, or even as much light as is ordinarily admitted in a hatching-house for pike-perch, shad, and most fishes, is fatal to smelt eggs; therefore after the jars have been put in place, and the water turned on, a black curtain should be hung on each side of the battery, so that the eggs will be in complete darkness. Although the eggs are very adhesive, and frequently "ball" in the same manner as pike-perch eggs, they are very easily handled. It is only necessary to 


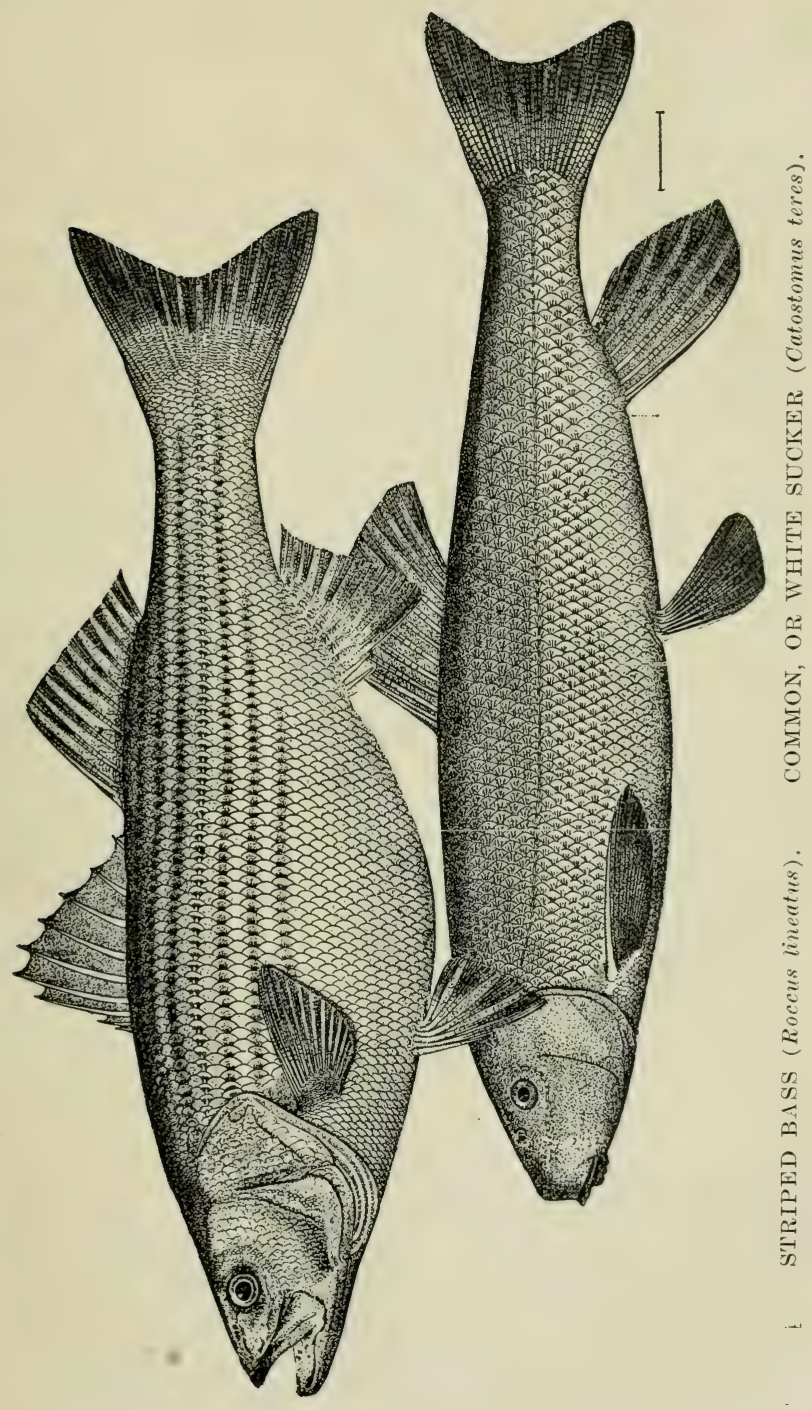





\section{WHITE PERCH, SMELTS, ETC. 215}

remove the jar, rub the eggs again through a tray, and return it to the battery. The period of incubation is from fifteen to twenty days according to the temperature of the water.

Although living the greater part of the year in salt water, smelts can be easily transported to fresh water, where they will live and multiply. They are so numerous, for example, in Lake Champlain that their catching is a local industry. They appear to grow more rapidly and to a greater size there than in salt water. The same may be said of the white perch. Along the coast of Massachusetts are many ponds which years ago were connected with the ocean by open channels, and were favourite resorts for white perch. Communication with the sea has since been cut off, so that the white perch have become land-locked; but they have accommodated themselves to their new environments, assumed a darker hue and acquired a greater size and weight.

Suckers.-A dissertation on the propagation of the sucker may cause a shock to some, surprise to others, derision from more, and protests from a few. One division of mankind re- 
gards, or affects to regard, the sucker as a worthless fish to be pursued and destroyed as relentlessly as a potato bug. Those who seriiously take this view, do so on the ground that it is destructive as a spawn-eater, and that it is equally responsible with the "hog" fishermen and water-pollution for the depopulation of trout-streams. A second division of human kind considers the sucker as valueless for food purposes-a fish with soft watery flesh and numerous thorn-like bones. A third division, nearly as large as the other two combined, does not care how much trout-spawn a sucker may eat, or of what sins it may be accused; and pities the man, and considers him lacking in taste, who belittles the food-qualities of the sucker. The great majority of those who relish the flesh of a well-cooked sucker or mullet, boldly and without shame avow their preference for it over any species of fish which swims in fresh water. Few of them hesitate to affirm that in the spring, while the water is yet cold, the flesh of the sucker is firm and as palatable as that of the brook-trout.

Experiments in propagating the sucker were 


\section{WHITE PERCH, SMELTS, ETC. 217}

conducted in 1907 at Wayne, Pa., by Nathan Buller, who reported that at his station the suckers began to ripen about June 1, and by the 12th most of them were ready for spawning. It was found to be remarkably easy to take the eggs and milt, handled exactly as with brook-trout. The eggs passed from the female separately and as freely as those of the char, while the milt was extracted with ease. The fish were handled with great care, given a salt bath immediately after the stripping, and of the two or three dozen used none died. Each female, which was the size of the ordinary adult, yielded approximately 5,000 eggs. When first expressed, they were about the size of the spawn of lake-herring and of a whitish flesh-colour. They were treated the same as trout-eggs, and there was no adhesion during the period of resting and washing.

After fertilising and washing, the eggs were set aside for a quarter of an hour. Impregnation and water-hardening left the eggs round and increased the size about one half. In three days they changed to an oval form and showed a distinctly light spot, similar in shape to the 
circle of a "ringer" trout-egg. For a while it was thought by Mr. Buller that the eggs were all ringers, but after close watching it was seen that the ring kept changing and growing larger until the tenth day, when the outline of the embryonic fish became visible without a distinct sign of the head or eyes. On the 15 th day the young fish began to break from the shell and by the twentieth they were all out. When they first emerged, the fry were white and possessed a very heavy yolk-sac, which was entirely absorbed in five days.

Subsequently sucker propagation was tried by other fish-culturists with equal success, using jars instead of troughs. No trouble whatever was met with during the process of incubation. The eggs remained free, and during the entire period there was no indication of fungus. 


\section{CHAPTER XVII \\ FROG CULTURE}

A FEw years ago the Commonwealth of Pennsylvania, through its Department of Fisheries, began a series of experiments in frog-culture. The work was regarded as of tremendous importance, and it was watched with deep interest by fish-culturists all over the world. The effort to confine frogs and rear them to a marketable size was novel, and if successful would form a foundation of a great industry in which farmers would be the chief participants.

Frogs' legs have a very important place in the market of this country. Years ago the French were called a nation of frog-eaters, but France is no longer pre-eminent in this respect. The United States is now the chief consumer of this delicious food. For several years the demand has far exceeded the supply, and their 
cost is so high that frogs' legs are only within reach of the well-to-do.

Experiments and Problems.-At the time that Pennsylvania began experimenting there were no establishments in the eastern United States where frogs were reared. The entire supply was derived from wild frogs, the great bulk coming from the West and from Canada. Pennsylvania soon ascertained that frog-culture presents about as many difficult problems as did the earlier work with black bass, and also some which are not encountered in any branch of fish culture proper. The results were just sufficiently encouraging to warrant a strong hope of success at some future time. One disheartening feature is the frequency of the complete loss of young tadpoles. Often twentyfour hours will include the beginning and end of events which lead to complete disaster. On one occasion, while on a visit to one of the state hatcheries, I was shown a pond containing thousands of apparently healthy tadpoles. By the next morning every tadpole had disappeared. They had died, gases had generated, their bodies had burst, and the skins had sunk to the 
bottom of the pond and been buried in the mud.

Three Edible Frogs.-Three species were used in the experiments in Pennsylvania,-the leopard, the green, and the common bullfrog. The first is too small to be of much use for the food-market, but is much sought after by sportsmen as bait for certain game-fishes. The green frog has the reputation of being the most delicately flavoured; while the bullfrog is most hunted on account of its huge size, and the fact that there is meat to be found on portions of its back, and on the shoulders of the forelegs, as well as on the full length of the hind legs.

Partly because of the short time elapsing between the hatching of the tadpole and its development into a frog, and partly because it spawns early in April, the initial experiments were with the leopard frog, but it soon became manifest that it is not worth while to undertake the propagation of this small species except for the purpose of supplying anglers with bait. It was found that there is apparently less likelihood of complete failure in attempts to propagate the green, and the bullfrog, but the diffculties accompanying the work are legion, and 
no man, until these difficulties are removed, can expect to engage in frog-farming with any. marked degree of success.

In some respects the growing and mature leopard frog is easier to handle than the green or the bullfrog, because it is more gregarious in its habits. The green frog and the bullfrog are both solitary in their ways of living, and even during spawning time do not naturally come together in great numbers. Not so the leopard frog. Early in the spring, just before spawning, they gather by thousands in swampy places, where there are still pools of clear fresh water, and set up shrill peepings, incessant day and night, until the united volume of sound is almost deafening. It is at this time, and even a little later, that the marked difference between the habits of the leopard and the bullfrog are most pronounced. Amid the multitude of shrill cries, there will only occasionally, and at varied intervals, resound through the night, and sometimes in the daytime, the heavy booming notes of the bullfrog.

Whatever frog-farming is done in the United States is rudimentary. It is said that little or 
no attempt is made to separate tadpoles, young frogs, and frogs of mature market size. One man in Michigan, who had been carrying on the industry for 25 years, finally abandoned it as unprofitable "because the big frogs ate the little frogs, the little frogs ate the pollywogs, the large pollywogs ate the small pollywogs, and birds ate both." Frog culture is, therefore, a decided risk.

Site.-It seems probable that a profitable frog-farm requires three acres or more of land. About two acres ought to be occupied by a single pond; and a similar area by half a dozen or more smaller bodies of water for tadpoles and immature frogs. Any swampy or low-lying tract through which a stream of water flows will answer the purpose. The stream need be only sufficient to keep the ponds from becoming stagnant and foul. Water enough to fill a fourinch pipe will furnish an ample supply for a plant of three acres, and perhaps for one of six acres. It is unimportant whether the supply is secured directly from a spring or from a brook, and repeated roiliness is not harmful to either tadpoles or frogs. 
Three sizes of ponds are necessary; one, the smallest, for hatching eggs and carrying the tadpoles 'to frog' development; a second, much larger, to hold young frogs until they are over two years old; the third and the largest, for three-year-olds and over. All ponds should be excavated and have a generous strip of grasscovered ground around them. It is also desirable that there be a low embankment all around, so that occasionally the water may be raised and the entire area flooded to a depth of an inch or two for a few hours, in order to keep the soil wet,- - a condition dear to the heart of a frog.

Each of the small ponds must be surrounded by a fence so constructed that young frogs cannot escape, and it would be well similarly to enclose the large pond intended for mature frogs. The creatures are nomadic in their habits, and have been known to leave suddenly an apparently very desirable body of water for no ascertainable reason, and take up their quarters in what, to the human mind, seemed an inferior location.

The fence need not be more than $2 \frac{1}{2}$ feet high, but on the top there should be a board or 


\section{FROG CULTURE}

a strip of muslin at least six inches wide, projecting horizontally inward, so that frogs which succeed in climbing to the top cannot go any further. A frog can climb almost anything vertical, short of a smoothly planed board, and in trying to escape will display astonishing perseverance. Specimens have been seen clambering laboriously to a horizontal board and dropping invariably to the ground after reaching the top, only to repeat the effort again and again for hours at a time.

Ponds designed to hold frogs or tadpoles through the winter season must have soft muddy bottoms into which they can burrow and hibernate. It is also desirable that the banks of all ponds for fully developed frogs have sloping sides, so that the creatures can easily be screened to prevent their escape.

The average depth of the smaller ponds may be only a foot and a half or two feet; or a little more than the thickness of the heaviest ice likely to form in winter. A kettle is not as necessary as in a pond built for propagating warm-water fishes, yet it would probably be beneficial. A large pond for the adults may be 
built across a stream of water, provided the latter is of moderate size, and is not subjected to any floods; but if the pond is so constructed the upper end must be carefully screened to prevent escape of the captives.

As frogs subsist entirely upon living creatures, and will devour nothing dead, all ponds excepting those designed exclusively for tadpoles, must contain an abundance of watergrasses and flowering aquatic plants. Pondlilies are particularly effective. It is also desirable that flowering plants which thrive in wet places be maintained on the strips of ground around the ponds, as flowers and grasses attract insects and other small forms of life upon which frogs feed.

Each pond for hatching eggs and caring for tadpoles of the leopard species, should be at least 60 feet long and 20 feet wide. There is no necessity for it to be surrounded by a patch of grassy ground, nor to contain lilies and other flowering plants, because tadpoles will readily feed on dead fish and liver. Almost any kind of bottom will answer for tadpoles of the leopard frog. As this species is of little 
value, excepting to sportsmen for use as bait for fishing, the hatching-pond should be surrounded by a fence, because there will be no need to transfer the young after their metamorphosis to other and larger ponds.

As frogs almost invariably, when in the water, keep near the shore, it would probably be economy to make the ponds very narrow, not more than 20 or 30 feet wide. They might be in the nature of ditches, winding and twisting over the property.

The entire period, from the time the eggs of the leopard frogs are fertilised until the frogs are ready to be sold to the sporting-goods men, is only between three and four months. Hence, if this species is propagated for that purpose, and success is achieved, the returns are quick, and the season soon over.

Ponds for hatching green frogs and bullfrogs should be almost, if not quite, as large as those intended for the holding of the yearling and two-year-olds, and they should be just as deep. Pennsylvania found that ponds 275 feet long and 60 feet wide developed thousands of the tadpoles of the common green frog under fa- 
vourable circumstances, and would hold them for a year. A pond sixty by twenty feet developed only 10,000 green frogs.

Ordinarily, tadpoles of the common bullfrogs hatched one season do not develop into frogs until late in the spring, or early in the summer, of the following year; therefore the bottom of the tadpole pond should in this case have soft mud, at least a foot or two deep, and also grasses as resting places for the tadpoles. Tadpoles develop into frogs more quickly, and with less danger of loss, when they have something on which they may occasionally rest.

Leopard frogs spawn in April and the eggs are fertilised as they issue from the female. They pass from her in a string-like mass that almost instantly combines into a ball, which in a short while is from three to four times the size of the frog. Each egg is surrounded by a nearly colourless, gelatinous material, in which each egg is plainly discernible, and is black in colour when perfectly fresh. There are about 3,500 to a liquid quart. As the eggs approach development there occur several marked changes in colour. Sometimes the 
egg-masses are allowed to float freely in the pool in which they are deposited; sometimes, they are submerged and fastened to stems of water-plants and branches of bushes. The leopard frog deposits its spawn in pools on which the sun plays. It is rare to find eggs in dark places where the sunlight does not penetrate.

If a person intends to attempt the propagation of the leopard frog, there is seldom any necessity for maintaining breeders on his establishment, unless he purposes to market them for food, because the chances are, that from the edges of nearby swamps he can secure all the eggs for rearing that he requires. Ten quarts of leopard frog eggs are all that should be put in a pond of 60 feet by 20 feet, since that area of water will not safely carry more than 40,000 tadpoles past the development stage. A lesser number would be a greater exhibition of prudence. Overcrowding, even during the first three or four days after hatching, is almost certain to result in the loss of the entire stock, the most exasperating feature of which is that it generally does 
not occur until within a few days of the time when the hind legs should appear.

As the metamorphosis seems to draw heavily upon the vitality of the tadpole, it is important that the normal growth and strength be fully: maintained both by plenty of water room and an abundance of food. Over-crowding will almost invariably result in stunted growth and consequently lowered vitality, even if they appear to be healthy and are active until the very last. As the majority of a single hatching usually develops legs almost simultaneously, it generally happens that when there has been over-crowding, thousands will die within a few hours. Each tadpole is then only a shape of thick skin filled with a soft mushy material, without bones. In an hour or so after death this mushy material decomposes, the skin bursts and sinks to the bottom. The water, thus polluted, will probably kill the rest, and it is not an uncommon occurrence for the entire stock in the pond to die and utterly disappear within twenty-four hours.

Enemies.-Tadpoles have myriads of enemies. The most destructive to the leopard and the 
green frog is the fully developed daphnia. These minute, crab-like creatures cling to each tadpole by hundreds and thousands, sometimes completely covering the body, and so sapping the strength of the victim as to cause its death. The tadpole of the bullfrog is also subjected to similar attacks, but apparently not to the same extent, nor with as frequent fatality, since it is hatched later in the season and from its size seems to be able to offer greater powers of resistance.

Another dreaded enemy of the tadpole, particularly of the leopard species, is the larva of the water-beetle. This hideous creature is from four to five inches long, hangs in the water with its tail at the surface, and, stealing upon a tadpole as it passes, drives its powerful mandibles into its body and sucks the contents into its stomach. A few thousand larvæ of the water beetle will destroy a small pond of tadpoles in a few days. When they appear, there is only one thing to do; have all the force on the place wade through the pond with scap nets and dip out the destructive creatures.

Feeding.-Tadpoles will devour almost any 
kind of meat, but the best is fresh dead fish. Forty thousand tadpoles will easily consume 25 pounds of fish weekly. If desired, the fish may be ground or cut into pieces, but a few may be thrown whole into a pond. In a few moments the carcass will be completely covered by hundreds of tadpoles, and before very long there will be nothing left but a skeleton.

Development.-When the period of metamorphosis approaches, the tadpoles take less and less food, until, just before the change takes place, they cease eating altogether. Then the hind legs push out, ridiculously small for the size of the body. A day or two afterwards in the case of the leopard frog, and a week or two in the cases of the green frog and bullfrog, the forelegs break suddenly through the skin. When this occurs, the half-frog receives sustenance by absorption from the contents of its tail, as the fry of a fish absorbs the contents of the yolk-sac, or a plant the contents of the seed-leaves. The process causes the tail to become smaller and smaller, until finally there is only a small point at the base 
of the backbone, which remains all through life.

The period required for the absorption of the tail depends on the species and the temperature of the water. The tail of the leopard frog disappears much more quickly than that of either the green or the bullfrog. The tadpole of the green frog is about as large again as that of the leopard frog. The tadpole of the bullfrog is conspicuous both for its length and girth, and specimens six inches and more long are not rare.

The rule to sori and grade frequently fish into sizes holds good in frog-culture. It is strictly a carnivorous creature. It will in no circumstances eat anything but living food after the time it is fully developed from the tadpole. It will not only eat live fish and insects, but shows a decided inclination to cannibalism. 


\section{CHAPTER XVIII}

\section{THE MANAGEMENT OF AN AQUARIUM}

As aquarium for fish or other aquatic life is within the reach of almost any one. Receptacles for holding and displaying live fishes have come to be considered almost a matter of course as a part of the house furnishing, and more or less suitable vessels may be bought anywhere from five cents to a hundred and fifty dollars each. They may be had in globes, in pendants, or on stands; or in cylindrical, octagonal, or oblong tanks, made of glass, glass and iron, glass and brass, or any combination that the mind fancies. In size they vary from a miniature globe, capable of containing only one small fish, to a receptacle suitable for holding many dozens.

There is something very attractive about an aquarium, well kept, and large enough to hold several fish, water plants and perhaps a tiny 
MANAGEMENT OF AQUARIUMS 235

fountain. One of the most pleasant and enduring memories of an especially handsome house, artistically furnished, is of a sittingroom bay-window containing a large ornamental aquarium of Japanese fringed-tail goldfish and aquatic plants; it was surrounded by plants in pots and hanging baskets, and had in the aquarium a graceful fountain, the falling waters of which were just sufficiently loud to be heard in the room.

An aquarium need not necessarily be devoted to fish alone to be interesting. There are numerous forms of aquatic animal life, readily found in rural streams, pools or ponds, which may be utilised and become a source of constant interest. Tadpoles, newts, freshwater shell-fish, water-bugs and beetles, reveal a marvellous story to the observant eye. Some of these forms of animal life are important adjuncts to an aquarium when fish are to be tenants. Tadpoles and fresh-water snails should always be included, since they are scavengers and assist materially in keeping the aquarium clean and the water pure.

Certain water plants are also important in 
the successful maintenance of an aquarium. Some are of little value except as ornaments, but others furnish oxygen in considerable quantities, and so render it unnecessary to change the water frequently.

Goldfish are not the only species which may be carried in an aquarium. Many other attractive fishes may be kept in still water where there is an abundance of oxygenating plants. Indeed, within the last few years many tropical fresh-water fishes have been introduced into the United States for this purpose; some are of remarkable beauty, and all afford constant interest. Some of these foreign fishes bring forth their young alive, others, after depositing eggs in the sandy bottom of the aquarium, immediately dig a hole in another part, and transfer the eggs in their mouths from the first to the second hole and do this twice a day until the eggs are hatched.

If running water can be had the possibilities of the aquarium are endless, for a majority of fishes can be transplanted from the wild state, and kept in confinement and healthy for an indefinite period. Even brook-trout 


\section{MANAGEMENT OF AQUARIUMS 237}

will do well under such circumstances, provided the water-temperature during July and August does not rise too high. I have seen this fish carried successfully through both these months without the aid of ice or a refrigerating apparatus, by simply increasing the aëration of the water. Many native fishes common to the brooks and waters in the neighbourhood of the home make desirable and even pretty denizens of an aquarium; and they are of comparatively easy culture. The yellow perch, the sun-fish, the cat-fish, and the stickleback will do well in a still-water aquarium. Nearly all forms of minnows are as well adapted to the aquarium as the goldfish, which, by the way, belongs to the minnow family.

Choosing or Building an Aquarium.-The best and most convenient form of aquarium is an oblong tank of glass and metal. An allglass aquarium is not as desirable or as safe. The globe shape is not as easily kept clean and an all-glass vessel is very apt to crack and break owing to the unequal expansion and contraction from varying temperatures of the room and the water. 
It does not require any great amount of ingenuity for a person to make his own aquarium. A two-inch board, planed and grooved, four upright angle-irons, clinching-bands, angle-iron top-frame, a double or treble thickness of glass according to the size of the vessel, and a cement which can also be homemade; these with a little expenditure of time and care in fitting will make a neat, serviceable aquarium, nearly as good as any which can be bought.

Two precautions are to be observed; one that the aquarium be water-tight, and the other that there be plenty of room for the glass to expand and contract under varying temperatures. The grooves in the bottom board must be wider by the fraction of an inch than the thickness of the glass, and the panes must be a trifle shorter than the length and width. The cement should also be of such a consistency that it will always be soft enough to permit the expansion and contraction of the glass. Cement for fastening the glass to the frame can be bought at almost any store selling globes and fish; but an almost equally good one can be made of common putty, red lead, litharge, and sometimes a very small quantity of plaster of Paris. Before putting in the glass, the grooves and the inside of the angle iron should be thickly set with the cement, the glass then embedded, and fast- 


\section{MANAGEMENT OF AQUARIUMS 239}

ened firmly by the top frame and clinching-bands. The cement should then be pressed in firmly and smoothed with the putty-knife, and when it is partly dried be painted with asphaltum paint. The bottom, if of wood, should be given a slight coating of liquid cement to prevent warping.

While a two-inch board may be used for the bottom of an aquarium, it is more desirable to have it of slate, marble or concrete. The last named is substantial, much easier to secure and cheaper. To make a concrete bottom, fashion a wooden frame of the desired dimensions, and fill it with concrete, made of three parts of sharp sand and one of cement. Onehalf sand and half cement would possibly make a harder base, but it would be more liable to crack in drying unless re-inforced, than when made with the proportions first given. Immediately after placing the concrete in the form, large wire nails should be pushed in at regular intervals around the edge of the base. After the concrete has hardened the nails are withdrawn, leaving holes for the bolts which are to fasten the framework to the bottom. If the bottom be of slate or marble, then bolt-holes must be drilled in its surface, but it is not necessary to make grooves, as the angle-iron frame can be set on the surface with a thin layer of cement to prevent leakage. The frame-work is bolted to the bottom.

If the aquarium is to contain running water, then an outflow will be necessary. This may be made by. 
drilling a hole in the base near one end, and putting in a drain-pipe, which ought to be a little larger than necessary to carry off the ordinary overflow, as it may be imperative to turn on for a while a much heavier stream from the supplying pipe.

Many persons on purchasing or making an aquarium are impatient to put it to use immediately, but this is a mistake. Wash the tank a number of times, and change the water frequently for a week or ten days before stocking it. After being washed and filled the first time, heavily impregnate the water with salt, and allow the solution to remain for two or three days to thoroughly purify the aquarium; replace this with fresh water, and change several times in the next two or three days. Not until then ought the water intended for the fish to be introduced.

In the meantime, a quantity of river, stream, or bird sand may be secured, sufficient to cover the bottom of the aquarium to a depth of two or three inches. If it is river or stream sand, first wash it thoroughly in hot salt water and repeat the washing until every particle of vegetable matter and clay is removed. Dirty 
MANAGEMENT OF AQUARIUMS 241 sand breeds disease. When the sand is finally ready, and the aquarium drained, put in the sand and cover it with an inch of well-washed gravel and small pebbles. After the sand and gravel have been placed, water-plants may be introduced. Do not plant many since they grow with such rapidity that the aquarium will be overstocked soon, and some of them will have to be removed.

Stocking an Aquarium.-The best water for an aquarium is from a river, stream or pond. Rain-water which has been exposed for some time to the air is also excellent, but the exposure must be of some length to render it safe. If water is taken from a hydrant, it should first flow with full force into a bucket, so that it may be thoroughly aerated. Under no circumstances ought pump-water to be used, as it is what is commonly called "dead," that is without aeration. There is a prejudice in some quarters against hard or limestone water, but if taken from a spring or stream I feel that there is little or no danger in using it.

If the aquarium is to contain goldfish, or other species that will live in still water, it is 


\section{FISH CULTURE}

unnecessary to change the water frequently, especially if the tank be well provided with suitable aquatic plants. Simply replace that which has been lost through evaporation from time to time. If care be exercised and the aquarium kept clean, a complete change of water is only necessary about once in six months. It would be well to introduce at first a few snails and tadpoles, and then, after two or three days, the fish.

A careful person will wash the inside of the glass of a show-aquarium daily, or at least thrice a week, to keep the surface free from green slime, a vegetable growth (confervæ) which covers the glass and develops very rapidly in a fairly bright light, as when the aquarium is set near a window. The growth of the useful plants in the tanks and of its animal life requires that the aquarium should get considerable sunlight, but too much sunlight, together with the heat of a room, may raise the temperature of the water so high as to injure the fish because of the rapid loss of oxygen. Hence sensible care must be taken in this respect. Any fish or animal that may die 


\section{MANAGEMENT OF AQUARIUMS 243}

should be removed at once, since the decomposition is likely to foul the water, and injure the remaining fishes.

Water-temperature is an important factor for a successful aquarium. The common goldfish, such as are bought anywhere for from five to ten cents each, are not very particular about it, but some of the choicer varieties, especially those of the scaleless type, must have a fairly. even water-temperature throughout the year, and are liable to bladder-troubles when the temperature falls below 60 degrees. Therefore it is best that water for the aquarium which is to contain goldfish be not less than 60 nor more than 70 degrees. For tropical fishes the temperature must be maintained between 70 and 80 degrees. The green slime that develops on the glass in bright sunlight is not harmful to fish, but is an indication that the water is perfectly pure. Most goldfish culturists keep several tanks with so much confervæ in the water that the fish are almost invisible, and put into them, as "hospitals" fish that are a little "under the weather." A good supply of snails, especially the Japanese 
and African species, will keep the glass of the aquarium fairly clear of slime.

Purity of water is naturally of first importance. Fortunately it is generally easy to detect impurity. A disagreeable odor usually manifests itself, and almost invariably the water becomes slightly cloudy. Fish and snails coming to the top of the water on clear sunshiny days give a strong indication of foul water. When it becomes necessary to change the water in an aquarium, it is better not to dip it out but to draw it out by means of a siphon (rubber tube); when the tank is half empty, remove the fish by means of a small net. The water should also be replaced in the same manner so as not to displace the sand and gravel at the bottom.

Some people like to place rockwork in an aquarium. Where it can be done this is desirable both for the fish and as resting places for the tadpoles, and it should project a little above the surface of the water.

Care of Goldfish.-Goldfish, after the manner of other carp, like to jump once in a while, so there must be either a considerable space 
between the surface of the water and the top of the aquarium, or the top of the aquarium must be covered with wire netting, otherwise the owner will likely find a dead fish on the floor some morning. Such precautions are also advisable if cats are household pets, since they love fish, and are expert fishermen.

One requisite for the successful care of fish in an aquarium is to avoid coddling them too much. Never handle them except when absolutely necessary, and then only with the wet hands or with a small net. Above all things never overfeed aquarium fish. It is safer to give them a fair allowance every other day, rather than to supply them with food daily; but under no circumstances should they be given more than they will eat in a few minutes. If there is any food left uneaten at the end of five minutes, the fish are, generally speaking, given too much. Probably the safest food is the manufactured fish-food purchased from a dealer; and the granulated foods are more desirable than the foods that come in sheet form. A couple of pinches will be enough for half a dozen every. day. Tiny fragments of bread 
may occasionally be given, and, if extreme care be exercised, a very small quantity of uncooked oatmeal; but the last named is dangerous, since any which is uneaten will ferment. A tablespoonful thrown into an aquarium two feet long would probably kill every fish in twelve hours.

One of the best foods for goldfish, and indeed for almost any small fish is a minute aquatic creature called daphnia. It is related to the crab family, and under certain conditions is found by the million in still or stagnant pools with mud bottoms, and where aquatic plants are abundant. The daphnia is of a reddish hue, and swims with a short jerky motion. It is most abundant during the summer and early autumn, but it may be gathered in quantities even during the winter. The larvæ of daphnia develop on subaquatic plants, and the growth of that useful plankton may be encouraged by spreading cow or sheep manure over the bottom of the pond. Greater success is likely to result from using small fish rather than large. A greater number can be carried safely. Aquatic Plants for an Aquarium.-Aquatic 
MANAGEMENT OF AQUARIUMS 247

plants are necessary as an equipment for an aquarium, as they are both beautifiers and oxygen producers. Without their help it would not always be safe to allow the water to remain in an aquarium for an indefinite period without changing it.

Of the plants which grow in sand or gravel three stand forth prominently as the most valuable. They are the anacharis or waterweed, the sagittarias, and the ludwigias. These three all give forth a great amount of oxygen, and are beautiful and of rapid growth. The anacharis in particular is such a vigorous grower that often in a few weeks, when the sunshine is bright and the water warm, it will have to be thinned out. The Anacharis canadensis is the best species, and has dark green, ovate leaves, with light stems.

The sagittaria resembles somewhat the well known vallisneria, or giant eel-grass, but it is considered as a better oxygenator and does not fill up an aquarium as rapidly as the eel-grass. Sagittaria napana is as indispensable for oxygenating purposes as the anacharis, to which it also forms a very strong contrast in 
appearance. It has long strap-like leaves, springing from a nearly common base, almost like the leaves of a bulb, and is especially desirable for a small aquarium. The Ludwigia Mulerttii is called a submerged plant, but while its greatest growth is beneath the surface, it does push its head above the water and sometimes for several inches. It is exceedingly valuable for its oxygen-giving qualities, and is one of the prettiest of the sub-aquatic plants. It has small ovate leaves, having the upper part green and the under-side a dark rose pink. It is unlike any other aquatic plant and grows in thick bunches.

Eel-grass (Vallisneria spiralis) ought by all means to be placed on the list of sub-aquatic plants for the aquarium. It has the male and female flowers on separate plants; the male flowers are borne on straight short stalks, while the female blossoms are on a long spiral stalk. Both open and mature their flowers on or above the surface.

A favourite aquatic plant with most aquarists, and one found in nearly every store dealing with goldfish and aquarium supplies, is the 
MANAGEMENT OF AQUARIUMS 249

Washington plant, or Cabomba viridifolia, whose stem and leaves are fern-like in their gracefulness. The fan-shaped leaves are a brilliant glossy green and are slashed clear to the stem into thread-like sections.

The pond-weeds (Potamogeton) and the hornwort (Ceratophyllum) are both favourites, especially Potamogeton densus, with brownishgreen leaves attached opposite each other on a reddish stalk, but on account of the eagerness with which mollusks and fish attack and devour the leaves and stems it soon loses much of its beauty. The hornwort is an attractive and effective plant, with narrow forked leaves set round the stem in whorls. It is one of the commonest of our native water-plants, and takes to an aquarium as to the manner born. It may be tied together in little bunches, weighted with a piece of stone or lead and sunk to the bottom, where it will flourish just as well as though it were regularly planted.

The duck-weeds are favourites among the floating plants. They have minute generally rounded leaves which rest flat upon the surface of the water, and small roots that hang 


\section{FISH CULTURE}

vertically therefrom, about an inch below the surface. The greater duck-weed (Lemna polyrhiza), the lesser duck-weed (Lemna minor) and the thick duck-weed, (Lemna gibba) are the most attractive, although they have very little value for oxygenating purposes.

The water-poppy (Limnocharis humboldti) is one of the handsomest of the surface waterplants for small aquaria, as it possesses small heart-shaped leaves, and yellow, poppy-like flowers about an inch in diameter. The watercrow-foot (Ranunculus aquatilis) is also an excellent plant as a contrast to the waterpoppy, having beautiful green leaves, and pretty white flowers with many yellow stamens strikingly like strawberry blossoms. Many aquatic plants live principally in only partially submerged or in wet spots. One of the favourites is the forget-menot, or Myosotis palustris; and a good foil to the forget-me-not is the umbrella grass (Cyperus alternifolius). As a finishing touch to the rock work there may be planted the Lycopodium coesium or creeping moss. 


\section{MANAGEMENT OF AQUARIUMS 251}

Among tender aquatics, that is those not hardy but very effective for an aquarium, are to be found the following: Aponogeton distachyus, or the Cape Cod pond-weed, a winter-flowering plant having pretty white blossoms; Limnanthemum indicum, or water snow-flake, whose leaves float like those of the waterlily and whose flowers are white; Myriophyllum proserpinacoides or parrot-feather, a graceful foliageplant; and Pistia stratiodes, or water-lettuce, a floating plant like the duck-weeds.

The following are not merely desirable for an aquarium kept in the house but have the additional advantage of being hardy: Alisma plantago, or waterplantain, with pale rose blossoms; Juncus variegatus, or variegated rush, a very striking plant which grows both in and out of the water; Limnanthemum lacunosum, or floating-heart, a white-flowered plant; Menzanthes trifoliata, a three-lobed, white-blossomed aquatic; and Scirpus variegatus or variegated Siberian rush. 


\section{CHAPTER XIX}

\section{CULTURE AND CARE OF GOLDFISH}

THE house aquarium and the goldfish are so closely linked in the minds of the great majority of persons, that it seems fitting that in dealing with aquarium life first attention be given this member of the minnow family. It originated with the Chinese in remote antiquity, and was introduced into Europe between the 17th and 18th centuries, and into this country early in the 19th century. It has been produced from the Crucian carp, an Asiatic fish of the family, after centuries of careful selection and breeding, and is therefore one of the minnows.

The original colour of the Crucian carp is olive-brown, and when the young are hatched, and for some weeks after, they possess this hue of their primal ancestors. The goldfish also affords a striking example in another way of 
the instability of varieties developed from natural forms, although bred and selected with the greatest care for centuries; for if goldfish are left to themselves, as in an open pond, they will degenerate more or less rapidly and gradually revert to the original form and colouration of the Crucian carp. Moreover, a large proportion of fish hatched never do change from their sombre dress and take on the brilliant colour so much desired.

Many of the grotesque forms which mark some of the popular types of goldfish are the outcome of centuries of laborious work by the patient, persevering and ingenious Japanese, in taking advantage of some curious freak of nature.

It is a well known fact that if fish-eggs be given a jarring at a certain stage, or, more specifically, about the "eyeing" period, monstrosities may be produced. This occurs frequently among brook-trout, the most common irregularities being hump-back and looped. It is said that when the Japanese discovered this peculiarity they selected a pair of the most pronounced monstrosities, similar in form, reared them and bred from them. The most marked of the progeny were again selected and bred, and this process continued until a desired type was produced and fairly fixed by hatching without the jarring. Thus 


\section{4}

\section{FISH CULTURE}

were produced the fringe-tails, the balloon shape, the telescope, and some other of the outlandish forms seen in aquariums.

Fanciers have one or all three points in view when breeding so called fancy goldfish: The development of rounded form; the development of the fins; and the development of colour and markings. In the endeavour to attain these features, they have crossed and recrossed until there are now but two distinct classes, those with elongated and those with rounded bodies; and it has become exceedingly. difficult to subdivide one of these classes into clearly defined types. Nearly every variety has one or more pronounced features of another. It is among the multiple-tailed forms, however, that the greatest amount of selective breeding has been done. Colour-effects have been specially sought for, with calicos, blues, Moors, bronzes, whites, reds-and-whites, and other combinations as results. There need be no surprise, if, within a few years, a pale green fish be added to the list.

Varieties.-The following is a nearly complete list of the different varieties of goldfishes 
known to Americans and to be purchased of all dealers carrying a varied stock.

Commons: There are two varieties of the common goldfish, the American and the European. Both have elongated bodies, but the European is more slender, with flatter sides and a very deep fork in the tail-fin. The American variety has a decided arch in the front dorsal line, while the European has a back but little arched. The colour varies from deep orange yellow to white and from black to light bronze. Commons of particular colours, crossed with Japanese, have ressulted in many peculiarly hued fishes.

Comet: This is considered by many as one of the most graceful of the goldfishes, although not a favourite among fanciers, who regard rounded, egg-shaped bodies as the perfection of beauty. It is of American origin, having been produced by Hugh Mullertt, of New York, in 1889. It has a long slender body and a single tail, somewhat longer than the body, which usually droops gracefully in fully matured specimens, but in the younger it is held straight from the body. The dorsal, ventral, pectoral and anal fins are all of great length, the dorsal being nearly two-thirds the length of the fish.

Nymph: A nymph is similar to a comet, excepting that its body is short and rounded more in conformity with the general idea of beauty in goldfishes. The color is a rich, dark, reddish gold. 
Fan-tail: Herman T. Wolf, in his admirable work on goldfish breeds, has given such a clear description of the fan-tail, that I feel I can do no better than to reproduce it. He says: "The fan-tail is a scaled, short-bodied fish, very thick, round-backed and deep bellied, of almost oval outline; its body being best described as of short pumpkin-seed form, with the horizontal longer diameter of slightly greater length than a true oval. . . . It has a short, broad head, distinctly hog-nosed, a large mouth with full lips, erect nostrils, and eyes like the ordinary goldfish but larger. The long and erect dorsal fin sits far back on the spine, all the other fins being paired; the pectorals and ventrals are long and pendant, the double anal fins are long and extend almost straight backward, while the broad double tail, which is the principal characteristic of the fish, is divided quite to the base, and the two distinct tails stand directly vertical on the same plane and are carried straight out behind the body without the least drop or droop; the upper and lower lobes being of exactly the same length so that a perpendicular line from the end of the upper will exactly touch the lower lobe on each side. ... The perfectly developed fan-tail (when viewed from the rear) has the appearance of having two separate single tails placed side by side. The tail of the fan-tail never exceeds the body in length." A fan-tailed goldfish of full blood is of a rich golden red, with rather large scales which shine like burnished metal. At one time the 
fan-tail was among the commonest of the fine breeds, but the variety has been crossed and recrossed to such ap extent that a pure fan-tail is now comparatively scarce.

Fringe-tail: A fringe-tail is one of the most gorgeous of aquarium fishes. It is perfection in beauty, grace and richness of colour. Mr. Wolf says of it: "The long lace-like tail and fins, the rich, burnished, metallic lustre, the marvellous brilliancy of colour, the finely modelled form and the perfection of graceful movement, are truly typified in this justly prized fish." A perfect fringe-tail has a short and almost truly oval body, with a short head. The caudal fin, which is double and at least two and one-half times longer than the body, droops in graceful diaphanous folds. The ventrals, pectorals, and double anal, are all very long and pendant. The dorsal, the crowning glory of a fringe-tail, is arched high in front and curves evenly downward towards the caudal. The scales are small and of a rich, red, shining, gold colour. From fringe-tails were developed ribbon-tails and veiltails.

Ribbon-tail: The chief difference between a ribbon-tail and a fringe-tail is that the caudals are each divided for nearly or quite the whole length into ribbon-like parts.

Veil-tail: A veil-tail is extremely difficult to distinguish from a fringe-tail. The caudal is more voluminous, and is decidedly more diaphanous and 
veil-like, so that when the fish is moving through the water the tails wave and swing:

Squaretail: A squaretail is almost identical with a fringe-tail, but the lower edges of the tails have no indentations.

Tripod: A tripod has a so-called third tail-fin: the two lower parts project like the sloping roof of a house and the upper is like a ridge above it.

Scaleless goldfishes are found in all varieties, but the most conspicuous of the scaleless sort are pinkish or white, and they are much more tender than the scaled fishes. They are more liable to disease, particularly bladder trouble, but are favourites among fish-fanciers. A scaleless goldfish possesses scales, but they are covered by a skin. Among them are the following:

Telescope: This variety is so-called because its eyes protrude far beyond the sides of its head. In some the eyes are shaped like spheres, in others are ovoid, or like truncated cones, or segmented spheres, or the eyes may protrude upwards. The telescope originated in China, but was developed to its highest point in Japan, and fanciers have produced them in nearly every variety, so that there will be found telescope fringe-tails, fan-tails, and so forth. 


\section{CARE OF GOLDFISH}

Celestial: If there were oculists among goldfishes, the celestials would probably be among the first and most profitable patients, for this variety is afflicted with defective eyesight. It is a telescope having spheroid eyes, but instead of their facing from the sides of the head as in other fishes, they are upturned towards heaven, whence the name "celestial," a name further appropriate from the fact that it originated among the Chinese. They are pretty eyes nevertheless, for the small, dark pupils are surrounded by large clear yellow irises. The celestial has another unusual characteristic, namely, that it is without a dorsal fin. This gives the back a queer barrel-like appearance. Added to these oddities are two morea disposition to swim near the surface with its popeyes out of the water, and an apparent stupidity. There is little or no activity about the fish, any one can take it in the hand without a struggle, and it may be guided anywhere in an aquarium by gently pressing a stick against its sides. The head is very short and with only the suspicion of a snout. The body is eggshaped, tapering towards the tail. The colour is a pale reddish gold. The pectorals, ventrals and anal are all pendant, but short. The caudal resembles that of a young fringe-tail. It is said that in China, the celestial is regarded as a sacred fish and kept in many of the oriental temples. It is a very difficult fish to keep, and is therefore not found frequently among either breeders or in private aquaria. 
Lion-Head: The lion-head or hooded goldfish is as yet an exceedingly rare fish in the United States, although well-known among the Japanese. Its origin is disputed, some crediting it to Japan and some to Korea. Whichever its native place, the lion-head is certainly a very grotesque fish. It is nearly globular in form, red in colour and without a dorsal. It has a long double caudal, very similar to a fringe-tail, but with rather short pendant pectorals, ventrals and anal. When the fish is two years old, the short head becomes covered by a hood-like excrescence of crimson, due to the growth of hundreds, perhaps thousands, of small rounded tubercles, evenly covering the whole head and throat. As age increases the tubercles develop until they become long and hair-like, slightly resembling, excepting in their crimson colour, the mane of a lion. Viewed from the front, the face of the fish, when the hood is full grown, is not unlike that of the king of beasts. In younger specimens, while the tubercles are yet short, the growth has the appearance of an old woman's hood, or the be-whiskered face of the conventional hobo of the cartoonists.

Calico: Many consider the calico goldfish among the most beautiful of all the different types, excepting perhaps, the veil-tails. It is a square-tailed telescope; usually scaleless, with the head, body, tail and fins thickly mottled with blue, brown, yellow, and red and black. Like most of the choice types, the body of the calico is short and thick; the pectorals, ventrals and 
anals long and pendant. The dorsal is high and starts on the top of the arch of the body, which is midway of the head and tail. The tail, which extends from the vent to the caudal fin, is merely a stump.

Blue Telescope: Much attention has been given in recent years to the development of this beautiful fish. The back and upper sides are a velvety ultramarine blue, shading into a metallic reddish blue on the lower sides. The abdomen is white or greyish white. The double caudal and dorsal fins are dark bluish brown or black, and the other fins dusky grey or brown. It has a short, plump body. It usually requires a strong light to distinguish the blue from the black telescope.

Black Telescope: Less than ten years ago the black telescope, or moor, was a rare fish in this country. It was an importation from China, and came immediately into deserved popularity, on account of its brilliant black colour, beautiful form and graceful movements. But many persons have been disappointed in their specimens because after a time they lost their intense black colour and took on a reddish hue. This change is usually due to the infusion of another strain by accidental or intentional crossing. The whole body of a pure and mature black telescope, and the head, fins and eyes are a deep blue black of an even shade, as rich as the finest black velvet.

\section{Pleasure and Profit.-Goldfish can be made} the source of considerable profit and much in- 
terest. The business may be conducted successfully with fair profit in the house in which one dwells, or on a much larger scale in a greenhouse, and in open-air ponds. Between 5,000 and 10,000 salable goldfish may be reared in one room of a dwelling-house if the light and heat conditions are suitable. There are two thousand or more persons, in the city of Philadelphia alone, who raise goldfish for profit in their homes during their leisure hours. One of them informed me that he annually cleared from $\$ 200$ to $\$ 300$ from the stock he raises in his sitting-room. Another said that his net receipts were between $\$ 300$ and $\$ 500$ each year. Several men now devote their entire time to the work as a successful commercial enterprise. One devotes his sitting-room, cellar, roof and back yard, to it, and it is said that his yearly profits exceed $\$ 3,000$.

Aside from a desire to make money, the owners of aquaria will find their pleasure greatly increased if they rear young from their goldfish. By exercising ordinary care and by the observation of a few simple rules, a person may increase his stock by the use of two aquaria 
and one or two small vessels as for example, a small wash-tub.

Spawning Habits.-Goldfish begin spawning usually early in the spring. If there be maintained from the beginning of cold weather a water-temperature of 70 or 75 degrees, goldfish will begin to spawn early in February and sometimes the latter part of January. If the water-temperature be held at 60 degrees or thereabouts, throughout the winter, no eggs will be deposited before April or May, or, until a suitable warmth is imparted to the water. Where an aquarium is not exposed to the sunlight for several hours every day, I have known goldfish to go throughout the season without spawning. Peculiarities in the fish themselves also cause great variations in the time, especially when there is a considerable number of fish. In such cases some females will begin to spawn in February or before, while others will be far later, even on into August. Early spawning is greatly to be desired for several reasons. The early hatch will all develop their colour by early summer; the stock by autumn will grow almost if not quite equal in size to 
yearlings hatched in June or July; all the weak will have been weeded out by sorting or death; and the perfect specimens can be determined and separated from the others, to be kept for breeding purposes or big prices while the others go to market.

The approach of spawning-time is heralded by males chasing the females about the aquarium. It is then advisable to remove from the tank those which show signs of breeding, and place them in a receptacle by themselves. A breeding-tank should be arranged the same as a regular aquarium except that there must be many more plants, so many more that the fish will almost have to push themselves between the stalks. Breeders do not all follow the same practice with respect to the proportion of males and females which they place in the breedingtank, but the majority introduce more males than females. This is done for a variety of reasons, two of which are to ascertain which is the best "chaser" or "driver," and to incite the males to rivalry and a little quicker action. Some breeders place the breeding fish in the tank in the proportion of one female to two 


\section{CARE OF GOLDFISH}

males, others two females to three males, and others again in the proportion of three females to five males. I feel that one female to two males is the most satisfactory practice.

Fanciers select the breeders with great care, and with a well defined object in view. It is the male which is most likely to stamp its characteristics on the young, hence particular attention is given to his selection. It sometimes happens that when a choice female is ready for spawning, the desired male either is not quite ready, or if ready, is a sluggish driver. In that case it is advantageous to place the two in a tank and with them an inferior grade of male but one that is an active "chaser." The ardent driving of the inferior fish often excites the more desirable male to quicker action. When this is done, however, a very sharp watch must be kept on the three fish, and the undesirable male removed before actual spawning takes place; otherwise the hatch of young may be disappointing. About spawning time, males may easily be distinguished both by the "chasing" and by a number of whitish spots which appear on the gill-covers, but at other times 
of the year sex-distinction is sometimes diffcult. As is the case with many other species of fish, the favourite hours for spawning are those of darkness, usually those which just precede dawn. With the advancing season, however, daylight spawning becomes more frequent. Only a few eggs are deposited at one time, and it sometimes requires several weeks for the female to discharge them all.

Treatment of Eggs.-Goldfishes' eggs are very small, very light and very adhesive. They are so light that if free in the water, it requires nearly half an hour before they will sink many inches, and they will not hatch if they get very many inches below the surface. With grasses planted thickly in the breeding-tank, however, the eggs cannot fall very far without touching roots, leaves or stems, and the slightest touch is sufficient to fasten them firmly. These eggs are plainly visible, because they are pearly white.

When spawning begins the fancier should at least once a day remove from the tank all plants that may have eggs attached to them, because if the eggs are allowed to remain the 
mature fish will soon begin to eat them. These egg-bearing plants should be placed in pans filled with water of precisely the same temperature as that of the tank from which they are taken. Set the pan containing the eggs in a window where sunlight can fall upon it and leave it there until after the eggs hatch.

Eggs of the common goldfish may be as easily pressed from the female as from the trout, but are troublesome to hatch. This cannot be done by the jar method on account of their excessive buoyancy. The only known success was achieved by J. R. Berkhous, who placed the eggs on a wet flannel tray and submerged them in only four inches of water, admitted in only a slight dribble. Nearly every egg hatched.

Arrangements for Commercial Propagation. -A person who desires to go into the cultivation of goldfish on a large scale should have commodious quarters, perfectly adapted to the needs of the fish, such as glass houses and outside ponds. A glass house is only another name for a greenhouse such as a florist uses for forcing plants, and it should be heated with hot water, well ventilated and furnished with concrete tanks. A house 20 feet wide permits 
the construction of three rows of concrete tanks and two walks; two and a half feet will be a sufficient depth for the tanks, with three feet inside measurement for the width, and four inches will be a sufficient thickness for the concrete walls. Each tank, which will extend the length of the house, can be divided into sections of varying lengths, from six to twelve or more feet. Both for adornment and utility it would be advisable to have soil on each side of the tanks in which to grow plants that like moist places. An ample discharge-pipe should be set in each section, so that water can be drawn off quickly if desired, and so that constant running water can be had in any one section at a time. A one-inch inflow pipe will furnish plenty of water.

Outside ponds are important, even where a glass house is used. The commons will live well outside throughout the year, and so will some of the choice Japanese and Chinese types, notably those with scales. Ponds are useful also to hold some of the fish hatched inside very early in the season, transferring them about May, or when the water-tempera- 
ture is suitable, that is to say between 65 and 70 degrees. Large ponds are not needed. Eight or ten, thirty or forty feet long each, and about half that wide, will be found much more convenient and serve the purpose of the plant better than two with the same area in the aggregate. A pond or two 100 by 50 feet, would be suitable for commons, and would hold enough young fish to supply a large town.

No pond ought to be built in any shaded spot nor exceed a water-depth of 18 inches. Important features in goldfish culture for profit are rapidity of growth and transition of the greatest number of the young from olive to gold in the shortest space of time. Therefore the ponds ought to be in the open where the light is strong, and be shallow so that the temperature from the surface to the bottom can be raised quickly and be fairly even throughout.

To secure otherwise a proper temperature, the flow of a spring should not be used, or at least not until the temperature has been raised. Water from a creek, or some source from which coldness has departed, is best; and a contin- 
uous inflow and outflow for either brood-fish ponds or fry-ponds is not imperative if they contain plants.

Feeding.-The feeding of adult fish is not as difficult as might be imagined. Of course the very best food is daphnia, which can generally be secured in still-water ponds in which there are no fish. I believe there would be comparatively little difficulty in raising daphnia, by coating the bottom of the pond with soil bountifully mixed with cow or sheep manure. Dry crumbled bread makes an excellent fish-food, and it is not a difficult matter to secure recipes for prepared foods. The following is said to be excellent: One handful of earth worms; half a pound of salt cod-fish boiled; one ounce fresh ant-eggs; one ounce of fibre meat; two eggs uncooked, including the shells; one pound of corn meal, very fine; a quarter of a pound of rice flour, very fine; one package of gem of wheat; a quarter of a pound of yellow pea flour; quarter-ounce of table salt; quarter-ounce of epsom salts; one cup of ox blood and one pint of daphnia. Chop the worms very fine; crush the shells of the eggs to powder; mix the various 
ingredients and dry them in an oven, stirring constantly so that the mixture will not burn until it is granulated. The smell during the process of baking is unpleasant. When thoroughly dry it can be broken up into fine particles.

Care of Sick Goldfish.-A few years ago, the only remedy known to the average goldfish breeder in America was salt. To-day, every up-to-date fancier possesses an outfit of drugs, important among which are crushed rock-salt, epsom salts, castor oil, permanganate of potassium, peroxide of hydrogen, boracic acid, carbolic acid, salicylic acid, coal oil, turpentine, copperas, and balsams. Some of these drugs are merely used as antiseptics and fungicides, and some, notably carbolic acid, are extremely dangerous to use. Probably the most effective and best fungicide is permanganate of potassium. A small quantity of a strong solution of its crystals may be poured into the tank containing the fish; but the amount should only be sufficient to colour the water a pale cerise. If the tank is still-water, it should be siphoned off after fifteen minutes. If fungus or bacteria 
infest the tank, remove the fish and put in a strong solution of permanganate of potassium and leave it there for a day. The water may then be drawn off and the tank washed out and the fish given a bath in the washings. Fish will stand permanganate of potassium much better than is generally supposed. I had a very convincing proof of this recently. More than a handful of crystals of permanganate of potassium got scattered by accident in a tank containing 120 gallons of running water and twenty-four long-eared sun-fish. This happened in the evening. The next morning, although there had been a constant flow all night, the water in the tank was bright red-purple. Three fish were dead, and the remainder showed very slight signs of life. All with any life in them were placed in fresh running water into which much air was forced. Twenty-four hours later all except four had recovered, apparently none the worse for the terrible experience.

Signs of Illness.-In the majority of cases where the water-temperature is right and the water itself pure, if fish die suddenly it is the 
fault of the person supposed to care for the aquarium. It is not uncommon to receive a plaint something like this: "I cannot understand it. I have no luck with goldfish. I give them the best of care and feed them every day, yet they die." In this speech is to be found the crux of the whole trouble. Goldfish are liable to become diseased if too solicitously cared for. Persons inclined to neglect goldfish, and leave them to themselves, are more likely to achieve success in preserving them alive than he who coddles and pets them. Over-feeding, frequent handling, and even much changing of water, are very apt to produce disease and death.

A perfectly healthy goldfish always holds its dorsal fins extended, and all the other fins are flexible, work freely and possess a clean, translucent appearance, plainly showing their structure. The gill-covers are closely shut concealing the gills, and the body has a bright polished appearance, with the colours clear and distinct. People sometimes think that when goldfish seek the surface, remaining in a slightly inclined position and working their mouths partly in 
and partly out of the water, they are sick, and that the water needs changing; but this is not necessarily the case. Healthy fish often come to the surface on a cloudy, dull day, and are simply seeking minute food, vegetable or animal, which may be on the surface. Neither is a sluggish movement a positive or certain sign that they are ill, nor is activity always a sign of health. When the dorsal fin droops, and other fins become opaque, or seem to be coated or inflamed, or closed, or held close to the body, or when the colour of the sides fades, and the gill-covers expand above swollen gills, then the fish is sick and needs treatment. If the disease is an incurable one, kill the fish at once.

At the first signs of distress they should promptly be given a salt bath. Under no circumstances use table salt, as the process used in its preparation for the market is unhealthy for fish life. The best is crushed rock-salt, which can be obtained from any grocery store, and is the same as that used when making icecream.

The Hospital Tank.-Sometimes other methods are necessary. In that case the sick fish 
should be removed to a "hospital tank" for isolation and special care. It should be of such a form as to have a glass surface in all directions, so as to admit all the light possible. To prepare a hospital tank, first sterilise it by the use of salt water and then by permanganate of potassium. Put two inches of sand, or a little more, in the bottom and plant anacharis and one or two other aquatic grasses. Fill the tank with perfectly clean unfiltered water, and set it in a bright warm sunny spot. If at the end of a few days the water remains clear and sweet smelling, no further attention need be paid to it. Green algæ will presently begin to form on the glass and in the water, but do not disturb it, for the growth is a certification of water-purity, and its presence makes the hospital tank ready for service. The temperature of the water ought never to be below 70 degrees nor above 80 degrees. Fish placed in a hospital tank should be deprived of food, if possible for the entire period of confinement. Famine for a month is not too much in some cases. The sunlight must play on the tank for as much of the day as possible, and the green 
algæ be allowed to accumulate without hindrance.

Diseases and Remedies.-For ordinary indispositions the salt bath may first be tried. One way is to make a solution so strong that it is bitter to the taste, and leave the fish in it until it turns on its side. Then transfer it quickly to a pan or bucket containing fresh water. The fish will soon revive and perhaps exhibit some signs of animation, on the disappearance of which replace it in the salt water. Repeat the operation a number of times, after which it may be placed in the hospital tank for a day or so, or returned to the aquarium. This treatment is but for fungus. The temperature of the salt water must not be lower than the fresh to which it has been accustomed. Another course is to make a salt-solution so mild as to be scarcely detected by the taste, and put the fish in it for several days. The vessel containing the mild salt-solution should be set in a well ventilated, light and warm place, and the patient should be given no food, and, after feeding is resumed, but very small quantities. Salt is generally efficacious with asphyxia and the itch. Asphyxia 


\section{CARE OF GOLDFISH}

is due to inflamed gills, caused by poisonous gases or sudden changes of temperature in the water. Itch is common during the winter months, seldom in summer, and is supposed to be the result of microscopic parasites; a whitish substance, first noticed on the back near the head, rapidly coats the fish until the affected parts lose their brilliant colour and become dark or black. An infected fish will rub itself against the pebbles or sand on the bottom, or any object which may be in the water. Over-feeding is almost always the cause of this trouble, although occasionally it appears when the water is unduly cold.

Fungus is another common affliction, generally caused by the fish becoming bruised or handled roughly or with dry hands. It is a parasitic vegetable growth resembling a cobwebby mildew. When a fish is attacked care must be exercised not to remove it by rubbing, either out of the water or in fresh water, as this procedure will take along with it the scales and skin, leaving the flesh exposed. Generally fungus is easily removable by placing the fish in a strong solution of salt water and then carefully. 
sponging the body while submerged. If the case be severe, it would not be amiss to give the fish a wash-off with dioxogen, or even a short bath in a very mild solution of permanganate of potassium, after the salt bath and. sponging.

Among the fatal diseases are tuberculosis, dropsy, bladder disease and erysipelas. The fancier may well lose heart if the last named appears, for it is reasonably sure that not one but all the fish in the aquarium will be seized with it about the same time. After stating that it is indicated by what appears to be a nervous restlessness of the fish, Mr. Mullertt graphically describes diseased fish thus:

"They are seen swimming with very quick motions, darting hither and thither with great rapidity, and with no other apparent reason than a desire to flee from their torment, for it seems as though they must suffer from muscular pains. After this extreme activity, which covers a period of several days, the fishes (for they are all affected at the same time) huddle together at the bottom of the tank, now and then rising and resuming their mad capers. The external appearance in this case is characterised by a closed dorsal fin, bloody streaks on all the fins, which, instead 


\section{CARE OF GOLDFISH}

of being nicely rounded upon their extremities as in health, become agglutinated and appear like the spikes on a cat-fish. The tissues upon the spines decay, the latter looking like disarranged bristles of a brush. This is the beginning of the end. The appetite continues in good condition, the fish nevertheless becomes weaker and weaker, each succeeding day, until death takes place."

Bladder disease is most common among the scaleless goldfishes and is almost invariably caused by the water being too cold. When a fish contracts bladder trouble it is unable to maintain a normal position in the water, and almost without exception falls into a vertical position with the head downward. In this manner it moves sluggishly and awkwardly about, often resting on the bottom. Sometimes a fish will live nearly two years with the complaint before dying. It is doubtful whether it is curable.

No cure for tuberculosis is yet known. It should, however, be a preventable disease, for it is usually caused by mismanagement in an aquarium, especially as to impure water. When the disease is contracted, again using the 
words of Mr. Mullertt: "They [the fish] are seen swimming about in a careless, purposeless way, now and then stopping to make a vain attempt to remove something from their gills that annoys them. They are apparently coughing. Their appetite decreases. It is evident that the gills are out of order, they failing to take up oxygen for the blood." The fish loses flesh, the abdomen sinks, the head seems proportionately large, and in shape the fish becomes what fishculturists term a "spike tail." The gills show signs of decay, the fish becomes so weak it cannot properly balance itself and finally swims head downward and dies.

Dropsy is not a preventable disease and is liable to appear in the best conducted aquariums and ponds. It is characterised by a swelling of the body, which begins either near the tail or the middle and progresses toward the head. Its first appearance is signalised by a few scales included in a circle, which lose their firm attachment. Later when it becomes general the body swells until it is almost spherical, the scales become erect and the eyes protrude. Death will follow in at least four months. 


\section{CARE OF GOLDFISH}

Goldfish are also liable to tumour of the intestine, to several gill-troubles and other ailments, one of the worst of which is the infectious tail-disease. When a fish is infected by tail-disease or tail-rot, it must be taken from the tank at once and put by itself, and it should not be put in the regular hospital tank, but in a separate vessel, so that its disease germs will not infect other fish. First, however, dip the diseased tail in coal oil or turpentine, and then in phenol sodique. This should be done at least once daily. This treatment ought in a few days destroy the germs which rotted the tail. Then with a pair of scissors cut away the parts which were affected, being careful not to cut into the healthy parts, as this would injure the fish and perhaps cause an attack of fungus or a renewal of the tail-rot. Later, when the fish recovers, the tail will again grow.

If the goldfish be wounded, it should be given a light salt bath and the wound touched with some lotion like Turlington's Balsam, a substance something like artificial skin. A solution of five drops of carbolic acid in a gallon of water is often efficacious for wounds in fishes, 
but it is very dangerous to use this remedy. Under no circumstances should the fish be left alone a minute when in a solution of carbolic acid and water. The instant it begins to turn over, the fish must be removed and put into fresh water or death will follow immediately. The narrative of diseases may seem very discouraging; but no matter in what live-stock business a man is engaged the spectre of disease must be reckoned with. A goldfish-culturist is confronted with less trouble than the man who rears poultry, and has a happy time compared with the raiser of bees. Skill, which comes with time, love for the calling, perseverance and good stock, will yield gratifying returns both in enjoyment and money. 
INDEX 



\section{INDEX}

Aëration of water, 107

Animals, injurious, in ponds, 13,100

Aquarium, construction and management of, 234-244; stocking an, 241

Artificial nests, 35-43

Automatic feeders, 161, 189

Barrenness in fish, 35

Bass, black, culture of, 3-48

Bass, calico, culture of, 50,57

Bass, grass or calico, 50, 57

Bass, rock, eulture of, 51,57

Bass, striped, culture of, 207 , 210

Batteries of hatching-jars, 181

Bluegill (see Sunfish)

Bullhead, culture of, 60

Calico-bass, 50, 57

Cannibalism, 41, 50, 57, 202, 205

Care of ponds, 17

Carp, culture of, 70-84; kinds of, 79 ; value of, 73

Cat-fish, culture of, 59-69

Cat-fish, spotted, 59

Cat-fish, white, 61
Cat-fish, yellow, 61

Chara moss, 46

Cleaning ponds, 168

Cribs for black bass, 43

Dams, construction of, 9

Daphnia, 84, 231, 246; rearing of, 270

Deformities in fish, 253

Diseases of goldfish, 271, 276; of trout, 153, 155, 198

Domestication of pond fish, 33, 165

Eggs of fish, characteristics of, 109; hatching in jars, 185; of perch, 193, 209; separation of bad eggs, 109, 142; treatment of trout, 136, 138, 141, 151

Embryo, growth of the, 145

Eyeing of eggs, 148

False eggs, 142

Feathering of eggs, 150

Feeding of black bass, 19, 34, 45 ; of cat-fish, 65 ; of goldfish, 270; of trout, 108, 161, 170

Feeding of aquarium fish, 245, 270 
Fertilisation of eggs, artificial, 131

Fingerlings, care of, 160, 163; defined, 160

Floating-box, construction of, 194

Floor of ponds, treatment of, 6, 11, 100

Frogs, culture of, 215-233

Fry, care of, 38, 46, 56, 84, 147, 165, 197; emergence of, 146 ; habits of, 12,39 , $55,64,151$

Fungus, 143, 153, 277

Grass, or calico, bass (see (Bass)

Goldfish, 244, 252-282; rearing for profit, 262, 267; varieties of, 255

Handling ripe trout, 128

Hatchery for trout, equipment of, 105, 111

Hatching-boxes, how made, 121

Hospital tank, 275

Insects injurious to fish, 17, 231

Introduction of stock to ponds, 17, 29

Jars, hatching fish in, 178, 214

Large-mouthed bass, 47
Lightning killing fish, 102

Liver-paste, how prepared, 164

Kettle of pond, 10

Mating of black bass, 27, 30, 34 ; of trout, 126.

Meat, prepared as food, 164, 167

Milk, prepared as food, 164

Milt and spermatozoa, 131, 134

Minnows as food, 22

Muscallonge, American species of, 203 ; culture of, 203

Nests of black bass, 24, 32, 35; of bullhead, 63 ; of sun-fish, 53

Nest-boxes for black bass, 43

Outlets of ponds, 13

Perch, white, culture of, 208 Perch, yellow, culture of, 188 Pickerel, chain, culture of, 200 Pike, characteristics of, 202 Plants for an aquarium, 246; for fish-ponds, 14, 46, 226

Ponds for black bass, 9, 47; for carp, 72,75 ; for catfish, 61, 66; for frogs, 224 ; for goldfish, 268; for trout, 93

Raceways, advantage of, 104, 127 


\section{INDEX}

Ringer eggs, 141

Rock-bass, culture of, 51,57

Salmon, culture of, 174

Salt baths, 156, 276

Shade, need of, 97

Shelf of a pond, defined, 10

Shipping fish, 84, 106

Sides of ponds, $12,68,98$

Silversides, culture of, 175

Site of ponds for bass, 5; for trout, 93

Smelt, culture of, 212

Sorting of young fish, 67, 129, 169

Spawning of black bass, 30 ; of carp, 81 ; of cat-fish, 62 ; of goldfish, 263; of pike, 204; of perch, 191; of trout, 126
Spermatozoa, 131, 134

Stripping trout, 129, 132

Sucker, culture of, 215

Sun-fish, culture of, 49

Tadpoles, development of, 232;

habits of, 220, 228, 230

Temperature in trout-culture, 90, 108, 123

Trout, brook, culture of, 86 173

Water suitable for black bass, 3 , 10; for carp, 78; for brook-trout, 86

Water beetles, 231

Yearling trout, care of, 166 

NOV 81913 

